Rochester Institute of Technology

RIT Scholar Works

Theses

$12-12-2019$

\title{
A Framework for Firm-Level Critical Material Supply Management and Mitigation
}

Gillian A. Griffin

gag3488@rit.edu

Follow this and additional works at: https://scholarworks.rit.edu/theses

\section{Recommended Citation}

Griffin, Gillian A., "A Framework for Firm-Level Critical Material Supply Management and Mitigation" (2019). Thesis. Rochester Institute of Technology. Accessed from 


\title{
RIT
}

\section{A Framework for Firm-Level Critical Material Supply Management and Mitigation}

by

\section{Gillian A. Griffin}

\author{
A THESIS \\ Submitted in Partial Fulfillment of the Requirements for the \\ Degree of Master of Science in Sustainable Systems \\ Department of Sustainability \\ Golisano Institute for Sustainability \\ Rochester Institute of Technology
}

December 12, 2019 


\section{Committee Approval:}

Dr. Thomas A. Trabold Date

Associate Professor and Department Head, Sustainability

Dr. Gabrielle Gaustad

Date

Research Faculty, Golisano Institute for Sustainability

Advisor and Committee Chair

Dr. Callie Babbitt

Date

Associate Professor, Sustainability

Committee Member

Dr. Jennifer L. Schneider

Date

Professor, College of Applied Science and Technology

Committee Member 


\section{Table of Contents}

Table of Contents ...................................................................................................................... 3

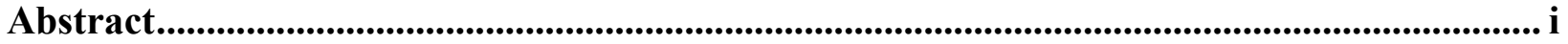

Acknowledgments ......................................................................................................................................... ii

Table of Figures................................................................................................................................. iii

Table of Tables .................................................................................................................................... v

Chapter 1 - Introduction .......................................................................................................................... 6

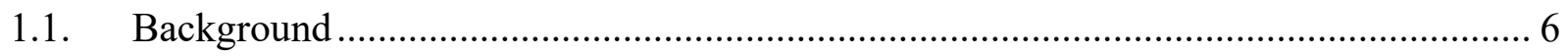

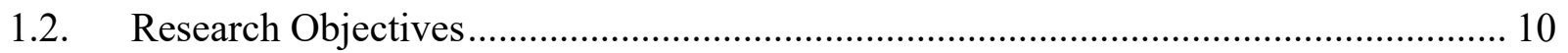

2. Chapter 2 - Methodology ........................................................................................................... 10

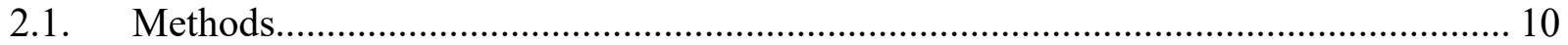

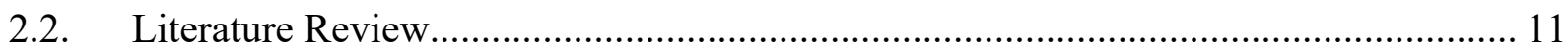

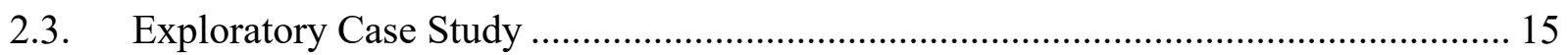

2.4. Analysis of Existing Firm-Level Frameworks.......................................................... 18

2.5. Internal Indicators for Firm-Level Risk Assessment and Mitigation ........................... 19

2.6. Developing a Novel Framework ………………........................................................ 19

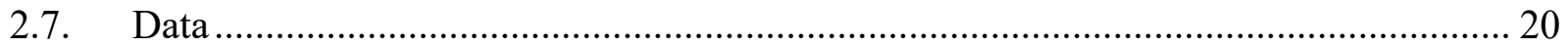

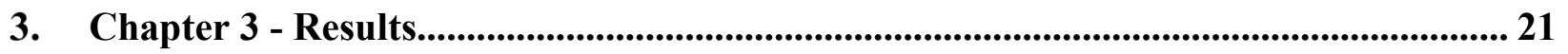

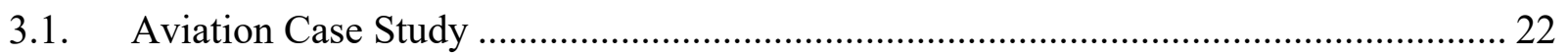

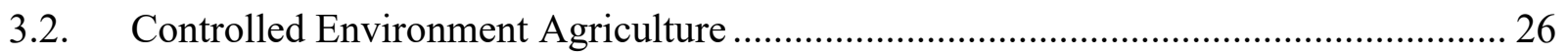

3.3. Firm Response: Supply Disruption Profile ……………………………………....... 33

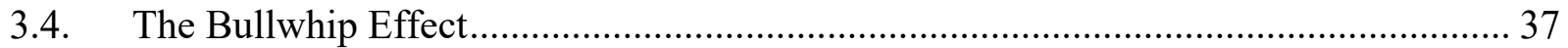

3.5. Firm-Level Indicators and Criticality Assessment Framework for Firms ..................... 40

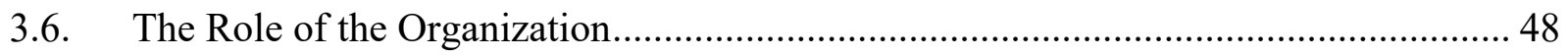

4. Conclusions .................................................................................................................................... 51

4.1. Recommendations for Future Research .............................................................. 54

Appendix A ......................................................................................................................... 56

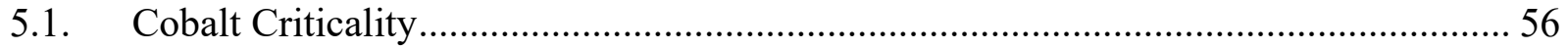

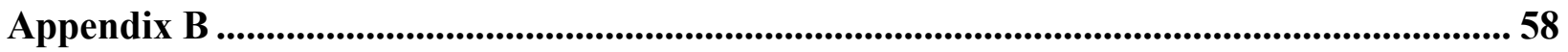

6.1. Criticality Assessment Literature Summary …………………….......................... 58

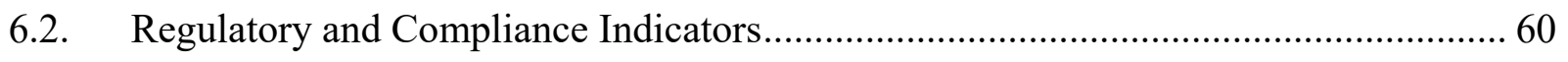

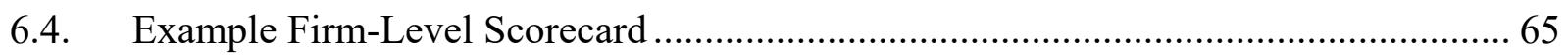




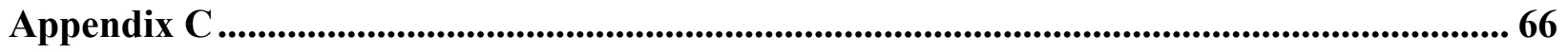

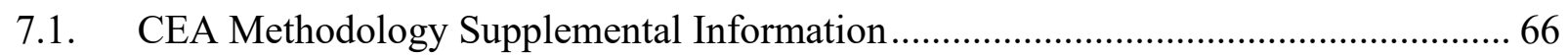

7.2. Determining Critical Material Intensity of Horticultural Lighting Technologies ........ 71

7.3. Mass and Cost of Critical Materials by Lighting Technology …………….................. 72

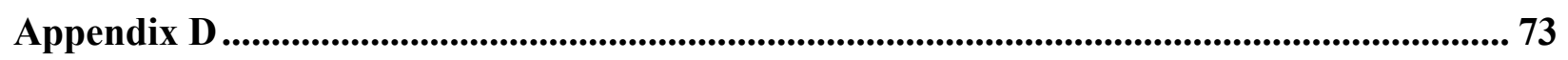

8.1. Price Volatility and Firm Performance ................................................................... 73

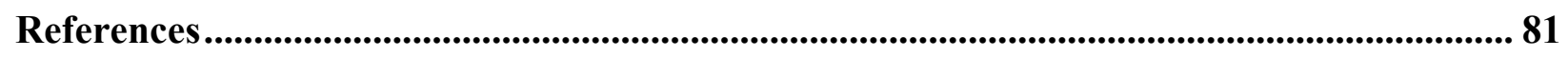

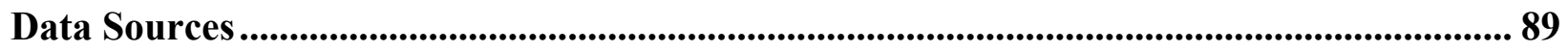




\begin{abstract}
Organizations of all sizes are vulnerable to critical material supply disruptions. Although there is a significant body of literature that examines how large entities such as nations and governments can assess and mitigate criticality, there is very little work that addresses firm-level criticality in a way that is actionable for businesses. This work uses literature review and case study analysis to understand the impact of critical material supply risk at the firm level, and to determine salient internal indicators. A total of 42 criticality studies were reviewed and the findings were used to develop a framework to assess and monitor criticality risk using internal firm-specific data. The framework incorporates three categories of risk including product concept viability, production, and profitability. It also contains four key business functions including finance, procurement, marketing, and production. These aspects were chosen because they are relevant to all businesses that produce and sell manufactured goods, and because they represent dynamics that are within the control of an individual firm. Unlike the global and national level indicators emphasized in most current research, the indicators proposed in this research are derived from data such that firms can compile it with reasonable ease. Finally, this work considers the role of the organization in criticality risk assessment and mitigation through an examination of the data needed to complete the aforementioned framework and the likely sources of that information. The findings of this analysis elucidate the gap between internal and external and micro and macro criticality assessment, as well as provide a framework for firmlevel criticality mitigation.
\end{abstract}




\section{Acknowledgments}

I would like to express my sincere gratitude to my advisor, Dr. Gabrielle Gaustad, for her continuous insight, support, and confidence during my tenure as a student in the M.S. program in Sustainable Systems at the Golisano Institute for Sustainability at the Rochester Institute of Technology. Dr. Gaustad's guidance and encouragement allowed me to venture into challenging new areas of research which substantially broadened my understanding of sustainability, and inspired me to keep exploring realms previously unknown to me.

I would also like to acknowledge the valuable expertise and feedback provided by Dr. Callie Babbitt in the context of sustainable food-energy-water systems. Further appreciation goes to Dr. Jennifer Schneider for her valuable inputs on the use of metrics and indicators in corporate decision making.

Finally, I would like to acknowledge funding from the United States National Science Foundation (NSF), through CBET award \#1454166 and support from the Center of Excellence in Advanced and Sustainable Manufacturing at the Rochester Institute of Technology which is supported through the New York State Department of Economic Development (DED). 


\section{Table of Figures}

Figure 3.1.1. Price Volatility of Rhenium, 1975 - 2017 (Polyak 2017, Polyak 2018)............24

Figure 3.1.2. Unit Cost of Rhenium per Trent XWB Engine vs. 2017 Gross Margin of Rolls-

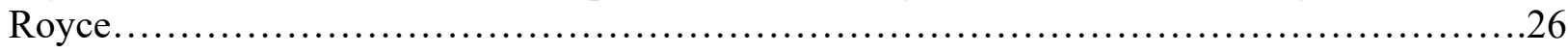

Figure 3.2.1 Annual Financial Performance of CREE vs. Price of Rare Earth Elements..........31

Figure 3.2.2. Annual Financial Performance of CREE vs. Price of Gallium...................... 31

Figure 3.3.1. Conceptual Timeline of Firm Response to Supply Disruption.....................34

Figure 3.4.1. Bullwhip Effect Conceptual Model............................................38

Figure 3.4.2. Example order penetration point and reliance on materials for various industries based on (Agarwal et al. 2012, Gaustad et al. 2017, Olhager 2003, Schoolderman \& Mathlener

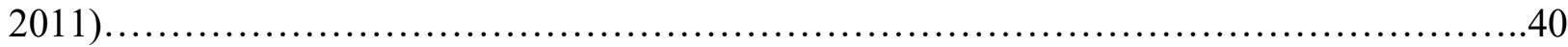

Figure 3.5.1. Firm-Level Indicators by Category \& Sub-Category .............................41

Figure 3.5.2. Framework Structure for Firm-Level Criticality Assessment......................42

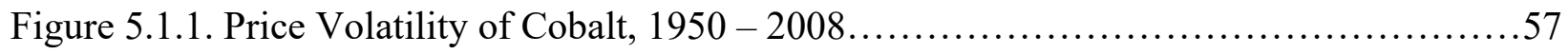

Figure 7.2.1.: Determining Critical Material Intensity of Horticultural Lighting Technologies...71

Figure 8.1.1. Annual Price of Rhenium vs. Annual Profit of GE, Boeing, and Pratt \& Whitney,

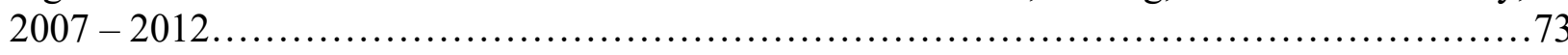

Figure 8.1.2. Quarterly Price of Rhenium vs. Quarterly Profit of GE, Boeing, and Pratt \&

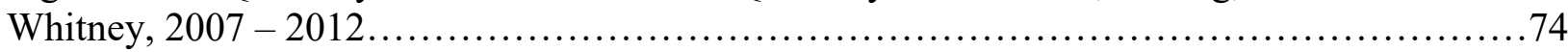

Figure 8.1.3. Annual Financial Performance of Boeing vs. Price of Rhenium....................75

Figure 8.1.4. Annual Variation in Boeing Financial Performance vs. Price of Rhenium.........75

Figure 8.1.5. Quarterly Financial Performance of Boeing vs. Price of Rhenium..................76

Figure 8.1.6. Quarterly Variation in Boeing Financial Performance vs. Price of Rhenium........76

Figure 8.1.7. Annual Financial Performance of General Electric (GE) Aviation vs. Price of

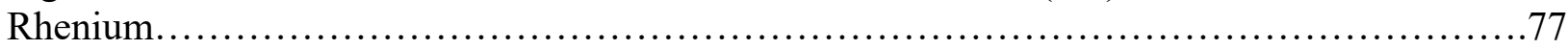

Figure 8.1.8. Annual Variation in General Electric (GE) Aviation Financial Performance vs.

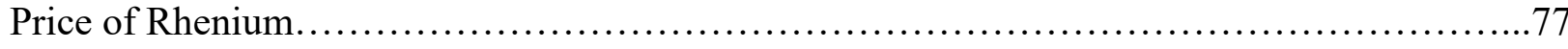

Figure 8.1.9. Quarterly Financial Performance of General Electric (GE) Aviation vs. Price of

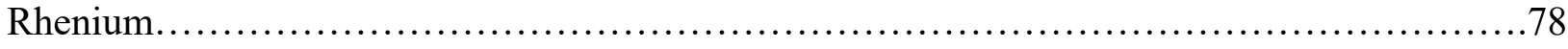

Figure 8.1.10. Quarterly Variation in General Electric (GE) Aviation Financial Performance vs.

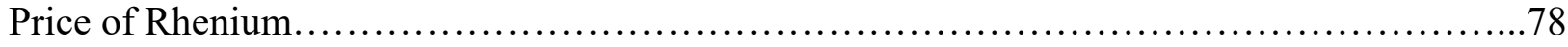


Figure 8.1.11. Annual Financial Performance of Pratt \& Whitney vs. Price of Rhenium

Figure 8.1.12. Annual Variation in Pratt \& Whitney Financial Performance vs. Price of Rhenium...................................................................... 79

Figure 8.1.13. Quarterly Financial Performance of Pratt \& Whitney vs. Price of Rhenium......80

Figure 8.1.14. Quarterly Variation in Pratt \& Whitney Financial Performance vs. Price of

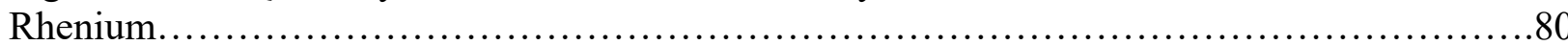




\section{Table of Tables}

Table 3.2.1. Competing demand for critical materials used in LED horticultural lighting

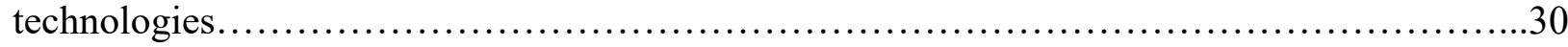

Table 3.5.1. Criticality Indicators................................................. 43

Table 3.6.1. Internal Criticality Indicator Data and Sources at the Firm Level.................49

Table 6.1.1. Criticality Assessment Literature Summary...............................58

Table 6.2.1. Regulatory and Compliance Indicators..................................60

Table 6.3.1. Indicators in Existing Firm-Level Criticality Studies...........................60

Table 6.4.1. Example Firm-Level Scorecard.........................................65

Table 7.1.1.: Critical Material Composition per Light Bulb (given in grams).................66

Table 7.1.2.: USDA “Healthy U.S.-Style Eating Pattern” Intake Recommendations by Volume

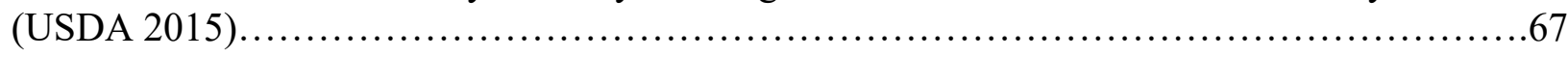

Table 7.1.3.: Total Growing Space per Person, per Crop Annually..........................68

Table 7.1.4. Number of Bulbs per Crop............................................... 70

Table 7.3.1. Mass and Cost of Critical Materials by Lighting Technology.....................72 


\section{Chapter 1 - Introduction}

\subsection{Background}

The extraction and use of raw metals for the production of goods and technologies has increased by 19 times over the past 100 years. The use of some individual metals, such as aluminum, has increased by a factor as high as 1000 (Graedel, Barr et al. 2012). Because these raw materials are used by a rapidly growing global population for a wide range of products, demand is expected to increase further. The rapid consumption of some of these finite resources — such as cobalt, rhenium, platinum group metals, and rare earth elements — is noteworthy because these materials are strategically important for renewable and clean energy technologies, national defense, numerous technological innovations that improve our daily lives (e.g., smart phones, laptops, healthcare equipment), and even emerging methods of urban agriculture that require artificial lighting to produce food. Referred to as critical materials, these minerals and metals are vulnerable to supply disruptions and price volatility. In order to mitigate risk and promote the sustainable development of the technologies that depend upon them, demand for critical materials must be monitored and supply must be managed. In addition to the environmental and social benefits of critical material-dependent products such as solar panels, wind turbines, and electric vehicles, there are financial benefits. Many economies, including the U.S., are heavily dependent on critical raw materials for manufacturing as well as the underlying science and technology innovations that make them competitive. To maintain the innovation and economic growth that drives society forward and makes it possible for future generations to enjoy the same or better quality of life as the current generation, the firms that rely on critical materials need to understand and be able to mitigate their risk.

The precise definition of a critical material varies but here we focus on two dimensions for firms: (a) supply disruptions and (b) high economic and/or strategic importance.

Supply Disruption: Critical material supply disruptions are caused by many different and often interdependent dynamics. For example, scarcity concerns the physical availability of materials and can be measured by factors such as crustal abundance, reserve levels, mine production, static depletion times, and national stockpiles. Other factors that can cause supply disruption include natural disasters, politics, conflict, production bottlenecks, and lack of producer diversity. 
Some materials have codependence with primary production, for example cobalt and tellurium are commercially obtained as a byproduct of copper mining. This can cause supply issues as an increase in demand of the byproduct material may not have an economic impact on the production of the parent material (Bustamante and Gaustad 2014). Import reliance and lack of producer diversity may exacerbate other supply issues (Bustamante and Gaustad 2014) (Buijs and Sievers 2011) (Gunn 2014). Geopolitical risk is defined as political and governance activity across the globe that may restrict or limit critical material availability. Components of this category may include conflict, political instability, violence, government trade policies and interventions, corruption, and government effectiveness.

Volatility in demand may cause supply risk due to unbalanced markets, competing technology demand, and artificial inventory fluctuations across the supply chain (i.e. the bullwhip effect). Ecological damage that occurs as a result of raw material extraction and processing, such as soil degradation, air pollution, water contamination, and loss of biodiversity may cause supply risk issues if producing firms cannot keep up with regulatory compliance.

For each cause of supply disruptions there are multiple indicators used to identify supply risk. Achzet and Helbig (2013) found that the most frequently observed indicators are country risk, country production concentration, depletion time, and by-product dependency. The next most frequently observed indicators are company concentration in mining corporations, demand growth projections followed by recycling and recyclability, substitutability, import dependence, and commodity prices (Achzet and Helbig 2013). Less common indicators include things such as production costs in extraction, stock keeping, mine/refinery capacity, future market capacity, and investment in mining (Achzet and Helbig 2013).

Economic and Strategic Importance: A key impact of critical material supply disruption is market vulnerability to sudden price spikes (Duclos, Otto et al. 2010) (Graedel, Barr et al. 2012). Price spikes affect firm competitiveness by creating uncertainty in costs, product pricing, earnings, and credit availability, thus affecting short-term profitability and long-term survival (Agarwal, Ofori et al. 2012). Surveys and reports published by leading business consulting firms highlight this as a growing concern among modern businesses and the academic literature supports these findings (Agarwal, Ofori et al. 2012) (Schoolderman and Mathlener 2011). Additional studies (e.g. (Chapman, Christopher et al. 2002) (Helferich and Cook 2002) (Martha and Subbakrishna 2002)), have also reported costly consequences of disruptions. 
Recent emphasis on lean supply chain management principles in corporations makes firms more vulnerable to supply disruptions because they tend to have limited stockpiles. It also poses significant challenges for supply chain managers tasked with maintaining operational efficiencies while also increasing supply resilience (Hendricks and Singhal 2005a). Material shortages can slow or halt production in manufacturing plants, increase costs, and quickly diminish a firm's competitive advantage and revenue. For example, in early 2000 a phone chip supply disruption caused by a fire in a manufacturing plant impacted two companies, Nokia and Ericsson. Nokia responded aggressively to the supply disruption by securing alternate suppliers, modifying product designs to accommodate different chips, and communicating regularly with the original manufacturer. Ericsson was slow to take action and therefore unable to expediently secure an alternate supplier. As a result, the company sustained an estimated revenue loss of $\$ 400$ million and soon after exited the consumer cell phone market (Sheffi and Rice Jr 2005).

As demonstrated in the Ericsson case, negative consequences of critical material supply disruptions in sectors such as manufacturing, transportation, electric power, and telecommunications can be enduring and can impact multiple business sectors. In a study of supply chain disruptions in publicly traded firms, Hendricks and Singhal found that stock returns, share price volatility, and profitability are all negatively impacted by supply disruptions (Hendricks and Singhal 2005a, Hendricks and Singhal 2005b). Across nearly 800 disruptions analyzed, stock returns were found to drop, on average, $33 \%$ to $40 \%$ over a three year time period and, notably, Hendricks and Singhal assert that this underperformance can be observed in the year prior to the supply disruption (Hendricks and Singhal 2005a). Share prices were found to have $13.5 \%$ higher volatility in the year following the supply disruption than in the year prior to the disruption (Hendricks and Singhal 2005a). In terms of impact to firm profitability, Hendricks and Singhal reported that, on average, firms that experienced a supply disruption faced an operating income decrease of $107 \%$, a drop in return on sales of $114 \%$, a drop in return on assets of $93 \%, 7 \%$ lower sales growth, $11 \%$ growth in cost, and $14 \%$ growth in inventories (Hendricks and Singhal 2005b).

In terms of recovery, Hendricks and Singhal found that it can take two or more years to return to the performance levels prior to a disruption (Hendricks and Singhal 2005a). Some firms never return to the same performance levels that existed prior to the disruption (Sheffi and Rice Jr 2005). Additionally, firms lack clear contingency plans and well-defined roles for 
managing disruptions. Mitroff and Alpaslan assessed the crisis readiness of Fortune 500 companies over two decades and found that $75 \%$ to $95 \%$ of companies analyzed were not prepared for any kind of disruptive event (Mitroff and Alpaslan 2003). This was further corroborated by Hillman and Keltz (Hillman and Keltz 2007).

Commonly cited criticality mitigation strategies from a national and international perspective include increasing resiliency to supply disruptions and developing leading indicators of such disruptions. Ways to build resiliency primarily relate to the production and processing of raw materials. This could mean improving extraction methods to make the production of critical raw materials more cost efficient, less damaging to the environment, and less prone to labor exploitation; increasing end-of-life material recovery efforts; manipulating trade policy and international relations to minimize the negative impacts of controlling producers such as China; and diversifying production whenever possible to offset supply vulnerability caused by producers with a supply monopoly. Additional strategies include the development of substitute materials and dematerialization. The development of leading indicators is more complex because drivers of supply threats include things like geopolitical conflict, political corruption, physical scarcity, and natural disasters which are difficult to quantify and prone to uncertainty.

The critical material frameworks developed by entities like the U.S. Department of Energy and the EU reflect the complex web of factors that contribute to criticality. They generally include indicators that span three categories, social, environmental, and economic. For example, country concentration, by-product dependency, production costs in extraction, risk of strategic use, market balance, and climate change vulnerability. To quantify these indicators requires data that is not easily accessible, as well as high-level expertise to analyze that data, which furthermore must be aggregated into an indexed score. For example, to determine the supply risk of a given critical material could involve information about geological availability (i.e., where in the world does the material naturally occur), technical availability (i.e., can the material be economically extracted), and environmental and/or social barriers to mining the material (e.g., water contamination, labor disputes, armed conflict). Risk may also need to be assessed temporally (e.g., short term vs. medium term), further complicating an already time and resource intensive process.

Unlike the national and international bodies that have developed systematic frameworks for assessing criticality, most firms lack an integrated and recurring way to track and measure 
critical material supply disruptions in a way that is adaptable to their specific business operations and strategies. Firms have access to published findings such as the U.S. Department of Energy's Critical Materials Strategy (2011) but have little control or leverage on the external factors emphasized in many current criticality assessment methodologies. Whereas governments can influence trade policies, regulations, and other macro level factors that impact both demand and supply of critical materials, firms rarely have influence outside of the primary tiers of their supply chains. An individual firm can't access government stockpiles of critical materials, levy tariffs, or resolve political conflicts that inhibit production of critical materials. And yet, firms do influence demand for critical materials through the technologies and products that they choose to develop and bring to market. There is a disconnect between the demand created by firms and the critical material supply.

\subsection{Research Objectives}

This work aims to address the following research questions:

1. What is the specific impact of criticality to firms?

2. How can firms create a criticality risk assessment framework that can be used efficiently and effectively for their specific business operations and strategies?

In terms of broader impact, this research is intended to develop a concept (i.e., a framework), for firm-level criticality assessment and mitigation based on insight gained from a review of the literature, an analysis of current assessment practices at the firm-level, and analysis of two industry-specific criticality scenarios (aviation and controlled environment agriculture).

\section{Chapter 2-Methodology}

\subsection{Methods}

Criticality assessment is a complex undertaking with internal and external variables as well as macro and micro level variables. There are also several levels of analysis (e.g. global, national, industry, material, country of origin), and many different analysis methodologies such as traditional risk assessment, supply chain management, and sustainability practice. Given this, a multi-factor approach was used to examine critical material supply risk from a firm 
perspective. First, literature review was conducted in an effort to understand how criticality is currently being assessed. Second, an exploratory case study of the use of rhenium in the aviation industry was used to evaluate the impact of critical material price volatility on firm performance. Third, eleven existing firm-level studies (Rosenau-Tornow, Buchholz et al. 2009, Duclos, Otto et al. 2010, Lloyd, Clifton et al. 2012, Lloyd, Lee et al. 2012, Nieto, Guelly et al. 2013, Bensch, Kolotzek et al. 2015, Gardner and Colwill 2016, Lapko, Trucco et al. 2016, Hallstedt and Isaksson 2017, Kolotzek, Helbig et al. 2018) — a subset of the 42 studies initially reviewed and noted in section 1.2-were analyzed to identify data and indicators for criticality assessment. Fourth, a firm-level risk analysis was conducted to determine internal indicators relevant to firmlevel supply disruption mitigation. Finally, a framework for firm-level criticality assessment was developed by combining the above analysis, firm organizational structures, and the role of inventory and demand management as characterized by an established economic phenomenon, the bullwhip effect.

\subsection{Literature Review}

There is a large body of literature that defines criticality, identifies specific materials as critical, and establishes clear indicators of criticality. The literature also examines the formal methodologies that have been developed by nations and governments for the purpose of assessing and mitigating criticality (Graedel and Reck 2016). The U.S. Department of Energy, the U.S. Department of Defense, the European Union, and Germany are just some examples. There are also initiatives between government and industry that exist for the purpose of addressing critical material supply risk (e.g., the U.S. Critical Materials Institute, the European Institute of Innovation and Technology Raw Materials in the EU, the National Institute of Materials Science in Japan). Each of these entities is concerned with things like the quantities of critical raw materials consumed, extracted, imported, and exported in their respective geographical areas and globally; trade dependencies and other vulnerabilities stemming from the high production concentration of some critical materials in places like China; the particular uses of critical materials; future demand for critical raw materials; and future uses of critical raw materials.

A review of 42 of the most relevant criticality studies to-date was conducted in an effort to understand how criticality is currently being assessed. These studies include peer-reviewed 
journal articles, research project reports, and policy reports. We conducted our search using Google Scholar, ScienceDirect, Wiley Online Library, and Web of Science. Keywords queried include critical material supply risk, critical material framework, criticality assessment, criticality framework, raw materials criticality, and raw material assessment. The overall set of literature identified included topics such as material recovery and recycling, demand forecasting, supply chain resilience, supply chain management, crisis readiness, and criticality assessment methodologies. We focused on studies that specifically addressed criticality assessment and that did so using a defined scope, explicit risk indicators, and a model, framework, or framework. For broad studies that didn't address firm-level criticality assessment we relied on the more highly cited works. We did not use any criteria for firm-level studies. Our goal was to identify all literature that incorporated a firm-level scope.

The metrics used in each study can be organized into six broad categories as follows, with significant overlap among these categories.

- Scarcity risk concerns the physical availability of critical materials. Indicators may include crustal abundance, reserves, mine production, static depletion times, stockpiles, substitutability, and recycling.

- Geopolitical risk quantifies risk stemming from political and governance activity across the globe that may restrict or limit material availability. Geopolitical dynamics impact the export, pricing, and regulations of materials supplied. The most commonly used indicator is the Herfindahl-Hirschman Index (HHI) which can show the presence of monopolies. The World Governance Indicators (WGI) are the primary geopolitical stability indicators used to weight the HHI. This category also includes regulatory and compliance indicators. As shown in section 5.1 in Appendix A, cobalt is an instructive example of how geopolitical risk can impact criticality.

- Demand risk is a key determinant of material availability that considers the volatility of demand relative to a supplier's ability to scale up or down. It is most often assessed using demand projections derived from sources like consultancy and market analyst reports, expert opinion, and assumed annual growth rates relative to economic growth.

- Environmental risk considers environmental damage that may occur as a result of raw material extraction and processing. The primary tool used for this assessment is the Environmental Performance Index (EPI). Life cycle assessment (LCA), and the 
Comprehensive Environmental Response, Compensation, and Liability Act (CERCLA), are also used to assess environmental risk.

- Supply chain risk refers to factors that can influence material procurement due to suppliers, manufacturers, and distributors of critical materials. Examples include the number of suppliers of a given material as well as the physical concentration of a material in a particular geographic area (e.g. a country).

- Market risk is a determinant of the market viability of products that rely on critical materials. The primary factor of market risk in this context is material price. Indicators include price volatility, price spikes, cost competition, and ability to pass on increased costs to consumers. One example of market risk is a price spike due to rapid market adoption of products containing critical materials such as electric vehicles or solar panels. Another example is competing demand for critical materials due to emerging technologies in different industries and/or novel applications of critical materials.

Although the actual materials assessed and the specific metrics used vary from one study to the next, each study aims to assess criticality in terms of vulnerability to supply disruptions. The studies reviewed represent criticality metrics in addition to those proposed by the U.S. National Research Council (NRC) in 2008. The NRC was among the first research groups to suggest metrics that consisted of two key dimensions of criticality: supply risk and impact of supply disruption. All of the evaluated studies are listed in Table 6.1. in Appendix A.

The major point of distinction among the studies reviewed is the scope of each criticality assessment, which varies from global, to European, to national, to firm level. Of the 42 studies, 10 assess criticality at the global level exclusively (Buchert, Schüler et al. 2009, RosenauTornow, Buchholz et al. 2009, Bauer, Diamond et al. 2010, Bauer, Diamond et al. 2011, Brown, Bide et al. 2011, Achzet and Helbig 2013, Helbig, Kolotzek et al. 2017, Sustainability, Survey et al. 2017, Brown 2018, Jasiński, Cinelli et al. 2018), 4 focus exclusively on Europe (EC 2010, EC 2014, Deloitte Sustainability et al. 2017, Blengini et al. 2017), 9 focus exclusively at the national level (Council 2008, Morley and Eatherley 2008, Angerer, Marscheider-Weidemann et al. 2009, AEA Technology 2010, AEA Technology 2011, Hatayama and Tahara 2015, Glöser-Chahoud, Tercero Espinoza et al. 2016, Bach, Finogenova et al. 2017, Daw 2017), and 11 focus exclusively on the corporate or firm level (Duclos, Otto et al. 2010, Lloyd, Clifton et al. 2012, Lloyd, Lee et al. 2012, Nieto, Guelly et al. 2013, Bensch, Kolotzek et al. 2015, Gardner and 
Colwill 2016, Lapko, Trucco et al. 2016, Miehe, Schneider et al. 2016, Hallstedt and Isaksson 2017, Gardner and Colwill 2018, Kolotzek, Helbig et al. 2018). An additional 7 studies address the global, national, and firm levels (Graedel, Barr et al. 2012, Graedel, Gunn et al. 2014, Graedel, Harper et al. 2015, Graedel, Harper et al. 2015, Nassar, Graedel et al. 2015, Helbig, Wietschel et al. 2016, Knobloch, Zimmermann et al. 2018). The final study in the group of 42 focuses on the global and national level (Nassar, Graedel et al. 2015). There is a useful diversity of approaches within each scope as well. The British Geological Survey provides a supply risk assessment index that considers factors that effect material availability for 42 elements at the global level (Brown, Bide et al. 2011). Conversely, the Öko Institute provides assessment methodology for just a select few materials required for renewable and energy efficient technologies at the global level (Buchert, Schüler et al. 2009). The parameters of the studies conducted on a national level differ by country. Developed nations such as the U.S., the U.K., and Germany each focus on criticality assessment methods that affect their respective economies specifically.

As evidenced by the literature discussion above and in Appendix A, the majority of the existing work on criticality assessment focuses on risk quantification derived from primarily external factors (e.g. geological and economic availability, policy and regulation, geopolitical risk, environmental, etc.). While fundamentally relevant to criticality, external factors can't be directly controlled by individual firms. For example, some of the most frequently used indicators concern supply from a geopolitical perspective. These include the Policy Potential Index, the Human Development Index, the World Governance Indicators, and the Fund for Peace's Failed State Index. Intended to capture risk in the countries that supply critical materials (due to things like taxation and regulation, vulnerability to political conflict or collapse, standard of living, government corruption, and likelihood of violence), these indicators are even further outside the sphere of influence of an individual firm. Nevertheless, ten out of eleven firm-level studies incorporated one or more indicators in the geopolitical category (Rosenau-Tornow, Buchholz et al. 2009, Duclos, Otto et al. 2010, Lloyd, Clifton et al. 2012, Lloyd, Lee et al. 2012, Nieto, Guelly et al. 2013, Bensch, Kolotzek et al. 2015, Lapko, Trucco et al. 2016, Miehe, Schneider et al. 2016, Hallstedt and Isaksson 2017, Kolotzek, Helbig et al. 2018).

While a majority of the studies incorporated demand indicators, only four of the eleven studies that consider the firm-level perspective incorporated such indicators in their assessment 
methodologies (Duclos, Otto et al. 2010, Bensch, Kolotzek et al. 2015, Lapko, Trucco et al. 2016, Kolotzek, Helbig et al. 2018). Demand is relevant to any business and as such, most firms use forecasting tools to predict future product sales for themselves and competitors within their industry. However, forecasting for other industries that might compete for the same materials is often outside of a firm's scope.

Although many studies did include some criticality indicators that are environmental in scope, these were primarily regulatory in nature. From a business perspective, the implication here is that environmental indicators of criticality, such as material recovery potential, recyclability, and R\&D funding committed to the development of substitute materials, aren't relevant to firms. Also absent from studies reviewed in this work are metrics related to lost profit correlated to environmental harm caused by a firm's use of critical materials, or lost profit due to negative media exposure related to that environmental harm. Furthermore, no studies could be found that consider specific environmental impacts such as air, land, and water pollution, carbon emissions, or hazardous waste, as they specifically relate to obtaining and using critical materials at the firm level. In their work on material supply chain resilience, Sprecher et al. report that environmental considerations were omitted from their framework altogether because their interviewees indicated little to no concern for them (Sprecher, Daigo et al. 2015). A total of 13 regulatory and compliance indicators were found in the environmental, geopolitical, and supply chain categories; all of them were external and none of them directly considered environmental impact caused by firms or any downstream effect to firm profit. These indicators are listed in Table 6.2 in Appendix B.

\subsection{Exploratory Case Study}

The case study approach used in this paper was chosen because the research conducted here is preliminary and primarily conceptual. Very little work has been done on firm-level criticality assessment to date, and this approach allows criticality assessment to be explored from the perspective and scope of a firm rather than that of geography, politics, or the environment, all of which are extremely broad and have been studied extensively. Through the use of two firm-level case studies we can begin to establish parameters around firm-level criticality risk.

The first case looks at the aviation industry's use of one material (rhenium), used in one application (jet turbine blades), in one industry. This case specifically examines the price 
volatility of rhenium and its impact on the cost of production of jet engines. Price volatility is the chosen metric because it is easily measurable and material costs have significant impacts on the financial well-being of firms.

To conduct the aviation case study, the following steps were taken. First, historical pricing, supply (in terms of world reserves and production), consumption, and material applications for rhenium were established using data from the U.S. Geological Survey (USGS) (John 2015, Polyak 2018). Second, the material cost of the amount of rhenium required to manufacture one jet engine was estimated using data from Rolls-Royce plc (a leading manufacturing of jet engines), and pricing date from the USGS. Third, the pricing data was plotted over time in real dollars and in 2017 (inflation adjusted) dollars. Fourth, the material fraction of total material cost for one jet engine was calculated. This was done using the dry engine weight of one jet engine and the average amount of rhenium needed for one jet engine. Given the material fraction, material cost was determined using the price of rhenium in a given year, and the list price per jet engine. This metric was calculated based on 2008 and 2017 rhenium prices. The year 2008 was chosen because the rhenium market experienced a price spike at that time. The year 2017 was chosen because it was the most recent year for which the USGS published rhenium pricing data. Finally, the rhenium fraction of total cost (\%) and the price of rhenium per kg (\$USD) were plotted against the year-over-year change in gross margin which was obtained from corporate annual reports. The specific calculations were made using the following parameters and assumptions: the jet engine used in this analysis is the Trent XWB manufactured by Rolls-Royce plc.; the average amount of rhenium needed to manufacture engines for one aircraft is 50kg; the list price per engine in 2017 was \$35M USD; and gross margin data is based on revenue from the aviation sector only, as listed in Rolls-Royce plc annual reports.

The second case looks at the lighting industry's use of six critical materials (cerium, europium, gadolinium, gallium, indium, and yttrium), that are used to manufacture horticultural LED lighting. This case examines market demand rather than price volatility in order to highlight a second aspect of criticality that our work found to be prevalent. Specifically, market demand has material impacts on supply pressures commonly associated with criticality and, in the case of horticultural LEDs, market demand is generated by multiple market sectors such as electronics, healthcare, and general lighting. This means that the supply of critical materials needed for strategically important technologies (e.g., sustainable technologies), could be diverted 
to economically important applications (e.g., consumer electronics), regardless of the sustainability implications.

The methodological approach to the controlled environment agriculture case study has two components: the critical materials used in horticultural lighting, and the amount of light needed given certain food production requirements. In terms of critical materials, the first step was to establish the critical material composition (i.e., the type and quantity of materials), of LED grow lamps. Second, the critical material intensity (i.e., the type and quantity of materials needed to produce one unit of something), was determined. In this case, sole source lighting, as applied in controlled environment agriculture, is the thing being produced. One unit is defined as the number of grow lamps needed to produce an amount of food needed by a given population over a given period of time. Finally, the costs of the types and quantities of critical materials required by LED grow lamps were calculated and analyzed in terms of one unit of production.

Critical material composition was based on data in a 2017 report published by the Nordic Council of Ministers (Punkkinen et al 2017). The authors compiled multiple data sources and presented their findings in terms of estimated average weight per bulb. In order to account for differences across manufacturers, the authors assume an average weight of $0.185 \mathrm{~kg}$ per unit. Because the critical material composition data identified in the literature was given in composite form rather than by specific grow lamp product, we identified a typical light fixture - a high bay LED horticultural lamp manufactured by CREE - to serve as a proxy. The critical material composition per high bay LED fixture is listed in Table 7.1.1. in Appendix C.

The amount of light needed was defined in terms of number of fixture hours. The number of fixtures is a factor of the amount and quality of light emitted by a given grow lamp. The number of hours is a factor of the amount and quality of light required by a given crop. The total amount of light needed for a given level of food production was determined based on dietary needs, crop yields, required food production by mass, growing space, and plant light requirements.

In order to define a certain level of food production, a number of assumptions were made. First, a sample diet consisting of fruits and vegetables only was defined based on the United States Department of Agriculture's (USDA) "Healthy U.S.-Style Eating Pattern" recommendations for moderately active adults (2015). This information is shown in Table 7.1.2. in Appendix C. The sample diet consists of a total of 13 crops (peppers, broccoli, cantaloupe, eggplant, green beans, kale, onions, potatoes, spinach, strawberries, summer squash, and 
tomatoes), across the five categories of vegetables (i.e., dark green, red and orange, legumes, starchy, and other), and one category of fruit as specified in the USDA dietary guidelines (2015). Next, based on the USDA intake recommendations (by volume), and crop yields per crop, the amount of physical growing space needed to produce enough food for one person for one year was calculated (2015). This information is presented in Table 7.1.3. in Appendix C. Having established the square footage requiring artificial lighting, the number of grow lamps required to grow sufficient food was determined based on the amount and duration of light required by each crop relative to the amount of light provided by one grow lamp. An explanation of how to determine the amount of light required by crop, is included in Appendix C. Next, the total number of grow lamps needed to grow enough fruits and vegetables for one person for one year using sole source lighting in a controlled environment agriculture setting was calculated.

Finally, critical material intensity was calculated based on the critical material composition of one LED bulb, the population being fed, dietary requirements, growing space, and lighting requirements. To feed one person for one year under the scenario modeled in this work would require 12 high bay LED bulbs. To feed the projected world population in 2050 would require approximately 113.2 billion high bay LED bulbs. A schematic representing the methodology for determining critical material intensity is presented in Figure 7.2.1. in Appendix C.

\subsection{Analysis of Existing Firm-Level Frameworks}

The 11 existing firm-level studies identified in section 2.2. contain a total of 96 indicators of criticality studies (Rosenau-Tornow, Buchholz et al. 2009, Duclos, Otto et al. 2010, Lloyd, Clifton et al. 2012, Lloyd, Lee et al. 2012, Nieto, Guelly et al. 2013, Bensch, Kolotzek et al. 2015, Gardner and Colwill 2016, Lapko, Trucco et al. 2016, Hallstedt and Isaksson 2017, Kolotzek, Helbig et al. 2018). Analysis of these indicators included sorting them into the six broad categories of risk outlined in section 2.2. (scarcity, geopolitical, demand, environmental, supply chain, and market risk), and then breaking them down further into sub-categories based on the specific aim of each indicator. For example, within the category of scarcity, six subcategories were identified: physical/geological abundance (e.g. abundance of a given material in the earth's crust); production capacity (e.g. utilization of mine/refinery capacity); recycling (e.g. recyclability of a given material); stock/reserves (e.g. known stockpiles); substitutability (e.g. firm's ability to substitute one material for another due to supply disruption); and supply (e.g. 
percent of world supply used). Next, each indicator was identified as having an internal or external scope. Out of the 96 indicators identified, 79 were classified as external and 17 were classified as internal. Examples of indicators classified as internal in scope include impact on revenue, non-forecasted upside demand, delivery capability, and potential cost increase. Examples of indicators in the external scope include future market capacity, concentration risk, co-production risk, and environmental regulation. A table of the indicators reflecting this analysis and identifying the study from which each indicator was found can be found in Appendix A in the supplemental material (Griffin et al 2019).

\subsection{Internal Indicators for Firm-Level Risk Assessment and Mitigation}

Informed by the analysis of existing firm-level frameworks, a novel set of internal indicators intended to support the assessment of supply risk at the firm level was developed (Griffin et al 2019). Criteria used to select indicators included the availability of data needed for criticality assessment; the frequency with which that data is generated; the accessibility of the data in the regular course of business (i.e. whether or not the data is already being collected, analyzed, reported, etc.); the potential for a firm to influence the data being collected through its business strategies and objectives; the extent to which the indicators as a whole address the basic functions of any typical business; and the alignment of the indicators with existing key performance metrics such as revenue, profit, stock price, etc.

\subsection{Developing a Novel Framework}

The framework for firm-level criticality assessment was designed with the goal of being relevant to most any business that produces and/or sells manufactured goods, and to incorporate all major operational aspects of such firms. To accomplish this, three categories of risk to manufacturing-related firms were defined: profitability, design and concept viability, and production. The first category is intended to capture threats to the fundamental integrity (i.e. a product's ability to meet performance requirements if an originally specified critical material experiences a supply disruption), and market potential of products that rely on a given critical material. The second category is intended to capture threats to the manufacturing and distribution of products that rely on a given critical material. The third category is intended to capture threats to the financial sustainability of firms that produce products that rely on a given 
critical material. The selection of indicators for each risk category was driven by four core business functions that incorporate all activities needed to produce and/or sell manufactured product - finance, procurement, marketing, and production — as well as their potential to generate actionable data (Griffin et al 2019).

Unlike the global and national level indicators emphasized in most current research, these indicators must be derived from primary (and often proprietary), data. In addition, because the aim of this research is to provide an accessible resource for many different kinds of firms, this data must generally be available in the normal course of business such that firms can compile it with reasonable ease. The ultimate goal of the proposed internal indicators is to facilitate a holistic and multifaceted analysis of critical material supply disruption risk at the firm level (Griffin et al 2019).

\subsection{Data}

The data used in this research can be understood in three categories: academic, corporate, and government. A search of the academic literature provided data about current approaches and practices related to criticality assessment and mitigation. Examples include assessment frameworks, criticality rating systems, and lists of materials determined by the scientific community to be critical. Commonly cited journals include Resources Policy, Environmental Science \& Technology, and Resources, Conservation, and Recycling. The academic literature also provided material composition data used to calculate estimated material requirements.

Corporate documents included annual financial reports which provided insight to a firm's awareness of criticality risk. Securities Exchange Commission (SEC) mandated filings provided historical financial information used to analyze trends in revenue and profit. Additional corporate data included product specifications published in marketing materials.

Government data came from multiple sources including the British Geological Survey, the European Union Commission, the United Nations Department of Economic and Social Affairs, the U.S. Department of Agriculture, the U.S. Department of Defense, the U.S. Department of Energy, and the U.S. Geological Survey. This data included information about the physical, economic, and strategic characteristics of critical materials. 


\section{Chapter 3 - Results}

Current literature suggests that the impact of critical materials at the firm level is evident in supply disruptions, short-term profitability, and long-term financial sustainability. To assess this assertion, two case studies were conducted. The first examines the impact of rhenium price volatility on the aviation industry. The second examines the impact of rare earth elements, gallium, and yttrium price volatility on controlled environment agriculture. Price volatility was selected as the impact factor because material cost is highly relevant for manufacturing firms and because firms have direct access to purchasing and pricing data for at least the first tier of their supply chains. Firms also have some ability to influence the prices they pay through procurement and inventory strategies like hedging. The aviation industry was selected because it is the largest consumer of rhenium. Controlled environment agriculture was selected because an increasing percentage of the world's food supply will need to be grown indoors due to the negative impacts of climate change on conventional agriculture; in order to do so, a substantial amount of horticultural lighting reliant upon critical materials will be required (Griffin et al 2019).

Price volatility is a measure of the changes in the price of commodities over a short period of time, and can result in many negative impacts to firms. For example, an increase in the cost of goods sold (e.g. price of materials), a decrease in raw material and finished product supply (e.g. inventory on hand), a decrease in production efficiency (e.g. idle machine time), and a decrease in revenue due to lost sales. Other problems include uncertainty in costs, product pricing, earnings, and credit availability, thus affecting the short-term profitability and long-term survival of firms (Agarwal, Ofori et al. 2012). Specifically, price volatility negatively impacts margin, working capital, and share prices, with earnings shown to rise and fall as much as $10 \%$ to $30 \%$ (Agarwal, Ofori et al. 2012).

Each of these financial metrics can provide valuable insight to a firm's health and financial sustainability. A firm's margin represents the amount of money that it earns per sales dollar and is correlated to profit. When margins decrease, profit may decrease as well. At the product level, this may cause a firm to stop manufacturing a particular technology such as the more fuelefficient turbine blades used in GE's jet engines or the more efficient and effective LED grow lights used in controlled environment agriculture. A firm's working capital represents the amount of cash and other short-term assets (e.g. accounts receivable), that it has available to pay 
for operating expenses at any point in time. Low working capital increases a firm's financial risk. If a manufacturing firm is faced with a price spike for a material that it relies on, the firm's ability to service its short-term debt may be compromised. If the impact persists, a decline in working capital could threaten the viability of a firm overall. A firm's share price is the amount of money that a person is willing to pay for the firm's stock. Changes in share price impact a firm's ability to raise capital and are an indicator of the financial health of the organization. A decrease in share price may cause a firm to cut costs in order to increase margins. A firm might cut costs by abandoning certain products or through more invasive measures such as cutting funding for research and development.

\subsection{Aviation Case Study}

The predominant driver of the price of rhenium is demand created by the aviation industry which relies on this material to achieve high-temperature properties in blades and vanes for high pressure aero and industrial gas turbine engines. These turbines are in high demand because their ability to withstand extremely high temperatures enables increased performance and fuel efficiency in jet engines.

Rhenium is an expensive metal with historical price volatility that is used in the manufacture of superalloys, catalysts, and gas-to-liquid (GTL) refinery processes (Polyak 2017). It is a byproduct of copper ores with little to no direct mining, and approximately $80 \%$ of demand is met through primary production (MSP-REFRAM 2017). Secondary rhenium provides the remaining supply and is produced mostly through foundry and mill scrap recycling, and recycling of parts from jet engines that have reached end of life (Duclos, Otto et al. 2010). Estimated world reserves of rhenium are $11 \mathrm{kt}$ of which $5 \mathrm{kt}$ are found in the U.S. (John 2015). Despite the considerable reserves of rhenium located in the U.S., a lack of production facilities drastically limits what can be supplied domestically (John 2015). For example, in 2017, world production of rhenium was $52,000 \mathrm{~kg}$. Of the $42,600 \mathrm{~kg}$ consumed by the U.S. in the same year, $8,500 \mathrm{~kg}$ was mined in the U.S. which has a total of six mining operations: four in Arizona, one in Montana, and one in Utah (Polyak 2018).

Most of the remaining 34,100 kg of rhenium consumed in the U.S. in 2017 was imported from Canada, Chile, Germany, Kazakhstan, and the Republic of Korea (Polyak 2018). Additional sources included Estonia, France, Japan, Poland, and Russia (Polyak 2018). Although 
the United States currently has positive diplomatic relations with the majority of these countries, political conditions and trade policy are subject to change at any time. Particularly in the context of sustainable technologies, should demand for materials like rhenium dramatically increase, tariffs could make imports unfeasible. Foreign countries may also elect to stop exporting certain materials altogether. China's trade policies are of particular concern. In 2017 China produced $80 \%$ of the supply and accounted for more than $66 \%$ of global demand for rare earth elements, many of which are considered critical (GlobalData Energy 2018). Mancheri et al argue that China's influence on the resilience of the rare earth element supply chain is strong enough that trade policies affect China differently than they do the rest of the world (2019).

The cost of rhenium is based on prices issued by the London-based Minor Metals Trade Association and long-term purchasing agreements between the consumer and producer (Lipmann 2005). Because rhenium operates in an opaque market - most transactions are made through long-term contracts that aren't publicly recorded - it is susceptible to drastic and sudden price changes that are generally triggered by market speculation (Lipmann 2005, Polyak 2017). For example, in 2008, strong demand triggered by speculation and sudden large orders for new generation aircraft—built with blade turbines requiring rhenium — led to a price spike in which the cost of rhenium reached $\$ 12,500 / \mathrm{kg}$ compared to a more typical cost in the range of $\$ 1,800 / \mathrm{kg}$ to $\$ 2,600 / \mathrm{kg}$. By the middle of 2009 , the market corrected to a cost of $\$ 4,000 / \mathrm{kg}$ to $\$ 4,500 / \mathrm{kg}$ (EC 2014). This is illustrated in Figure 3.1.1. 
Figure 3.1.1. Price Volatility of Rhenium, 1975 - 2017 (Polyak 2017, Polyak 2018)

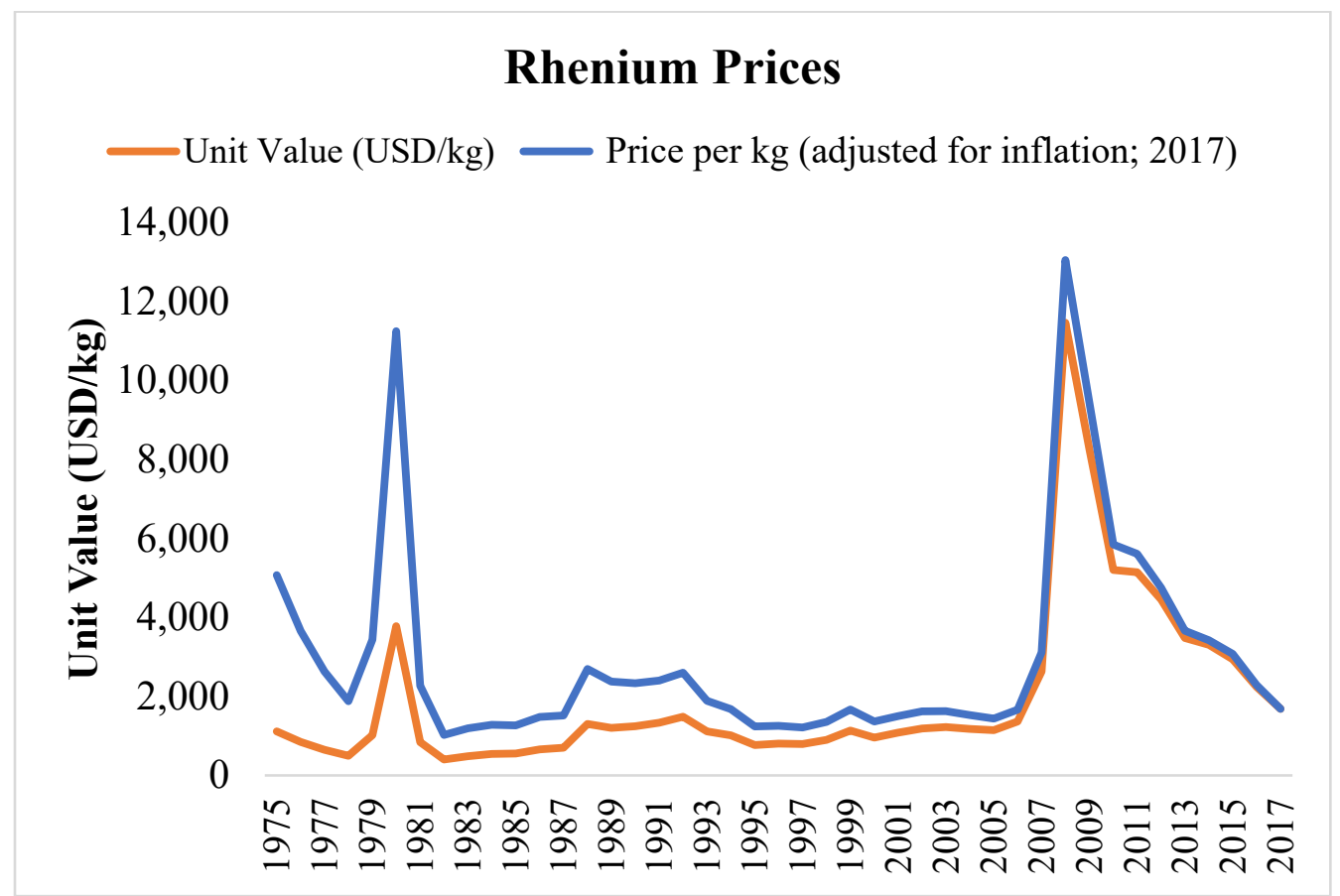

Although rhenium can be recycled from decommissioned gas turbines and catalytic converters, this secondary source does not necessarily relieve price pressure in the broader market because recycled rhenium has lower purity than rhenium derived directly from ore and therefore produces different technological results. General Electric (GE), for example, initially touted the use of recycled rhenium as a demand (and therefore cost), reduction strategy in the wake of the 2008 price spike (Duclos, Otto et al. 2010). Although possible from an engineering standpoint, the reduction and/or elimination of the use of rhenium in these engines was ultimately unviable because it resulted in decreased fuel efficiency (Duclos 2016). GE is currently pursuing and finding success with the development and implementation of ceramic framework composites (Kellner 2017).

The economic and strategic importance of rhenium in the aviation industry is evident in the cost of production. The average amount of rhenium needed to manufacture engines for one commercial aircraft, such as Rolls-Royce's Trent XWB, is 50kg (MSP-REFRAM). The cost for this amount of rhenium at the all-time high 2008 price of $\$ 10,400 \mathrm{USD} / \mathrm{kg}$ would be $\$ 520,000$ USD per aircraft vs. \$76,500 USD per aircraft at the 2017 price of $\$ 1,530 \mathrm{USD} / \mathrm{kg}$, a decrease of $85.29 \%$. Based on the 2017 list price of about \$35M USD per engine, a gross margin of $14.9 \%$, 
and the 2017 price of rhenium, the Trent XWB earns $\$ 5,215,000$ USD per engine on a revenue and cost basis (plc 2018). By comparison, the Trent XWB earns just $\$ 1,753,500$ USD per engine at 2008 rhenium prices. This is equal to a loss of $-9.89 \%$ in gross margin, or $\$ 3,461,500$ USD per engine. Material fraction of total material cost, which provides an indication of the importance of a given material with regard to product functionality and value, also demonstrates the criticality of rhenium in aviation. In this case, the amount of rhenium needed to produce one Trent XWB engine accounts for just $0.69 \%$ of the total dry engine weight of 7,277 kg (Agency 2013). At 2008 rhenium prices, the material fraction cost is equal to $1.99 \%$ versus $0.26 \%$ at 2017 prices. This is illustrated in Figure 3.1.2.

Despite the suggested role of speculation in the 2008 rhenium price spike, it is important to note that the broader macroeconomic climate was also extremely volatile at this time. The financial crisis of 2007-2008 resulted in a steep global recession in 2009 so, although the rhenium market did experience a market correction in 2009, real correlative relationships cannot be asserted between the cost of critical materials and firm profit based on this data alone. The circumstances surrounding a similar price spike that occurred in 1980 mimic those of the 2008 price spike. The single-crystal nickel-based superalloys that rely on rhenium for their high creep strength were emerging in the early 1980s when U.S. economy also experienced a significant recession (Mottura and Reed 2014). 
Figure 3.1.2. Unit Cost of Rhenium per Trent XWB Engine vs. 2017 Gross Margin of RollsRoyce

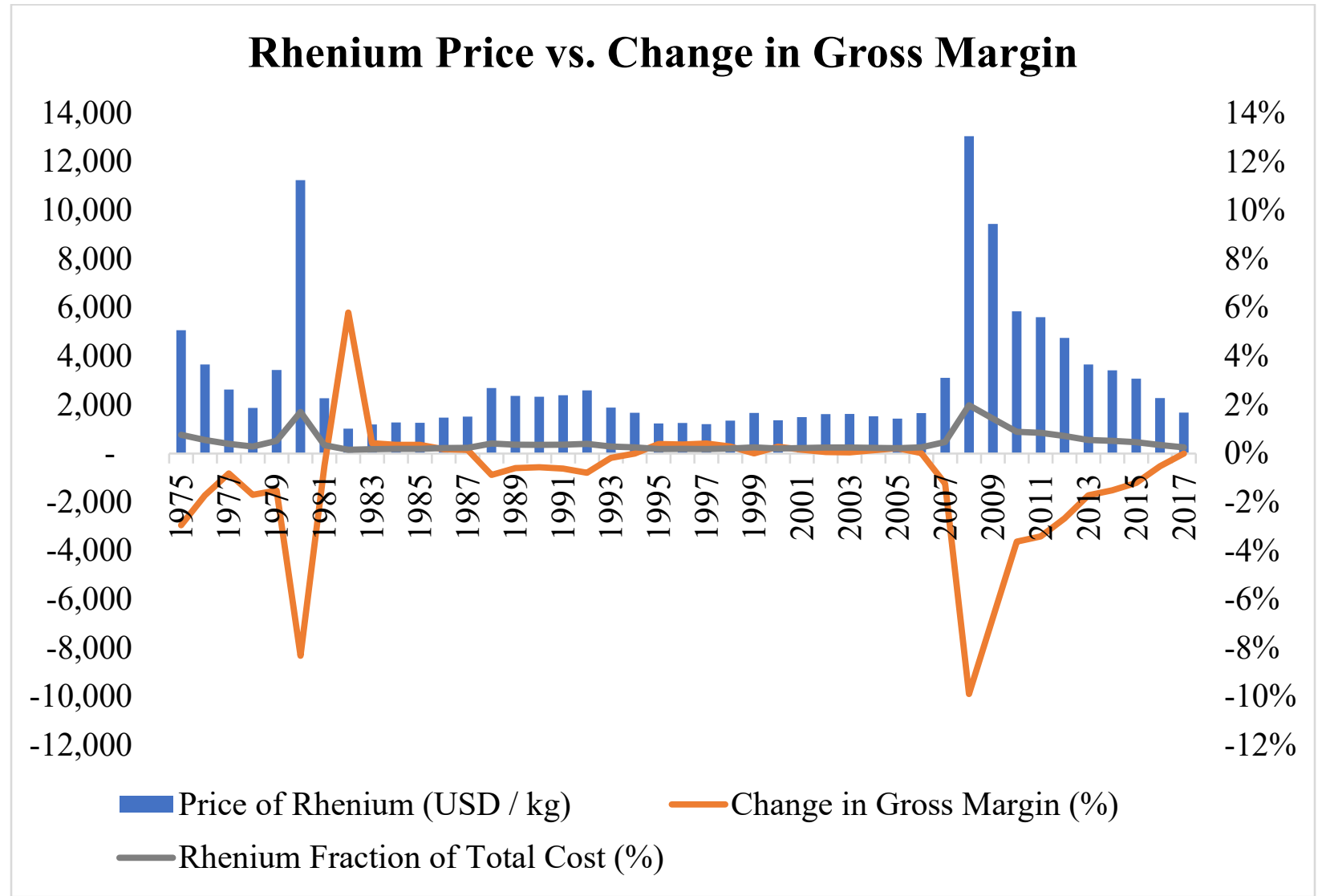

Although this case study focuses on the example of one aircraft manufacturer, Rolls-Royce plc is not the only aerospace firm that relies on materials vulnerable to price spikes. To further understand the dynamic between critical material price volatility and firm performance, annual and quarterly data was analyzed for three additional aircraft manufacturing firms that rely heavily on rhenium: Boeing, General Electric (GE), and Pratt \& Whitney (a subsidiary of United Technologies). This information is available in Appendix D.

\subsection{Controlled Environment Agriculture}

Controlled environment agriculture (CEA) is a form of urban agriculture that relies exclusively on artificial lighting (i.e., sole source lighting), for plant production. The reason CEA firms should care about critical materials is that the three primary types of horticultural lighting technologies - high intensity discharge (HID), linear fluorescent (LFL), and light 
emitting diode (LED) - all rely on critical materials. Critical materials are minerals and metals that are vulnerable to supply disruptions and high in economic or strategic importance. In the case of CEA, critical materials are important because they impact some of the specific characteristics of artificial lighting technologies that make crops successful or not.

This case focuses on LED lighting because, although these horticultural grow lamps are the most expensive, they are also the most energy efficient and have the longest lifespan. To manufacture LED grow lights requires critical materials such as cerium, europium, gadolinium, gallium, indium, and yttrium. These materials determine the spectrum (i.e., color), of light emitted by any given light bulb (Buchert et al 2012). Because plants require light from specific wavelengths on the light spectrum (Runkle 2015), the utility of any artificial lighting used in plant production is dependent on the material composition of the light bulbs being used. For example, yttrium, gadolinium, and cerium are commonly used to produce yellow hued light versus europium which is integral for producing red light (Buchert et al 2010). This is particularly relevant to LED lighting because this technology can be customized to emit the spectrum of light required at different plant growth stages and by different crop types in order to optimize yield.

There are six critical materials included in the controlled environment agriculture case. These include gallium, indium, and four rare earth elements (cerium, europium, gadolinium, and yttrium).

- Gallium is a metal used primarily for semiconductors, LEDs, and PV components. Primary deposits of gallium are found in Australia, China, Brazil, and India. Annual production capacity is 180 metric tons per year versus a recycling capacity of 200 metric tons per year worldwide (Jaskula 2019). However, the stated recycling capacity includes material that is not economically viable to recover (Jaskula 2019). United States consumption of gallium was equal to an estimated 23 metric tons in 2018 (Jaskula 2019).

- Indium is a metal used in the production of infrared detectors, high-speed transistors, PV cells, and LEDs. Most often derived as a byproduct of zinc ores, primary sources of indium can be found in China, Peru, Canada, Australia, and the United States. In 2010, primary global indium production was 570 metric tons (Anderson 2019). United States consumption of indium was an estimated 170 metric tons in 2018 (Anderson 2019). 
- Rare Earth Elements are a group of 17 elements that share similar properties, and are comprised of the 15 lanthanides, scandium, and yttrium (Gambogi 2019a, Gambogi 2019b). They are produced almost exclusively by China where $97 \%$ of rare earth mining and concentration occurs (Gambogi 2019a, Gambogi 2019b). Of particular note is the fact that $80 \%$ of the world's supply of phosphors used for lighting technologies is consumed by China (Gambogi 2019a, Gambogi 2019b). The following four rare earth elements are commonly used in LED lighting (Gambogi 2019a, Gambogi 2019b).

- Cerium is a metal used for a wide variety of applications including nuclear technologies, pigments, ceramics, metallurgical alloys, catalysts, glass and polishing, and phosphors such as those used in LED lighting.

- Europium is a metal used in the production of nuclear technologies, defense technologies, ceramics, and phosphors such as those used in LED lighting.

○ Gadolinium is a metal used in nuclear technologies, ceramics, glass and polishing, and phosphors such as those used in LED lighting.

- Yttrium is a metal used in the production of nuclear technologies, defense technologies, ceramics, metallurgical alloys, and phosphors such as those used in LED lighting.

Production and consumption of rare earth elements is reported in aggregate with the exception of yttrium. In 2017, China reported production of 180,000 metric tons of rareearth-oxide equivalent (Gambogi 2019a). Although the United States did not produce any rare earth elements in 2017, it did produce 15,000 metric tons in 2018 (Gambogi 2019a). The only other country with mine production above 2,600 metric tons per year is Australia which produced 19,000 metric tons in 2017 and 20,000 metric tons in 2018 (Gambogi 2019a). United States consumption of rare earth elements was estimated at 9,500 metric tons in 2018 (Gambogi 2019a). In addition to the other 16 rare earth elements, China is also the dominant producer of yttrium (Gambogi 2019b). In 2018 China produced an estimated 5,000 to 7,000 metric tons of yttrium (Gambogi 2019b). Domestic consumption of yttrium was estimated to be 400 metric tons in 2018 (Gambogi 2019b).

Supply dynamics similar to those discussed with regard to rhenium and the aviation industry are relevant to the six critical materials being discussed in the context of horticultural LED 
lighting and controlled environment agriculture. This includes a reliance on effective diplomacy between the United States and important producers like China. It also includes dependence on the political conditions and trade policies of producing countries as well as the consumption patterns of those same countries. In terms of cost and pricing, all six critical materials are traded in an opaque market, as is the case for rhenium. In depth current and historical pricing data is not publicly available but rather must be obtained directly from buyers and sellers, or from information brokers such as the Shanghai Metals Market (SMM Information \& Technology Co, Ltd). The cost of rare earth elements in particular is largely controlled by China. In fact, rare earth price spikes in 2010 and 2011 have been attributed to China's decision to cut its export allowances (GlobalData Energy 2018). Complicating the situation is the current trade war between the United States and China through which tariffs are compromising trade relations (GlobalData Energy 2018).

The economic and strategic importance of the critical materials (e.g., cerium, europium, gadolinium, gallium, indium, and yttrium), used in horticultural LED lighting is evident in market demand. Compared to rhenium, which has concentrated demand from the aviation industry, the critical materials needed to manufacture horticultural lighting are also used for numerous other technologies with strategic and/or economic importance. Some of these are listed in Table 3.2.1. LED lighting designed for horticultural applications is especially vulnerable to competing demand for the required critical materials. The reason for this is that LEDs are low cost, high efficiency, have myriad uses, and are being rapidly adopted. For example, the number of household installations of LED bulbs in 2014 was 195 times that of 2009 (DOE 2016). Between 2008 and 2016, the price of a typical household LED bulb dropped by 90\% (Romm 2016). 
Table 3.2.1. Competing demand for critical materials used in LED horticultural lighting technologies

\begin{tabular}{|l|l|l|}
\hline Material & $\begin{array}{l}\text { Light } \\
\text { Technology }\end{array}$ & Strategic/Economic Importance \\
\hline Cerium & LFL, LED & $\begin{array}{l}\text { Nuclear, pigments, ceramics, metallurgical alloys, catalysts, } \\
\text { glass and polishing, phosphors }\end{array}$ \\
\hline Europium & LFL, LED & Nuclear, defense, ceramics, phosphors \\
\hline Gadolinium & LED & Nuclear, ceramics, phosphors, glass and polishing \\
\hline Gallium & LED & Semiconductors, LEDs, PV components \\
\hline Indium & LED & Infrared detectors, high-speed transistors, PV cells \\
\hline Yttrium & LFL, LED & Nuclear, defense, ceramics, metallurgical alloys, phosphors \\
\hline
\end{tabular}

LED horticultural lighting is in high demand due to the growth of indoor farming (Agrilyst et al 2017). The expansion of controlled environment agriculture in particular is driven by declining outdoor growing conditions related to climate change and increased urbanization. Increased strain and pressure on water resources, an increase in the occurrence and extremity of severe weather events, and increased temperature are just some of the ways that climate change is making it more difficult to grow food using conventional, open field methods. Second, as more and more people move to urban areas it will become less efficient to produce food in rural areas far from population centers (United Nations Department of Economic and Social Affairs 2017). The transportation, distribution, and logistics involved will become more expensive and generate more emissions. In other words, the strategic and economic importance of the critical materials required to manufacture the lighting necessary for controlled environment agriculture is simply the ability to produce enough food to feed the world population.

As in the aviation case, horticultural lighting manufacturers rely on materials vulnerable to price spikes. Figure 3.2.1. shows the gross margin of a leading LED manufacturer, CREE, before and since the price spike in rare earth elements that occurred around 2010. Rare earth elements are used to manufacture horticultural lighting technologies and have very few or no substitutes. Figure 3.2.2. shows CREE's gross margin along with the price of Gallium, which is a critical material that this manufacturer relies upon heavily. 
Figure 3.2.1 Annual Financial Performance of CREE vs. Price of Rare Earth Elements

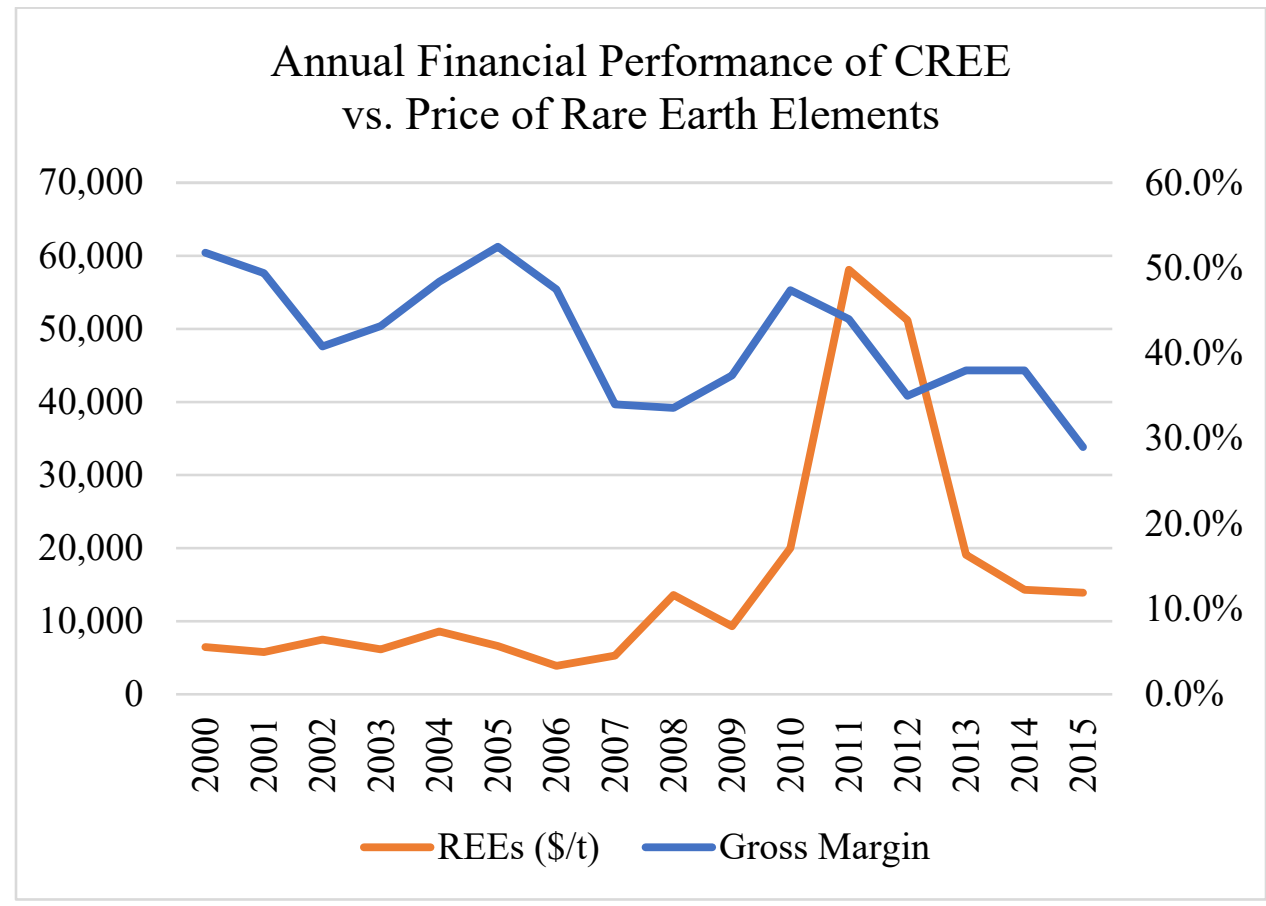

Figure 3.2.2. Annual Financial Performance of CREE vs. Price of Gallium

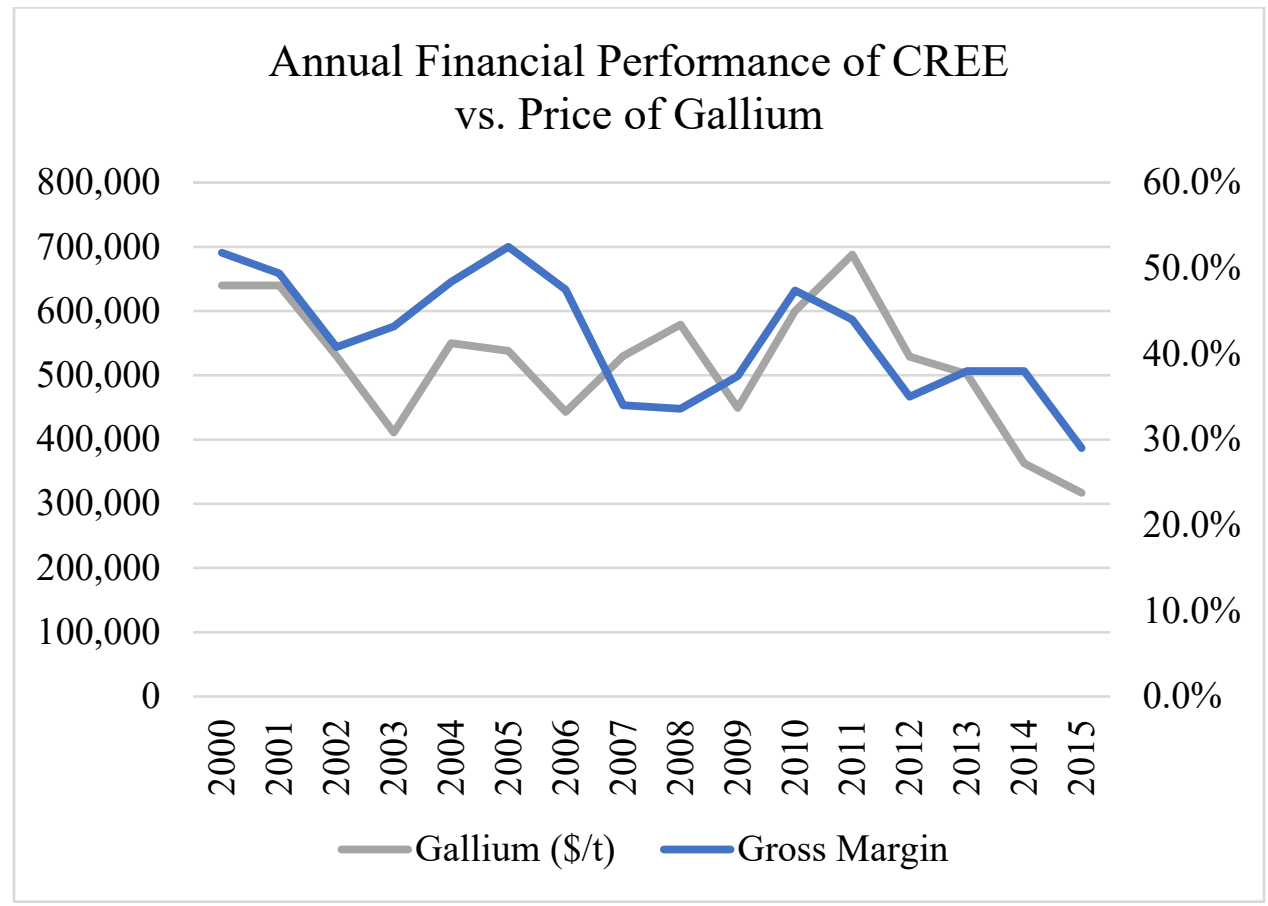


In the aviation case, manufacturers are vulnerable to criticality fallout primarily due to the extremely long process of manufacturing aircraft. Agreements about the number of aircraft to be purchased at what price are contracted years ahead of actual production, and the fulfillment of orders can occur over a period of years (Lipmann 2005, Polyak 2017). This makes it very unlikely that increased costs due to price volatility and supply disruptions can be passed on to the consumer. In the horticultural lighting case, manufacturers are similarly vulnerable but for different reasons. Despite having the benefit of dramatically shorter production times, lighting manufacturers face an extremely competitive market, the wide availability of many substitutes (e.g., by technology or brand), and are forced to absorb any price spikes due to price competition (CREE 2018).

Going back at least as far as the year 2000, CREE has commented on supply risk in its SEC 10-K filings. The company notes, in reference to sources of raw materials, that it depends on "certain key materials and equipment used in critical stages of our manufacturing process" and that its suppliers "can be subject to many constraints limiting supply that are beyond our control" (CREE 2000-2018). The company also states that it is reliant on sole or limited source suppliers and that, although alternate suppliers exist, the process of vetting them can take six months or longer. Finally, CREE notes the difficulty and additional cost associated with obtaining certain raw materials that are concentrated in conflict zones and therefore subject to transparency and accountability regulations enforced by the Dodd-Frank Wall Street Reform and Consumer Protection Act (CREE 2012). As recently as 2017, CREE noted in its SEC 10-K that many of the raw materials required to manufacture its products are prone to high price volatility as well as variation in consistency and availability.

There are clear advantages and disadvantages to each of the three primary horticultural lighting technologies that differently impact their vulnerability to critical material risk. For example, the critical material requirement for fluorescent bulbs is considerably lower in mass and cost compared to HID and LED bulbs (see Table 7.3.1. in Appendix C). However, supply disruptions and price volatility have somewhat of an equalizing effect on the three technologies. The cost and availability of critical materials becomes irrelevant when neither manufacturers nor business consumers can absorb or compensate for the financial impact. For example, if HID, fluorescent, and LED lighting were simultaneously unavailable and/or unaffordable, manufacturers might resort to producing the comparatively inefficient and ineffective technology 
of incandescent bulbs to grow plants. However, even that technology relies on critical materials. The filaments and lead wires are made of tungsten. Rolls-Royce can continue to produce jet engines without rhenium; these engines won't be as fuel efficient as the Trent XWB, but they will effectively power aircraft. Horticultural lighting capable of emitting specific spectrums of light, on the other hand, can't be manufactured without critical materials like tungsten, cerium, europium, gallium and yttrium.

The critical material risk to horticultural lighting manufacturing has multiple implications beyond the firm. For example, assume that a significant percentage of agriculture has shifted to controlled environment methods. If horticultural lighting manufacturing becomes limited, unpredictable, or too costly, how does food get produced? Each type of light bulb-HID, fluorescent, and LED — has a lifespan ranging between 6 and 14 years depending on the technology and usage. This means that the impact of a critical material supply disruption would lag significantly, assuming that currently deployed horticultural lighting varies in remaining useful lifespan. However, there are additional factors at play. For example, using LED lighting and indoor farming on a large scale may require more materials than are produced in a given year. Another mitigating factor might be trade policy. The vast majority of the critical materials used in horticultural lighting are produced in China. Although many of the critical materials used in horticultural lighting can be reclaimed from light bulbs at end of life, it is not yet clear that this strategy is efficient or economically feasible (Rhee et al 2013, Punkkinen et al 2017, Rahman et al 2017). With limited and often no production capacity in the United States, a supply disruption and/or price spike could theoretically last indefinitely.

\subsection{Firm Response: Supply Disruption Profile}

It is unlikely that firms will be able to prevent critical material supply disruptions altogether so their response to them when they occur is important. Figure 3.3.1. is an adaptation of a supply chain disruption profile developed by Sheffi and Rice (2005). It depicts changes to firm performance relative to a supply disruption and mitigation tactics over time, and includes several of the mitigation strategies such as hedging, substitution, and development of new materials and technologies. It may be surprising, but even firms that have long-term contracts in place for commodities can still experience delays in delivery of that commodity due to disruptions. Nokia had large losses due to a disruption in delivery of semiconductor devices that was caused by a 
supplier fire (a supplier that had long-term price contracts) (When the chain breaks 2006). General Electric also had long-term contracts in place for rhenium; these agreements may not always ensure commodity delivery when actual physical disruptions occur (Duclos 2016). Firms are then forced to get the commodity, part, or product from a different supplier that they do not have long-term contracts with and thus are forced to pay a much higher price.

Although the trajectory of the response shown assumes that the firm was engaged to some extent in hedging, we can clearly see that once the benefits of hedging have been depleted (i.e. short term inventory and alternate suppliers), the time to recovery and normalization is about three times as long as the time between the disruption and the use of short term solutions. One way that the profile is instructive on the goal of firm-level criticality assessment (i.e. to mitigate and/or prevent a negative impact on firm performance due to supply disruption), is to apply the scenario in Figure 3.1.2. For example, if Rolls-Royce had proactively identified substitutes or developed new materials and technologies in place of rhenium, these mitigation tactics could have been implemented directly following the assessment phase of the response, thereby substantially reducing the drop in firm performance and its duration.

Figure 3.3.1. Conceptual Timeline of Firm Response to Supply Disruption

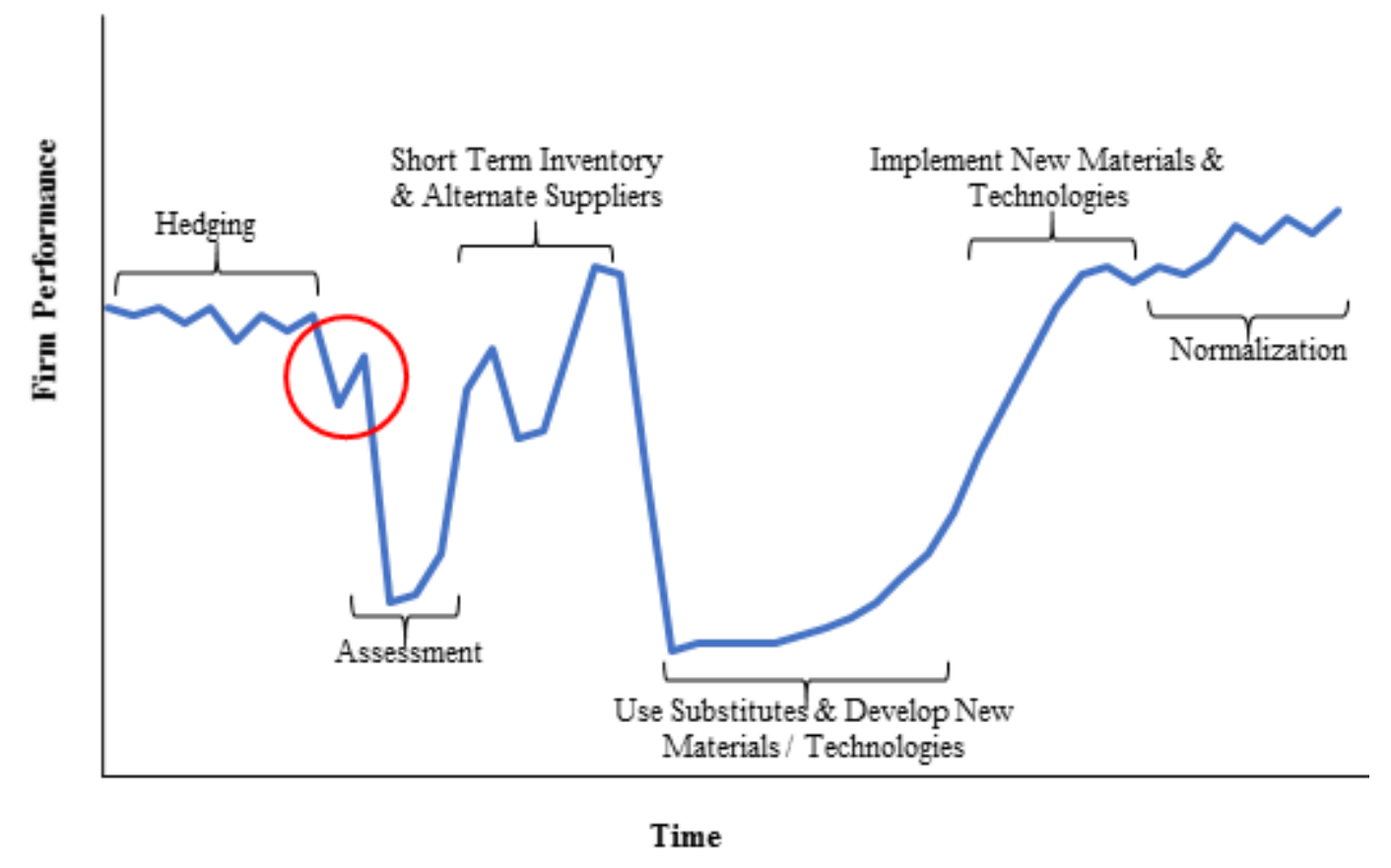

A number of additional insights and conclusions can also be drawn from the disruption profile. First, firm performance relative to a supply disruption appears to be correlated to time. 
Second, the severity of the disruption's impact varies throughout the profile suggesting that interim firm actions are correlated to that firm's progression through the profile. Third, the time from the disruptive event to recovery, as well as the time between stages, is contingent on a firm's actions. In other words, although supply disruptions create predictable impacts across organizations, an individual firm's response determines the ultimate outcome. This means that firm-level risk monitoring and mitigation is not only possible, but necessary.

Some of the ways that individual manufacturing firms can moderate the risk of critical material supply disruption involve material usage, product development, product design, and inventory management. For example, a firm might use one alloy in place of another, develop an entirely new alloy, reduce waste through increased materialization, or decrease the amount of material needed by increasing material efficiency. Another strategy might be cross-functional collaboration during product development; at least some of the information needed to assess criticality from the development stage is often located outside of R\&D, so involving engineering and procurement experts can make a determination of viability more efficient and prevent longterm risk. A third approach to risk mitigation is to design products that accommodate efficient extraction of critical materials at end-of-life and create mechanisms to maximize end-of-life material recovery. Inventory management strategies could include the use of long-term supply contracts, hedging, and supplier transparency. Large firms might also use vertical integration to acquire their suppliers or secure a primary source of material through mining rights and smelting plants (Cullbrand and Magnusson 2012). Vertical integration is a supply chain strategy and business model that firms use to gain more control over the inputs of production. Instead of using third-party suppliers to secure materials, firms with an integrated supply chain own the companies that provide the materials needed.

The success of these strategies depends on two things: associated costs (in terms of product quality, product efficacy, and financial expense), and timeliness of implementation. In the former case, a firm may have a substitute material available that is feasible but results in a lower durability; an alternate material that meets minimum requirements but results in lower performance; or the technological ability to extract a critical material from a product that has reached end of life that is not economical. In the latter case, a firm may complete a product redesign (which eliminates the need for critical material), only after it has lost most of its market share due to a supply disruption. 
General Electric (GE) provides a real-world example of firm-level risk mitigation that found success in terms of timely implementation but not cost. When confronted with a perceived shortage of rhenium (a material critical to the manufacture of turbine engines), GE's aviation segment used a multiple step internal strategy to address the impact of an externally driven supply disruption (Duclos, Otto et al. 2010). Below, we use GE's strategy and the disruption profile from Sheffi and Rice to demonstrate the firm-level impact and response (Sheffi and Rice Jr 2005).

The first action taken by GE took place before the rhenium shortage occurred, corresponding with the preparation stage of the disruption profile. By examining each material that it deemed critical to its operations, GE was then able to evaluate each material based on four sub-risks: GE $\%$ of world supply, impact on GE revenue, ability to use substitute materials, and ability to pass through cost increases to consumers. Each of these sub-risks can be quantified and tracked using internal data. Once known, additional preventive action can be taken such as hedging, securing long-term supply agreements, material stockpiling, redesigning products to decrease material utilization, and developing new technology that requires no or fewer critical materials.

After the disruptive event occurred (i.e. the perceived rhenium shortage), GE conducted a material usage audit that was then used to determine sources and sinks of rhenium in the products being manufactured. This corresponds with the first response stage of the disruption profile and it enabled GE to fully assess its ability to internally mitigate the risk at hand. Next, although GE couldn't control the initial impact of the disruption, they could take steps to move toward the recovery stage of the disruption profile. Beginning with the initial impact stage and through the time of the full impact and preparation for recovery stages, GE took four actions based on its assessment in the third stage of the disruption profile. First, GE employed a common foundry practice called revert which allowed them to reuse casting waste. Second, GE developed a chemical process that enabled them to reuse grinding chips of rhenium for high value alloys. Third, GE developed a cleaning process to recycle material from products that have reached end of life. Finally, GE developed two new alloys that require significantly less rhenium content.

Having successfully reduced rhenium usage, GE entered the recovery stage. Based on the information available, it's difficult to gauge the long-term impact of the rhenium supply disruption to GE but two conclusions can be drawn. First, although the turbine engines 
manufactured with the new alloys developed during the recovery phase of the supply disruption did successfully operate, they were ultimately unviable from a business standpoint because the reduction of rhenium resulted in decreased fuel efficiency (Duclos 2016). Second, despite the market failure of the new alloys, GE was still able to mitigate risk by using internal data and resources to minimize material waste and increase utilization efficiency.

\subsection{The Bullwhip Effect}

In addition to understanding the mechanics of a supply disruption over the course of its impact on an individual firm, broader market dynamics must be considered. One important example of this is the supply chain and its many interdependencies, as illustrated by the bullwhip effect. A phenomenon in which inventory levels get out of sync with demand, the bullwhip effect causes companies to over- or under-order from suppliers, and results in artificially amplified demand over time. The underlying disconnect between buyers and sellers throughout the supply chain leads to increasing operational inefficiencies such as excess inventory, lack of inventory, lost production time, lost sales, and, ultimately, lost profit and market share.

Lee et al. have identified four underlying mechanisms that cause the bullwhip effect: demand forecast updating, order batching, price fluctuation, and rationing and shortage gaming (Lee, Padmanabhan et al. 1997a, Lee, Padmanabhan et al. 1997b). Demand forecast updating is a process in which firms determine future operational needs (e.g. materials, capacity, production scheduling), based on historical sales. When a firm places an order based on this information, the next level of the supply chain bases its production, including safety stock, on that signal. Order batching happens when firms order periodically rather than based explicitly on demand and when firms experience surges in demand (e.g. a new product is more popular than forecasted). Rationing happens when demand exceeds supply and producers ration their products in response. Shortage gaming is when customers exaggerate their orders to compensate for rationing.

The triggering event of the bullwhip effect is an increase in demand at the downstream end of the supply chain (in this case, aircraft orders from airlines). Represented by the yellow line in the conceptual model in Figure 3.4.1., inventory levels begin to diverge after a modest increase in demand at the retail level followed by increasing amplification further up the supply chain. The retail inventory and backorder quantities fluctuate the least followed by the wholesale level, 
the distributor level, and finally the factory level. The areas of the graph in which some levels of the supply chain have positive inventory levels, and some have backorders highlight potential areas for supply disruption. For example, in the middle of the graph, the factory backlog is extremely high and all other supply chain actors are reducing their backlogs. In response, both the factory and the distributor next develop safety stocks that far surpass subsequent inventory levels at the wholesaler and retailer levels of the supply chain. These fluctuations and mismatches across supply chain actors result in inefficiencies that threaten a firm's stability such as higher raw material costs, carrying costs due to excess inventory, increased labor costs due to overtime needed to fill overdue orders, and poor customer service.

Figure 3.4.1. Bullwhip Effect Conceptual Model

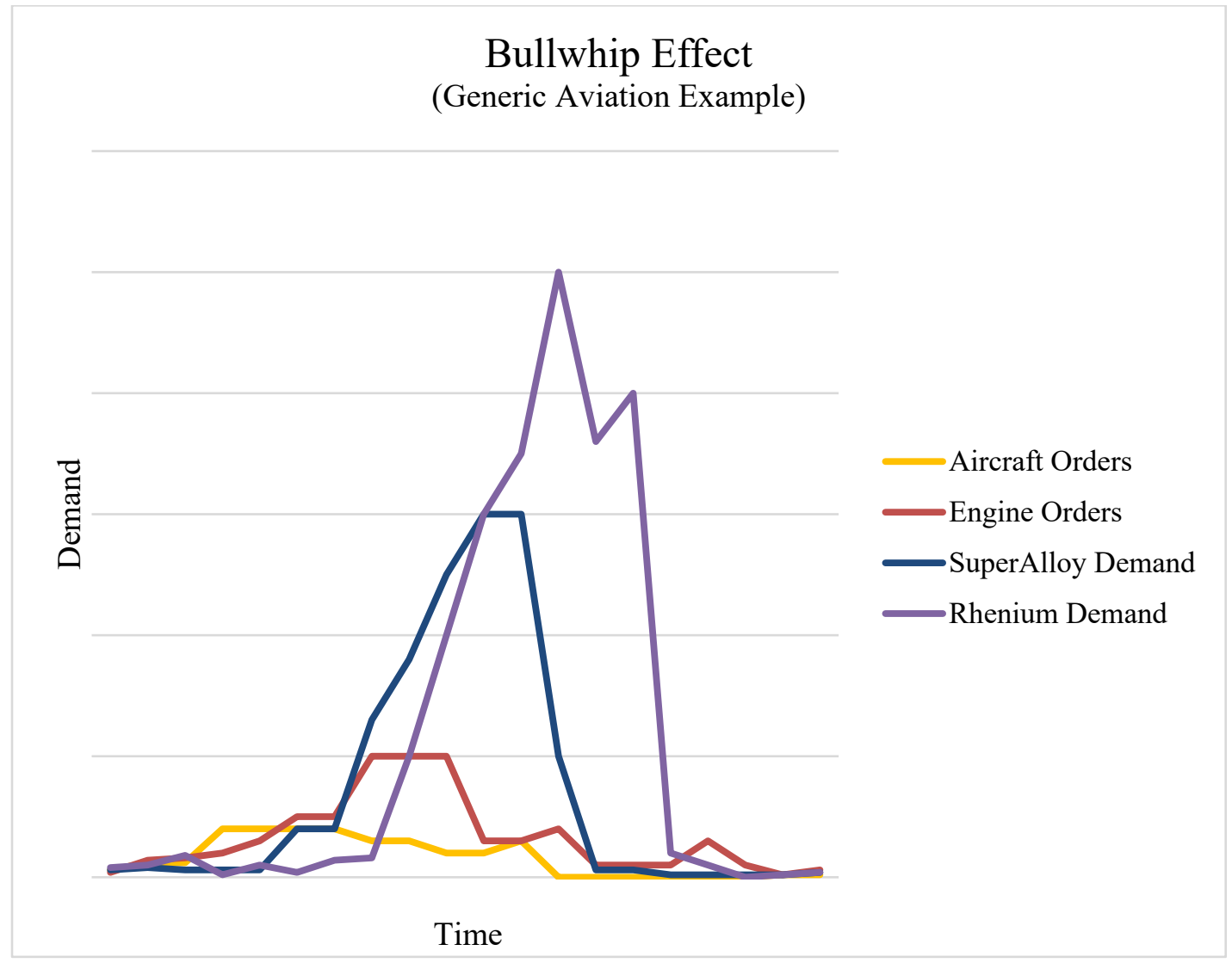

The relevance of the bullwhip effect to firms that rely on critical materials, and therefore often face supply disruptions, is an increase in the degree of uncertainty in risk measurement. Firms can use performance metrics such as backlog (i.e. undelivered goods), fill rate (i.e. ratio of 
on time orders to late orders), zero-replenishment (i.e. the absence of orders from a tier in the supply chain during a regular order period), and slope metrics (i.e. bullwhip slope, inventory instability slope, and work in process instability slope), to mitigate risk in their own inventory and supply levels, but they have to rely on market signals to measure this same risk beyond the first tier in their supply chain (Cannella, Barbosa-Póvoa et al. 2013). This means that when the supply chain experiences a bullwhip, each tier of the supply chain is faced with this same dilemma, and the degree of uncertainty in risk measurement increases with each tier.

Figure 3.4.2. illustrates two of these key parameters for firms that greatly influence the impact on them in the face of a supply disruption. The bullwhip effect can be illustrated by the order penetration point, i.e., where in a typical process the firm lies in terms of delivering its product. In the aerospace examples, those firms design to order and are therefore at the highest order penetration point. In comparison, most consumer products and electronics are made to be shipped directly to customers and have a low order penetration point (to the right on the Figure). On the $y$-axis is the reliance of the industry on materials as it relates to profitability. Both aerospace and the automotive industry for example, rely heavily on material price margins in order to deliver on profitability. One can see that the aerospace case is therefore somewhat of an extreme - a combination of both high order penetration point, and high reliance on materials in their product. 
Figure 3.4.2. Example order penetration point and reliance on materials for various industries based on (Agarwal et al. 2012, Gaustad et al. 2017, Olhager 2003, Schoolderman \& Mathlener 2011).

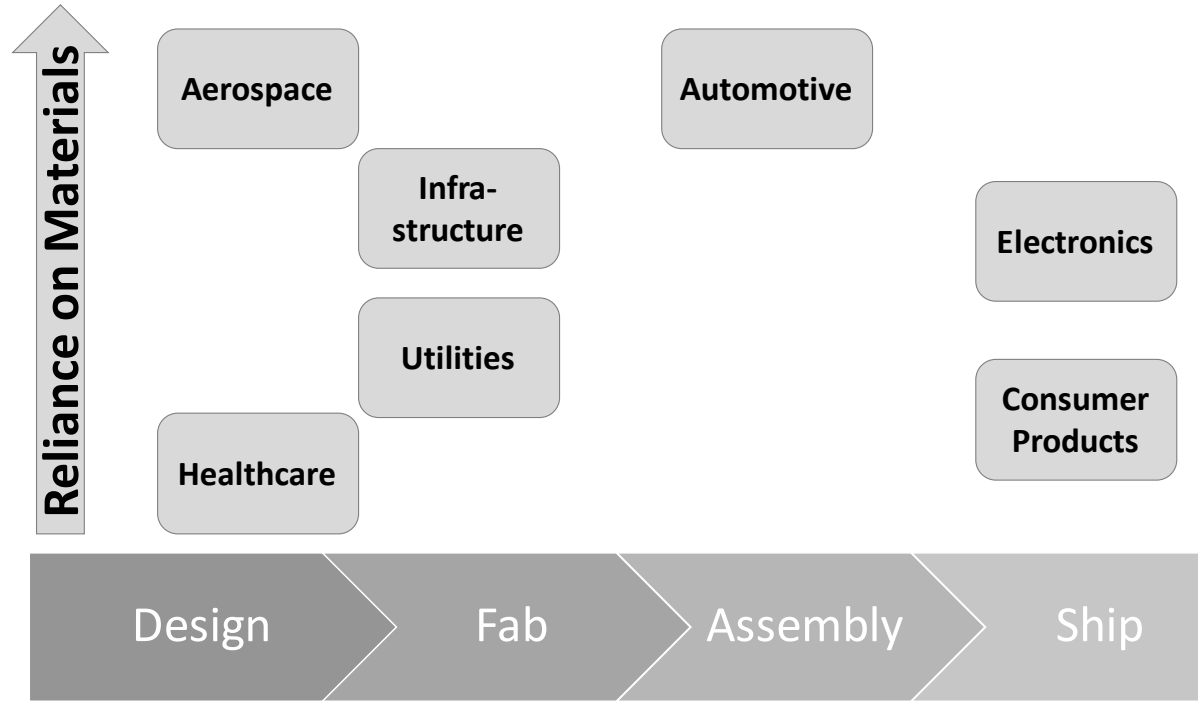

Order Penetration Point

\subsection{Firm-Level Indicators and Criticality Assessment Framework for Firms}

A comprehensive set of indicators spanning six broad categories (i.e. demand risk, environmental risk, geopolitical risk, market risk, scarcity, and supply chain), was identified in our analysis of existing firm-level criticality assessment methods. In general, these indicators were distributed fairly evenly as shown in Figure 3.5.1., with the highest percentage of indicators being found in the Market Risk category. Although these indicators incorporate all three of the core facets of sustainability (i.e. social, environmental, and financial), only $18 \%$ of them can be considered internal indicators, meaning that they can be derived from data generated at the firm level. Conversely, $82 \%$ of the indicators found can be characterized as external indicators. This finding is consistent with our assertion that current criticality assessments rely primarily on external data. Although external indicators - such as investment in mining, static reach reserves, and sourcing and geopolitical risk - are important and pertinent to criticality assessment at all levels, they can rarely be influenced by individual firms. 
In order to address the gap in firm-level criticality assessment methods, we further analyzed our findings and identified four sub-categories of internal indicators among the 11 firm-level studies reviewed: business risk, substitutability, supplier risk, and supply. As shown in Figure 3.5.1., 14 indicators concern business risk, 1 concerns substitutability, 1 concerns supplier risk, and 1 concerns supply. This is instructive because it gives an indication of what data and metrics are important and relevant to individual firms. For example, all of the business risk indicators fall into the broader category of market risk which is a determinant of the market viability of products.

Figure 3.5.1. Firm-Level Indicators by Category \& Sub-Category

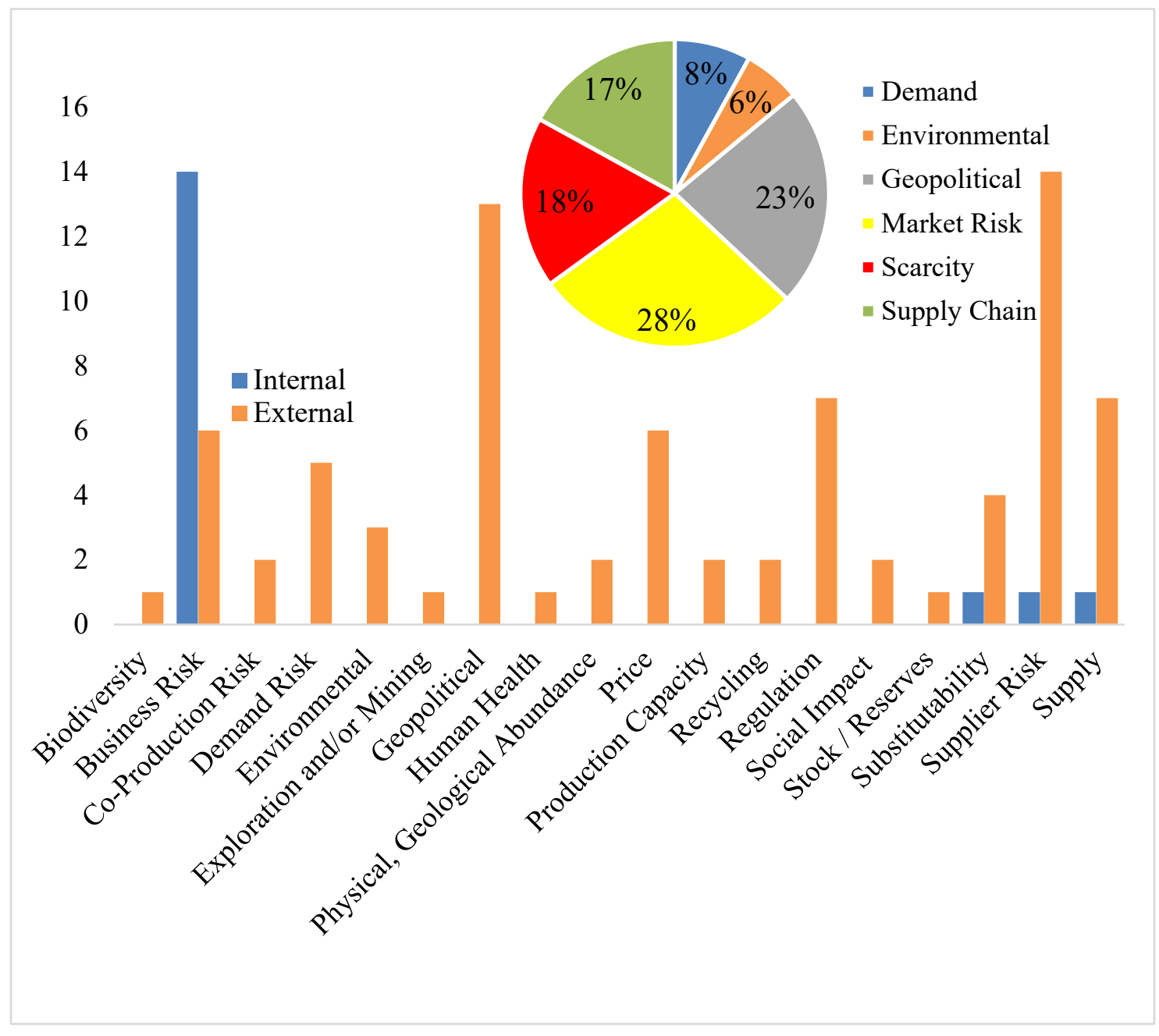

As a first step toward developing a criticality framework designed specifically for use at the firm level, five key components of assessment were identified: business purpose, application, metrics, risk levels, and indicators (Griffin et al 2019). This structure is depicted in Figure 3.5.2. 
Each of these components reflects assessment approaches and trends across the 11 firm-level studies. For instance, all of the firm-level studies incorporated metrics, risk levels, and indicators. Specific assessment themes found in the existing firm-level studies that were incorporated into the framework developed through this research include the treatment of risk, business performance, substitutability, and product-based risk assessment. For example, multiple studies employed unprescribed risk levels and control limits, and thresholds defined by individual firms. Risk was often categorized qualitatively (e.g., very high, high, medium, low, very low), and correlated to firm-determined control limits and thresholds that could be qualitative (e.g., concentrated, high risk, some diversity and/or risk, U.S. based), or quantitative (e.g., $<50 \%, 50 \%-100 \%, 200 \%-500 \%,>500 \%$ ) (Duclos 2016, Rosenau-Tornow et al 2009, Lloyd et al 2012a). Indicators were used to directly relate criticality risk to business performance (e.g., impact on revenue, ability to pass through cost increases, demand risk) (Duclos 2016, Lloyd et al 2012a, Lloyd et al 2012b, Miehe et al 2016, Kolotzek 2018). Rather than relying solely on supplier metrics (e.g., number of suppliers available), some studies incorporated metrics for substitutability in order to assess alternatives that firms have more control of and better access to (Duclos 2016, Lloyd et al 2012a, Kolotzek 2018). Product-based risk assessment was an approach used by four studies to understand risk exposure based on unit cost and revenue (Duclos 2016, Lloyd et al 2012b, Miehe et al 2016, Kolotzek 2018).

Figure 3.5.2. Framework Structure for Firm-Level Criticality Assessment

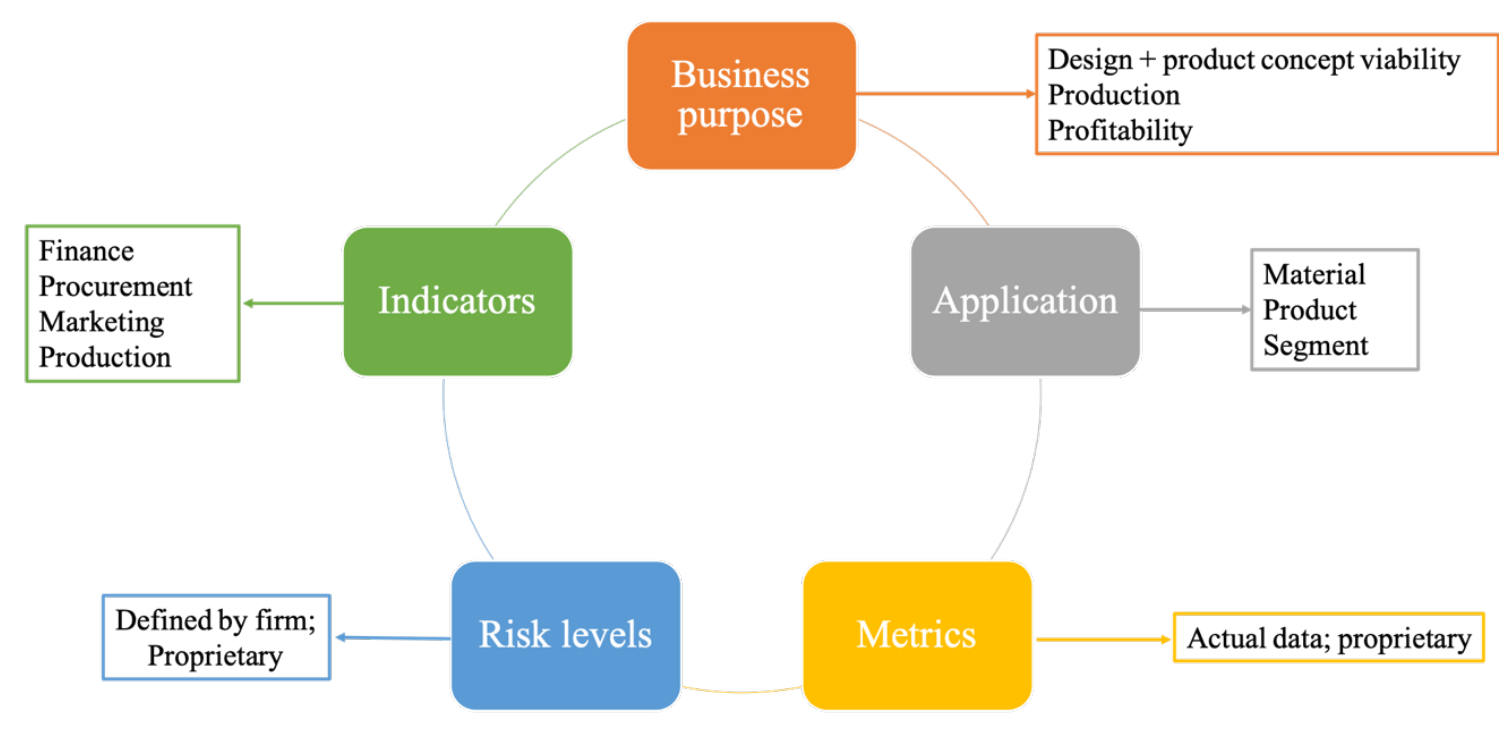


Using product viability in the context of market risk as a starting point, the emphasis of our assessment framework is definitively on a firm-level scope rather than a market, industry, national, or global one. The indicators themselves are correlated to three key functions present in any firm: profitability, design and product concept viability, and production. Each of these business elements has organization-wide impact and relies on resources and processes from multiple areas across a firm. In addition, vulnerability in one or more of these areas can constitute a threat to business sustainability. The purpose of this design is to produce information that has universal relevance to firms, a connection to the fundamental tenets of business noted above, a representation of cross-functional organizational dynamics (i.e. finance, procurement, marketing, and production), and the availability and accessibility of the underlying data in the regular course of business (Griffin et al 2019). A list of the specific indicators is presented in Table 3.5.1.

Table 3.5.1. Criticality Indicators

Profitability

\begin{tabular}{|l|l|l|l|}
\hline Finance & Indicator & Definition & Relevance \\
\hline Procurement & Revenue & $\begin{array}{l}\text { Income from sales of products } \\
\text { relying on critical material }\end{array}$ & $\begin{array}{l}\text { An indicator of risk exposure relative } \\
\text { to products that do not require critical } \\
\text { material }\end{array}$ \\
\hline Marketing & Price Elasticity & $\begin{array}{l}\text { The ratio of percentage change in } \\
\text { quantity demanded to percentage } \\
\text { change in price } \\
\text { price of a material over a given }\end{array}$ & $\begin{array}{l}\text { An indicator of market stability; high } \\
\text { levels of volatility signal high levels of } \\
\text { uncertainty and risk }\end{array}$ \\
\hline Production & Substitutability & $\begin{array}{l}\text { The extent to which it is possible to } \\
\text { demand to changes in price; changes } \\
\text { in price that don't impact demand are } \\
\text { inelastic vs. changes in price that do } \\
\text { impact demand which are elastic }\end{array}$ \\
critical material & $\begin{array}{l}\text { Higher substitutability allows firms to } \\
\text { use alternative materials when faced } \\
\text { with supply disruptions due either to } \\
\text { cost or scarcity }\end{array}$ \\
\hline
\end{tabular}


Design \& Product Concept Viability

\begin{tabular}{|c|c|c|c|}
\hline & Indicator & Definition & Relevance \\
\hline Finance & $\begin{array}{l}\text { Material Fraction } \\
\text { of Total Material } \\
\text { Cost }\end{array}$ & $\begin{array}{l}\text { Percentage of total product cost } \\
\text { from critical materials }\end{array}$ & $\begin{array}{l}\text { Indicator used to evaluate the } \\
\text { importance of a given critical material } \\
\text { with regard to product functionality } \\
\text { and value }\end{array}$ \\
\hline Procurement & Supplier Risk & $\begin{array}{l}\text { Availability of suppliers with } \\
\text { limited conduct violations }\end{array}$ & $\begin{array}{l}\text { If publicized, use of suppliers with } \\
\text { poor conduct can threaten the viability } \\
\text { of an entire firm }\end{array}$ \\
\hline Marketing & $\begin{array}{l}\text { Segment Market } \\
\text { Share }\end{array}$ & $\begin{array}{l}\text { Percentage of total sales in a given } \\
\text { market segment }\end{array}$ & $\begin{array}{l}\text { Market share is an indicator of relative } \\
\text { competitiveness and capacity to scale } \\
\text { operations }\end{array}$ \\
\hline Production & $\begin{array}{l}\text { Material } \\
\text { Utilization }\end{array}$ & $\begin{array}{l}\text { Ratio of the raw material weight } \\
\text { used in production to the weight of } \\
\text { the finished product }\end{array}$ & $\begin{array}{l}\text { An indicator of material waste; higher } \\
\text { utilization reflects more efficient and } \\
\text { economical production }\end{array}$ \\
\hline
\end{tabular}

\section{Production}

\begin{tabular}{|c|c|c|c|}
\hline & Indicator & Definition & Relevance \\
\hline Finance & Gross Margin & $\begin{array}{l}\text { Percentage of revenue retained as } \\
\text { gross profit }\end{array}$ & $\begin{array}{l}\text { The higher the percentage, the more } \\
\text { sales dollars retained which can be } \\
\text { used to cover costs and service debts; } \\
\text { a measure of organizational stability }\end{array}$ \\
\hline Procurement & $\begin{array}{l}\text { Inventory } \\
\text { Variance Ratio }\end{array}$ & $\begin{array}{l}\text { Ratio between inventory variance } \\
\text { magnitude and demand variance } \\
\text { ratio }\end{array}$ & $\begin{array}{l}\text { A quantification of inventory } \\
\text { fluctuation that signals changes in } \\
\text { holding and backlog costs, and can be } \\
\text { used to measure inflated average } \\
\text { inventory cost per period; higher } \\
\text { ratios signal higher holding and } \\
\text { backlog costs }\end{array}$ \\
\hline Marketing & $\begin{array}{l}\text { Supplier } \\
\text { Reliability }\end{array}$ & $\begin{array}{l}\text { The percentage of deliveries that are } \\
\text { on time and complete orders }\end{array}$ & $\begin{array}{l}\text { Production delays due to raw material } \\
\text { delay can be extremely expensive }\end{array}$ \\
\hline Production & $\begin{array}{l}\text { Production } \\
\text { Efficiency }\end{array}$ & $\begin{array}{l}\text { Ability to produce the highest } \\
\text { quantity with the least resources at } \\
\text { the lowest cost and the highest } \\
\text { profit }\end{array}$ & $\begin{array}{l}\text { A decrease in production efficiency } \\
\text { could signal a supply problem }\end{array}$ \\
\hline
\end{tabular}

Combined with the indicators, the framework also reflects findings from each of the case studies presented in this work. In the aviation case, the concurrence observed between firm performance and the price volatility of rhenium informed three of the indicators included our framework: revenue, price volatility, and gross margin. Analysis of price volatility informed another indicator, material fraction of total material cost. In the controlled environment agriculture (CEA) case, concurrence was again observed between price volatility and firm performance. However, in the CEA case, impacts to firm performance were in terms of not just profitability but of product viability. 
In the aviation case, the impact of a rhenium supply disruption does not immediately threaten production because manufacturers do have access to substitute materials and because the material fraction of total cost is quite low. This means that, although the manufacturer may incur a higher cost of production, production itself is not immediately vulnerable. This is also related to the fact that aircraft manufacturing is a niche market with extremely long lead times. Switching costs are very high once a purchasing contract has been executed and there are very few competitors in the market. Using substitutes decreases engine efficiency and performance but does not compromise the overall integrity of the product.

In the CEA case, on the other hand, supply disruptions threaten production more quickly and more severely. There are two reasons for this. First, the lighting industry is low margin and extremely competitive. There are many manufacturers and switching costs are low. Second, if substitute materials are used to manufacture horticultural LED lamps, the characteristics of the light that they emit can be substantively altered. Given the highly customized nature of horticultural LED lamps (which is part and parcel of their value proposition), if there is a critical material supply disruption or price spike, consumers will be quickly incented to purchase an alternative, less expensive technology. However, in the form presented in Table 3.5.1., this set of internal indicators does not stand alone. So why would a firm want to use this tool?

A fundamental characteristic of the indicators is that it does not specify the scope of criticality or risk to be measured. Each firm has unique needs and circumstances (e.g., firm size, segment, industry, type, and number of products). In designing the tool with limited structure, it can be used to focus on a specific raw material; a particular product or group of products; product or segment profitability; sales volume; research and development; or other priorities. In this way, the tool addresses inter and intra firm variability and can be uniquely adopted by any organization. Given its underlying function - to assess criticality risk - the most important flexible aspect of the tool is the lack of defined risk limits. The reason firms need a firm-level assessment methodology that relies on internal data is that the existing criticality assessment frameworks measure aggregate risk that does not take into account firm-specific parameters such as working capital, number of suppliers, labor available, specificity limits (i.e., process and product performance targets), and control limits (i.e., allowable performance variation). This tool enables a firm to set unique control limits on degrees of risk and establish indicator bounds that reflect its specific circumstances, priorities, and strategies (Griffin et al 2019). 
Defining criticality risk based on internal conditions using internal metrics represents the ultimate utility of the tool. When the value of an internal indicator changes from one reporting period to another, firms can mitigate (or capitalize) on it through internal action. When external factors impact an individual firm, the only course of action is to react. For example, if a firm identifies a decrease in supplier reliability it can investigate this signal to determine if the cause lies with a specific supplier or if the change is a harbinger of broader supply chain delays. Similarly, if a firm determines that substitutability is low for a particular product group of products, it might try to develop its own substitute material or diversify its product offerings to include products with high substitutability.

The tool can also be used to help firms strategically manage unforeseen negative events (i.e. Black Swans). When a firm defines control limits and risk thresholds specific to its own operations (rather than national or global criteria), it can not only measure variability, but benchmark variability against its own limits. In so doing, the firm can characterize a supply disruption in terms of the appropriate response. When firms experience variations that are within control limits, they can revise risk thresholds to improve signaling. When firms experience variations that are beyond control limits, there is a bigger problem. An example of the difference between variations within and beyond control limits is a delay in shipment versus a price spike. If production slows or target delivery dates are compromised because a critical material is temporarily unavailable, variation is within control limits and a firm can likely survive the disruption. If the cost of a critical material suddenly and unexpectedly increases dramatically, variation is beyond control limits and a firm may not survive the disruption. The framework developed here is meant to address this variability so that it can be uniquely adopted by any organization. It also aims to provide an approach to criticality assessment that can be distilled into a firm-level scorecard that can be used to track and predict risk. An example of what a firmlevel scorecard might look like is presented in Table 6.4. in Appendix B (Griffin et al 2019).

More specifically, the framework can be implemented starting with just one material, product, or segment of focus. The next step would be for the firm to identify sources of data and any related parameters from existing internal reporting. For example, revenue from the material, product, or segment being analyzed as a percentage of total firm revenue could come from marketing, sales, or finance. Given this information, a firm should next define risk thresholds and control limits. For example, if revenue drops by $\mathrm{X} \%$, the firm will stop its production. 
Similarly, a high level of risk might be defined as a decrease in revenue of Y\% compared to a moderate level of risk which is defined as no change in revenue, or a low level of risk which is defined as Z\% increase in revenue (Griffin et al 2019).

In general, the risk levels defined by each firm are most useful when they correspond to a range of quantitative metrics. This is important because the risk level and underlying ranges of values represent another way that firms can operationalize the framework to suit their individual needs. For example, the dispersion of supplier reliability values may be wider for a firm with readily accessible secondary suppliers compared to a firm with only one supplier for a particular material or component. Similarly, a firm that relies on a critical material for $5 \%$ of its revenue has more relaxed constraints compared to a firm that relies on a critical material for $50 \%$ of its revenue.

A further consideration regarding criticality risk assessment is the relationship between the indicator and the timing of the decision(s) that it informs. Generally, business performance management consists of both leading and lagging indicators. Leading indicators are predictive in nature in that they are meant to inform decisions that precede an economic impact or change. They are also a crucial element of an efficient and effective framework. For example, substitutability - the extent to which it is possible to substitute another material for a critical material - is something that can be evaluated prior to a supply disruption. If there is a high level of substitutability, supply disruption risk is low, and a firm can expect to be able to effectively manage such an occurrence by simply using an alternative, readily available material. In this case the firm may decide to start or continue production of a technology involving critical materials. If there is a low level of substitutability, a firm can use this information to make decisions about whether it will manufacture a product at all and, if so, what kind of commitments it will make to its clients (e.g. number of products manufactured per period), and how much margin it is willing to absorb if a supply disruption increases the cost of delivery to the client. Conversely, lagging indicators are meant to inform decisions that follow an economic impact and to substantiate trends and patterns. For example, price volatility - the percentage difference in the price of a material over a given period of time - is an indicator of market stability. By monitoring price volatility, a firm can make decisions about which products to produce when and in what quantities, based on the levels of uncertainty and risk reflected in historical data (Griffin et al 2019). 
While there is latitude with regard to how a given organization can implement the firm-level criticality framework, there are a number of considerations to be made. First, although historical trends may be useful in understanding and assessing criticality, the framework is designed to be used on a more dynamic basis. For instance, the use of internal metrics (which are generated and available in the normal course of business), is intended to shorten the time between data generation and criticality assessment in order to improve the timeliness of firm response to a predicted or observed supply disruption. The framework should be updated quarterly at a minimum. This time period was chosen for a number of reasons: it is a common reporting period, annual data may no longer be relevant by the time it is available, and correlation can be seen on a quarterly basis. Second, the framework can and should be used to inform a firm's mitigation strategy choices. For example, the price volatility metric can be used in combination with the material fraction of product cost and price elasticity to determine whether a firm should invest resources to redesign a particular product or simply maintain modest safety stock. Similarly, a firm could use segment market share and supplier risk to negotiate long-term contracts with suppliers. Finally, the framework is designed to leverage existing internal business data to give the firm information that it can use to directly influence internal outcomes. Although there are salient external factors and data sources related to material criticality, the focus here is on factors over which firms have some degree of control (Griffin et al).

\subsection{The Role of the Organization}

Critical material risk assessment and mitigation have been extensively studied from perspectives external to individual firms such as physical availability, geopolitical conflict, global demand, and environmental hazards (see Table 6.1. in Appendix B). While relevant and impactful at the firm level, these factors are largely outside the control and influence of individual businesses. Conversely, firms can influence internal factors (e.g. product allocation, capital expenditures, supply chain strategy, research and development investment), that drive their individual profitability, design and product concept viability, and production efficiency. In fact, business organizations routinely compile data and prepare both internal and external reports to do so. Some of these include quarterly and annual financial reports, legally mandated tax and SEC filings, accounting audits, and assurance audits. It follows then that, conceptually, firms should be able to leverage existing data and reporting structures to assess criticality risk. In 
practice, however, there is little evidence of this approach. One reason for this may be that, just as the impacts of supply disruptions effect areas across an organization, remedies are also influenced by multiple areas and therefore can't be implemented by any one department or functional area alone. That is, the organizational structure of a firm plays a central role in its ability or inability to assess and mitigate criticality risk.

One practical demonstration of this dynamic is the dependency between research and development and procurement. Without information from a firm's research and development resources, procurement won't be able to contract the correct quantities and types of materials. This is especially relevant when a firm is ready to scale up from a prototype (i.e., one unit) to full scale production (i.e., dozens, hundreds, thousands, or even millions of units) because of the significant increase in volume. Without procurement, research and development won't know what alternate materials are available in what quantities and at what cost, and they won't know if procuring the necessary materials is possible or financially feasible. Both of these scenarios limit a firm's ability to effectively respond to a supply disruption. The former situation could, for example, result in production delays and compromise profits. Similarly, the latter situation could lead to the development of a new product that is cost prohibitive to implement at scale. Using the internal criticality indicators in Table 3.5.1., Table 3.6.1. provides several examples of the relationship between organizational structure and risk assessment in an individual firm.

\section{Table 3.6.1. Internal Criticality Indicator Data and Sources at the Firm Level}

\section{Profitability}

\begin{tabular}{|l|l|l|l|}
\hline Indicator & Information Needed & Source of Information & Org. Position \\
\hline Revenue & $\begin{array}{l}\text { Products containing critical } \\
\text { materials }\end{array}$ & Research \& Development & Materials Engineer \\
\cline { 2 - 4 } & \# of units sold / sales volume & Accounting and Finance & Accountant \\
\cline { 2 - 4 } & \$ per unit, per product & Marketing & Marketing Manager \\
\hline Price Volatility & Material pricing data over time & Procurement & Cost Estimator \\
\cline { 2 - 4 } & Supplier contracts & Procurement & Purchasing Agent \\
\hline Price Elasticity & Sales volume & Accounting and Finance & Accountant \\
\cline { 2 - 4 } & Pricing data over time & Procurement & Cost Estimator \\
\cline { 2 - 4 } & Ability to pass on cost increase & Marketing & $\begin{array}{l}\text { Market Research } \\
\text { Analyst }\end{array}$ \\
\hline Substitutability & Product material composition & Research \& Development & Materials Engineer \\
\cline { 2 - 4 } & Change-order cycle time & Production & Industrial Engineer \\
\cline { 2 - 4 } & $\begin{array}{l}\text { Technical feasibility of } \\
\text { substitution }\end{array}$ & Research \& Development & Materials Engineer \\
\hline
\end{tabular}




\section{Design \& Product Concept Viability}

\begin{tabular}{|l|l|l|l|}
\hline Indicator & Information Needed & Source of Information & Org. Position \\
\hline Material Fraction of & Product material composition & Research \& Development & Materials Engineer \\
\cline { 2 - 4 } & Cost of critical materials used & Procurement & Purchasing Agent \\
\cline { 2 - 4 } & Total cost of materials used & Procurement & Purchasing Agent \\
\hline Supplier Risk & Number of suppliers & Procurement & Purchasing Manager \\
\cline { 2 - 4 } & Supplier contract details & Procurement & Purchasing Manager \\
\cline { 2 - 4 } & Lead time by supplier & Procurement & Purchasing Agent \\
\hline \multirow{3}{*}{$\begin{array}{l}\text { Segment Market } \\
\text { Share }\end{array}$} & $\begin{array}{l}\text { Revenue per product / business } \\
\text { unit }\end{array}$ & Accounting and Finance & Accountant \\
\cline { 2 - 4 } & Total segment revenue & Marketing & \\
\cline { 2 - 4 } & Sales volume & & Market Research \\
& Material Utilization & Aesign specified composition & Accountant \\
\cline { 2 - 4 } & Actual composition & Research \& Development & Materials Engineer \\
\cline { 2 - 4 } & Ability to reclaim materials & Production & Industrial Engineer \\
\cline { 2 - 4 } & Materials reclaimed & Production & Materials Engineer \\
\hline
\end{tabular}

\section{Production}

\begin{tabular}{|l|l|l|l|}
\hline Indicator & Information Needed & Source of Information & Org. Position \\
\hline Gross Margin & Revenue & Accounting and Finance & Accountant \\
\cline { 2 - 4 } & Cost of goods sold & Accounting and Finance & Accountant \\
\hline $\begin{array}{l}\text { Inventory Variance } \\
\text { Ratio }\end{array}$ & Fluctuations in net inventory & Production & $\begin{array}{l}\text { Supply Chain } \\
\text { Manager }\end{array}$ \\
\cline { 2 - 4 } & Fluctuations in demand & Marketing & $\begin{array}{l}\text { Market Research } \\
\text { Analyst }\end{array}$ \\
\hline Supplier Reliability & Sales lost to supply issues & Production & $\begin{array}{l}\text { Supply Chain } \\
\text { Manager }\end{array}$ \\
\cline { 2 - 4 } $\begin{array}{l}\text { Production } \\
\text { Efficiency }\end{array}$ & $\begin{array}{l}\text { \#ate of delivery delay / failure } \\
\text { scheduled to be produced }\end{array}$ & Procurement & Purchasing Agent \\
\cline { 2 - 4 } & $\begin{array}{l}\text { Margin of goods produced / } \\
\text { margin of goods scheduled to be } \\
\text { produced }\end{array}$ & Production & Production Manager \\
\cline { 2 - 4 } & $\begin{array}{l}\text { Technical feasibility of } \\
\text { substitution }\end{array}$ & Research \& Development & Materials Engineer \\
\hline
\end{tabular}

The information in Table 3.6.1. highlights the definitive challenge faced by firms contending with criticality assessment and mitigation: effective cross functional communication and collaboration. Across 16 indicators in 3 primary business functions there are a minimum of 33 types of information needed from 5 major functional areas and 11 organizational roles. Although some pieces of data are used for multiple indicators (e.g. sales volume, revenue, material pricing), only one of 16 indicators does not require information from at least two organizational positions. Further complicating matters is variation in data units (e.g. 
quantitative, qualitative, discrete, binary, ordinal, etc.), reporting baselines, and the timeliness of available information, all of which undermine the goal of criticality assessment and mitigation.

A comprehensive assessment of a firm's risk environment is an important objective of the firm level criticality indicators such as those in the framework in Table 6.3. in Appendix B. However, in order to accomplish this, risk monitoring and mitigation must be integrated into broader firm practices and a complementary ethos must be diffused throughout the organization. Without management support and a firm culture congruent with cross-functional collaboration and information sharing, the firm-level approach to criticality is likely to fail, particularly in organizations that follow a silo structure or a rigid hierarchical structure. In addition to firm culture and organizational structure, the success of firm level criticality mitigation is dependent on communication with management and key decision makers. Given the complexity of criticality, the importance of clear, concise communication about supply risk and mitigation to management cannot be understated. Particularly in cases where the appropriate mitigation strategy is cost and resource intensive (e.g. product re-design or new material development), leadership buy-in is crucial.

\section{Conclusions}

In this paper we presented a review of literature addressing firm-level criticality and conducted a two-part gap analysis to better understand the differences among current approaches and scopes of criticality management. The first component of the research gap that this work attempts to fill is to understand some of the specific ways that individual firms are impacted by criticality. To do so, we considered criticality in terms of commonly understood and commonly experienced threats to firm viability such as loss of revenue, loss of market share, and loss of profit. Although this is a large and complex question that remains incompletely answered, this work does identify specific firm-level costs related to criticality. For example, in the RollsRoyce scenario in the aviation case, we established the material intensity of rhenium by mass and cost in one Trent XWB engine. Using this information along with publicly available data about the list price of these engines, the gross margin earned by these engines, and historical rhenium prices, it was determined that the 2008 spike in the price of rhenium was equal to a loss of almost $10 \%$ in gross margin relative to the 2017 price of rhenium. 
Although the controlled environment agriculture case doesn't demonstrate specific firm-level costs related to criticality, it does demonstrate specific impacts. For example, manufacturers of LED lighting used in horticultural applications face strong competing demand and price competition. Whereas the demand for rhenium is concentrated in the aviation industry, there are multiple uses for each critical material needed to manufacture LED grow lights, as well as multiple uses for LEDs themselves. Second, in their annual SEC 10-K filings, LED manufacturer CREE explicitly acknowledges the firm's vulnerability to supply constraints outside of its control, such as reliance on sole or limited source suppliers. CREE also reports impacts that include high price volatility and variation in consistency and availability. Finally, CREE makes note of the cost and difficulty of complying with regulations, such as the DoddFrank Wall Street Reform and Consumer Protection Act, on material sourced from areas of geopolitical conflict.

Both cases offer a second insight to specific firm-level costs. In the aviation case we plotted the price of rhenium against firm-level financial performance data over time. Using annual and quarterly revenue and profit results from Boeing, General Electric Aviation, and Pratt \& Whitney we established correlational industry trends in line with the Rolls-Royce findings. In the controlled environment agriculture case, we plotted the price of rare earth elements and gallium against the annual financial performance of CREE, a major manufacturer of LEDs used for horticultural lighting applications. The ways and extents to which both aviation and horticultural lighting manufacturing firms are impacted by criticality are extremely complex and are not yet causally substantiated. However, these findings establish a basis for pursuing the next component of the research gap addressed by this work: how can firms create a criticality risk assessment framework that can be used efficiently and effectively for their specific business operations and strategies? That is, how can individual firms monitor critical material supply risk?

In addressing the second component of the research gap, we found that critical material supply risk assessment has two primary characteristics across existing frameworks and approaches, independent of the size and scope of the assessing entity. The first is the quantification of externally driven risk factors such as geological and economic availability; policy and regulation; geopolitical risk; environmental risk; etc. Although different firms do use some of the same indicators, they also use some unique indicators. The second characteristic is 
that criticality is generally addressed on an aggregate basis (e.g. global, national, industry), rather than on an individual firm basis. While fundamentally relevant to criticality, we assert that external factors can't be directly controlled by individual firms. Similarly, criticality challenges faced by firms necessarily vary from those faced at the industry level or above. Finally, because firms inherently differ in size, scope, and resources, the focus on external factors also presents a challenge to successful criticality mitigation at the firm level.

Given these findings and the resulting conclusion that no existing criticality assessment framework was sufficient for individual firms, the main contribution of this paper is a criticality assessment framework that uses dynamic, micro-level, internal indicators to guide firm decisionmaking related specifically to criticality risk at the firm level. Risk analysis was used to develop a new framework to be used by firms with existing, internal, firm-level data. Potential threats to an uninterrupted material supply (e.g. price volatility, supplier reliability, substitutability) were determined, and correlations between potential events and likely outcomes were identified (e.g. loss of revenue due to a price spike in a material needed to produce a good with a high material fraction of product cost).

Although we contend that all of the metrics proposed in the firm-level criticality framework are relevant to all firms, there are no doubt metrics not included that are necessary for some firms and not others, as well as some metrics in our framework that are more or less relevant across firms. Therefore, the framework needs to be integrated into individual firm decision-making processes and adapted as appropriate; this requires some interpretation and analysis by individual firms. For example, selection criteria and indicator weightings will vary across and within firms based on things like which critical materials are used and the market characteristics of the products being manufactured with those materials. One application may be more susceptible to low production efficiency and another may be more vulnerable to price elasticity.

As shown in the criticality assessment tool, some indicators will have higher risk than others. Sensitivity analysis should be conducted to determine the appropriate risk levels for each indicator used to assess criticality at a given firm. A similar approach is recommended for evaluating supply risk mitigation strategies which will impact firms differently. For example, one firm may benefit greatly from using long-term supply agreements whereas another firm may be better off developing a substitute material or increasing material utilization. Integration of the framework also requires buy-in from internal stakeholders throughout the organization, starting 
with management. Similarly, internal data related to supply is still, to some extent, contingent on the knowledge and activities of stakeholders up the supply chain. That is, some "internal" data requires external input and insight. For example, material cost data can be elusive and time consuming to identify in large supply chains, especially when firms purchase components and parts rather than raw material. This lack of supply chain transparency is an anticipated barrier to successful implementation of the framework.

\subsection{Recommendations for Future Research}

This research has led to several key findings about the way we think about, measure, monitor, and value critical materials. It has also uncovered opportunities for firms to improve their analysis of metrics relevant to criticality risk. One way to help companies do this is to apply the framework proposed in this work to real world data from companies that need to manage criticality risk. Doing so would allow us to explore different ways that firms might use and interpret the indicators in general. For example, can the indicators be used to effectively identify thresholds or tipping points beyond which risk exceeds a firm's tolerance? Which indicators do firm's find most useful? Does the utility of a given indicator vary across market segments or industries? Another area of exploration is the impact of integrated supply chains on criticality mitigation. Can large conglomerates actually influence the production of critical materials, or are broader market forces that cause supply disruptions more powerful? Are there manufacturing companies that own mines or rights to mines used to produce critical materials? If so, is this strategy cost effective? Future research should also address how firms might use modular manufacturing to mitigate risk; is it feasible to design technologies with contingency components in case of supply disruption?

This work focuses squarely on the firm perspective because, through their decision making, firms have considerable influence on the direction and progression of technology which, in turn, has ramifications for advancements in sustainability. Specifically, we focus on manufacturing firms at the upper end of the supply chain. However, because the impacts of criticality aren't contained to any one tier in the supply chain, another important area of future research is the impact of criticality to stakeholders across the supply chain. For example, in the aviation case some additional stakeholders include the airlines that purchase aircraft, the consumers who travel by air, and businesses and organizations that rely on air transport. In other words, the cost and 
availability of fuel-efficient jet engines have macro level economic implications. Without the ability to affordably move people and goods in a timely fashion, barriers to economic growth and technological advancement—such as increased cost, decreased performance, and decreased productivity—-begin to emerge. In the controlled environment agriculture case, additional stakeholders include the farmers who rely on horticultural lighting to produce food as well as food distributors, food retailers, restaurants, and all consumers. The cost and availability of lighting needed for agriculture have wide-reaching impacts ranging from the profitability of food production to the availability and accessibility of food. As growing conditions change and present new challenges stemming from climate change, it becomes more difficult to maintain yields and less profitable to produce food in the first place.

The research presented here addresses the use of critical materials in two industries, aviation and controlled environment agriculture. While we did compare and contrast the ways that each of these industries is impacted by critical material supply disruptions, we did not address the broader impact of competition for the same materials across industries. One example of crossindustry competition for critical materials relates to LEDs because there are many different technologies that rely on this technology. These applications include general lighting, controlled environment agriculture (i.e. horticultural lighting), electronics (e.g., TVs, smartphones, video displays), and medical treatments such as LED phototherapy. If there is a scarcity event causing a price spike in the critical materials needed to manufacture LEDs, the impact will, in general, vary by industry. However, one industry of particular note is food production. Given that food security is now tied to criticality (due to the projected growth of controlled environment agriculture that relies heavily on LED lighting), future work should emphasize impact beyond a firm's financial bottom line.

Although this work is very price focused due to its emphasis on the criticality impact to firms, it's important to think about how environmental regulations might disrupt supply chains. Future work should investigate firm risk on the basis of exposure to environmental issues which may include soil, air, and water contamination; radioactive waste; and carbon emissions. Finally, future work should apply a formal, systems thinking approach to identify interdependencies within and between firms that impact criticality mitigation. This should focus on the organizational design, communication, and culture within a specific firm, and how those elements impact effective business practices and critical material supply chain resilience. 


\section{Appendix A}

\subsection{Cobalt Criticality}

Cobalt is a critical metal used in a broad array of products including aircraft engines, turbines, magnets, and cutting tools. Because two of cobalt's most notable characteristics include extremely high supply concentration and constant price volatility, it serves as an instructive example for understanding the firm level impact of criticality.

In the early 1970 s, $40 \%$ of all land based cobalt reserves were in Zaire (currently known as the Democratic Republic of Congo). Zaire and neighboring Zambia controlled 2/3 of world production of cobalt. During this period, the U.S. (which did not produce any cobalt domestically), was the world's largest consumer of cobalt but had access to just one supplier of Zairian cobalt, the African Metals Corporation. As shown in Figure 5.1., price volatility is evident in the periods from 1966 to 1976 and from 1980 to 2002 during which year-over-year cobalt price changes were as high as $41 \%$. The most famous and drastic cobalt price spike followed a political rebellion in Zaire (Alonso et al 2007). Between 1977 and 1979, prices increased by as much as $380 \%$, causing firms to reevaluate products, production technologies, and sourcing routes (Alonso et al 2007). The impact was so great that even national policies were changed (Alonso et al 2007).

Outcomes from market instability-derived supply problems extended from price increases to product changes requiring substitution and new material development. The extent of the outcomes appears to have been exacerbated by the high global dependence on production from a single region, Zaire's Shaba province, and by the importance of cobalt for crucial defense applications. Although many of the factors contributing to cobalt price instability over the past 50 years are external, and therefore outside of the control of individual firms (e.g. political rebellion, global macroeconomic trends, production capacity, refining capacity, and transportation routes), cobalt is an apt example for our purposes because it highlights how material availability affects individual firms and what individual firms have done to mitigate it. Forced to reevaluate their production options in light of cobalt cost increases, firms responded by using material substitution, developing new technologies, identifying alternative material suppliers and sources, hoarding and rationing, and reclamation and recycling. For example, the magnet industry substituted lower cobalt containing alloys for applications with limitations on 
weight, size, and energy (USGS, 2006). Similarly, although reducing the use of cobalt in superalloys was difficult due to limited substitutes and a simultaneous increase in demand for jet engines, the development of a recycling process for scrap superalloys doubled cobalt recovery after 1978 (Blechman, 1985).

Figure 5.1.1. Price Volatility of Cobalt, $1950-2008$

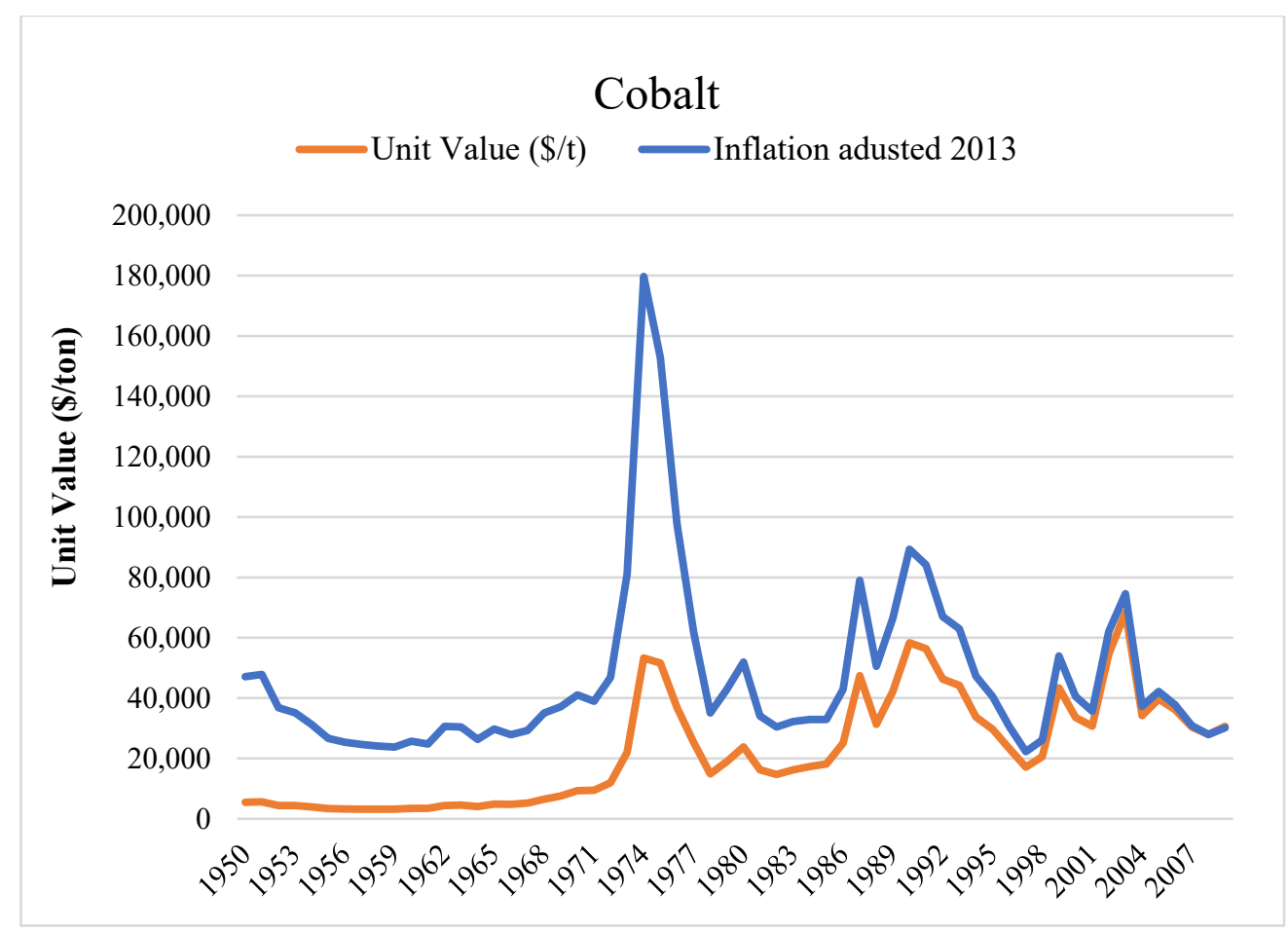




\section{Appendix B}

\subsection{Criticality Assessment Literature Summary}

Table 6.1.1. Criticality Assessment Literature Summary

\begin{tabular}{|c|c|c|c|c|}
\hline & Author(s) & Affiliated Institution(s) & Scope(s) & Title \\
\hline 1 & $\begin{array}{l}\text { AEA Technology } \\
(2010)\end{array}$ & $\begin{array}{l}\text { Scotland and Northern Ireland } \\
\text { Forum for Environmental } \\
\text { Research (SNIFFER) } \\
\text { Scottish Environment } \\
\text { Protection Agency (SEPA) } \\
\text { Northern Ireland Environment } \\
\text { (NIEA) }\end{array}$ & Scotland & Raw Materials Critical to the Scottish Economy \\
\hline 2 & $\begin{array}{l}\text { Achzet and Helbig } \\
(2013)\end{array}$ & University of Augsburg & Global & How to Evaluate Raw Material Supply Risks - An Overview \\
\hline 3 & $\begin{array}{l}\text { AEA Technology } \\
(2010)\end{array}$ & $\begin{array}{l}\text { Department for Environment, } \\
\text { Food and Rural Affairs }\end{array}$ & UK & $\begin{array}{l}\text { Review of the Future Resource Risks Faced by UK Business and an } \\
\text { Assessment of Future Viability }\end{array}$ \\
\hline 4 & $\begin{array}{l}\text { Angerer et al. } \\
(2009)\end{array}$ & Fraunhofer ISI & Germany & Raw Materials for Emerging Technologies \\
\hline 5 & $\begin{array}{l}\text { Bach et al. } \\
(2017)\end{array}$ & Technische Universität Berlin & National & $\begin{array}{l}\text { Enhancing the assessment of critical resource use at the country level } \\
\text { with the SCARCE method-Case study of Germany }\end{array}$ \\
\hline 6 & Bauer et al. (2010) & U.S. Department of Energy & Global & Critical Materials Strategy \\
\hline 7 & Bauer et al. (2011) & U.S. Department of Energy & Global & Critical Materials Strategy \\
\hline 8 & Bensch et al. (2015) & University of Augsburg & Firm & $\begin{array}{l}\text { Decision Support System for the Sustainability Assessment of Critical } \\
\text { Raw Materials in SMEs }\end{array}$ \\
\hline 9 & $\begin{array}{l}\text { Blengini et al. } \\
\text { (2017) }\end{array}$ & $\begin{array}{c}\text { European Commission, DG } \\
\text { Joint Research Centre, } \\
\text { Ispra, Italy } \\
\text { European Commission, DG } \\
\text { Joint Research Center, } \\
\text { Petten, Netherdands } \\
\text { European Commission, DG } \\
\text { GROW } \\
\text { Brussels, Belgium } \\
\text { Politecnico di Torino } \\
\end{array}$ & $\mathrm{EU}$ & $\begin{array}{l}\text { EU methodology for critical raw materials assessment: Policy needs } \\
\text { and proposed solutions for incremental improvements }\end{array}$ \\
\hline 10 & Brown (2018) & British Geological Survey & Global & $\begin{array}{l}\text { Measurement of mineral supply diversity and its importance in } \\
\text { assessing risk and criticality }\end{array}$ \\
\hline 11 & $\begin{array}{l}\text { Buchert, Schüler et } \\
\text { al. (2009) }\end{array}$ & $\begin{array}{c}\text { Öko-Institut e.V. } \\
\text { United Nations Environment } \\
\text { Programme }\end{array}$ & Global & $\begin{array}{l}\text { Critical Metals for Future Sustainable Technologies and their } \\
\text { Recycling Potential }\end{array}$ \\
\hline 12 & $\begin{array}{l}\text { British Geological } \\
\text { Survey (2015) }\end{array}$ & British Geological Survey & Global & $\begin{array}{l}\text { Risk List 2015: An update to the supply risk index for elements or } \\
\text { element groups that are of economic value }\end{array}$ \\
\hline 13 & Daw (2017) & Université Paris & National & $\begin{array}{l}\text { Security of mineral resources: A new framework for quantitative } \\
\text { assessment } \\
\text { of criticality }\end{array}$ \\
\hline 14 & Duclos et al. (2010) & GE & Firm & Design in an Era of Constrained Resources \\
\hline 15 & $\begin{array}{l}\text { European } \\
\text { Commission (2010) }\end{array}$ & Fraunhofer ISI & $\mathrm{EU}$ & Critical Raw Materials for the EU \\
\hline 16 & $\begin{array}{l}\text { European } \\
\text { Commission (2014) }\end{array}$ & $\begin{array}{l}\text { Fraunhofer ISI } \\
\text { Oakdene Hollins } \\
\text { Roskill } \\
\end{array}$ & $\mathrm{EU}$ & Report on Critical Materials for the EU \\
\hline 17 & $\begin{array}{l}\text { European } \\
\text { Commission (2017) }\end{array}$ & $\begin{array}{c}\text { Deloitte Sustainability } \\
\text { British Geological Survey } \\
\text { Bureau de Recherces } \\
\text { Géologiques et Minières } \\
\text { Netherlands Organisation for } \\
\text { Applied Scientific Research }\end{array}$ & $\overline{\mathrm{EU}}$ & Study on the Review of the List of Critical Raw Materials \\
\hline 18 & $\begin{array}{l}\text { Gardner et al. } \\
(2016)\end{array}$ & Loughborough University & Firm & $\begin{array}{l}\text { A Framework for the Resilient Use of Critical Materials in Sustainable } \\
\text { Manufacturing Systems }\end{array}$ \\
\hline
\end{tabular}




\begin{tabular}{|c|c|c|c|c|}
\hline 19 & $\begin{array}{l}\text { Gardner et al. } \\
(2018)\end{array}$ & Loughborough University & Firm & $\begin{array}{l}\text { A framework and decision support tool for improving value chain } \\
\text { resilience to critical materials in manufacturing }\end{array}$ \\
\hline 20 & $\begin{array}{l}\text { Glöser-Chahoud et } \\
\text { al. (2016) }\end{array}$ & Fraunhofer ISI & National & $\begin{array}{l}\text { Taking the Step towards a More Dynamic View on } \\
\text { Raw Material Criticality: An Indicator Based Analysis } \\
\text { for Germany and Japan }\end{array}$ \\
\hline 21 & $\begin{array}{l}\text { Graedel et al. } \\
(2012)\end{array}$ & Yale University & $\begin{array}{l}\text { Global } \\
\text { National } \\
\text { Firm }\end{array}$ & Methodology of Criticality Determination \\
\hline 22 & $\begin{array}{l}\text { Graedel et al. } \\
(2014)\end{array}$ & Yale University & $\begin{array}{l}\text { Global } \\
\text { National } \\
\text { Firm }\end{array}$ & Metal resources, use and criticality (in Critical Materials Handbook) \\
\hline 23 & $\begin{array}{l}\text { Graedel et al. } \\
(2015)\end{array}$ & Yale University & $\begin{array}{l}\text { Global } \\
\text { National } \\
\text { Firm }\end{array}$ & On the Materials Basis of Modern Society \\
\hline 24 & $\begin{array}{l}\text { Graedel et al. } \\
(2015)\end{array}$ & Yale University & $\begin{array}{l}\text { Global } \\
\text { National } \\
\text { Firm }\end{array}$ & Criticality of metals and metalloids \\
\hline 25 & $\begin{array}{l}\text { Hallstedt et al. } \\
\text { (2017) }\end{array}$ & $\begin{array}{l}\text { Blekinge Institute of } \\
\text { Technology }\end{array}$ & Firm & $\begin{array}{l}\text { Material Criticality Assessment in Early Phases of Sustainable Product } \\
\text { Development }\end{array}$ \\
\hline 26 & $\begin{array}{l}\text { Hatayama and } \\
\text { Tahara (2015) }\end{array}$ & $\begin{array}{l}\text { National Institute of Advanced } \\
\text { Industrial Science and } \\
\text { Technology }\end{array}$ & National & Criticality assessment of metals for Japan's resource strategy \\
\hline 27 & $\begin{array}{l}\text { Hatayama and } \\
\text { Tahara (2018) }\end{array}$ & $\begin{array}{l}\text { National Institute of Advanced } \\
\text { Industrial Science and } \\
\text { Technology }\end{array}$ & Global & $\begin{array}{l}\text { Adopting an objective approach to criticality assessment: Learning } \\
\text { from the } \\
\text { past }\end{array}$ \\
\hline 28 & Helbig et al. (2016) & University of Augsburg & $\begin{array}{l}\text { Global } \\
\text { National } \\
\text { Firm }\end{array}$ & How to Evaluate Raw Material Vulnerability - An Overview \\
\hline 29 & Helbig et al. (2017) & University of Augsburg & Global & $\begin{array}{l}\text { Benefits of resource strategy for sustainable materials research and } \\
\text { development }\end{array}$ \\
\hline 30 & $\begin{array}{l}\text { Jasiński et al. } \\
(2018)\end{array}$ & $\begin{array}{l}\text { University of Warwick } \\
\text { University of Coimbra } \\
\text { University of Sheffield }\end{array}$ & Global & $\begin{array}{l}\text { Assessing supply risks for non-fossil mineral resources via multi- } \\
\text { criteria decision analysis }\end{array}$ \\
\hline 31 & $\begin{array}{l}\text { Knobloch et al. } \\
(2018)\end{array}$ & $\begin{array}{l}\text { University of Bremen } \\
\text { Ökopol - Institute for } \\
\text { Environmental Studies }\end{array}$ & $\begin{array}{l}\text { Global } \\
\text { National } \\
\text { Firm }\end{array}$ & $\begin{array}{l}\text { From criticality to vulnerability of resource supply: The case of the } \\
\text { automobile industry }\end{array}$ \\
\hline 32 & $\begin{array}{l}\text { Kolotzek et al. } \\
(2018)\end{array}$ & University of Augsburg & Firm & $\begin{array}{l}\text { A Company-Oriented Model for the Assessment of Raw Material } \\
\text { Supply Risks, Environmental Impact and Social Implications }\end{array}$ \\
\hline 33 & Lapko et al. (2016) & $\begin{array}{l}\text { Politecnico di Milano } \\
\text { KTH Royal Institute of } \\
\text { Technology }\end{array}$ & Firm & $\begin{array}{l}\text { The Business Perspective on Materials Criticality: Evidence from } \\
\text { Manufacturers }\end{array}$ \\
\hline 34 & Lloyd et al. (2011) & Rolls Royce & Firm & $\begin{array}{l}\text { Ecodesign through Environmental Risk Management: A Focus on } \\
\text { Critical Materials }\end{array}$ \\
\hline 35 & Lloyd et al. (2012) & Rolls Royce & Firm & A Framework for Environmental Risk Management \\
\hline 36 & Miehe et al. (2016) & Fraunhofer ISI & Firm & $\begin{array}{l}\text { Criticality of material resources in industrial enterprises - Structural } \\
\text { basics of an operational model }\end{array}$ \\
\hline 37 & $\begin{array}{l}\text { Morley \& Eatherley } \\
(2008)\end{array}$ & $\begin{array}{c}\text { Resource Efficiency } \\
\text { Knowledge Transfer Network } \\
\text { Oakdene Hollins }\end{array}$ & UK & $\begin{array}{l}\text { Material Security: Ensuring Resource Availability for the UK } \\
\text { Economy }\end{array}$ \\
\hline 38 & Nassar et al. (2015) & Yale University & $\begin{array}{l}\text { Global } \\
\text { National } \\
\text { Firm }\end{array}$ & $\begin{array}{l}\text { By-Product Metals are Technologically Essential but Have } \\
\text { Problematic Supply }\end{array}$ \\
\hline 39 & Nassar et al. (2015) & Yale University & $\begin{array}{l}\text { Global } \\
\text { National }\end{array}$ & Criticality of the rare earth elements \\
\hline 40 & Nieto et al. (2013) & $\begin{array}{l}\text { The Pennsylvania State } \\
\text { University }\end{array}$ & Firm & $\begin{array}{l}\text { Addressing Criticality for Rare Earth Elements in Petroleum Refining: } \\
\text { The Key Supply Factors Approach }\end{array}$ \\
\hline 41 & $\begin{array}{l}\text { National Research } \\
\text { Council (2008) }\end{array}$ & The National Academies & US & Minerals, Critical Minerals, and the U.S. Economy \\
\hline 42 & $\begin{array}{l}\text { Rosenau-Tornow et } \\
\text { al. (2009) }\end{array}$ & $\begin{array}{c}\text { Volkswagen AG } \\
\text { Federal Institute for } \\
\text { Geosciences and Natural } \\
\text { Resources (BGR) }\end{array}$ & Global & $\begin{array}{l}\text { Assessing the Long-Term Supply Risks for Mineral Raw Materials - a } \\
\text { Combined Evaluation of Past and Future Trends }\end{array}$ \\
\hline
\end{tabular}




\subsection{Regulatory and Compliance Indicators}

Table 6.2.1. Regulatory and Compliance Indicators

\begin{tabular}{|l|l|l|}
\hline Indicator & Category & Study \\
\hline Impact of ecological implications on biodiversity (using ReCiPe) & Environment & Bensch et al. 2015 \\
\hline Environmental regulation (e.g. policy decisions, legislation) & Environment & $\begin{array}{l}\text { Gardner et al. 2018; } \\
\text { Hallstedt et al. 2017; } \\
\text { Nieto et al. 2013 }\end{array}$ \\
\hline Socio- and ecological impact risk & Environment & Hallstedt et al. 2017 \\
\hline Anthropogenic vs. natural flows & Environment & Hallstedt et al. 2017 \\
\hline $\begin{array}{l}\text { Impact of ecological implications on human health (using } \\
\text { ReCiPe) }\end{array}$ & Environment & Bensch et al. 2015 \\
\hline $\begin{array}{l}\text { Likelihood of substance becoming unavailable due to the } \\
\text { Registration, Evaluation, Authorization and Restriction of } \\
\text { Chemicals regulation (REACH) }\end{array}$ & Environment & Lloyd et al. 2012 \\
\hline Electric vehicle (ELV) directive non-compliance & Environment & Lapko et al. 2016 \\
\hline $\begin{array}{l}\text { Registration, Evaluation, Authorization and Restriction of } \\
\text { Chemicals regulation } \\
\text { (REACH) non-compliance }\end{array}$ & Environment & Lapko et al. 2016 \\
\hline Restriction of Hazardous Substances (RoHS) non-compliance & Environment & Lapko et al. 2016 \\
\hline $\begin{array}{l}\text { Waste Electrical and Electronic Equipment (WEEE) non- } \\
\text { compliance }\end{array}$ & Environment & Lapko et al. 2016 \\
\hline Emissions legislation non-compliance & Geopolitical & Lapko et al. 2016 \\
\hline $\begin{array}{l}\text { The California Transparency in Supply Chains Act (re: human } \\
\text { trafficking and slavery) }\end{array}$ & Supply Chain & Lapko et al. 2016 \\
\hline \begin{tabular}{l} 
Conflict Elements \\
\hline
\end{tabular} & Supply Chain & $\begin{array}{l}\text { Gardner et al. 2018; } \\
\text { Hallstedt et al. 2017 }\end{array}$ \\
\hline
\end{tabular}

\subsection{Indicators in Existing Firm-Level Criticality Studies}

Table 6.3.1. Indicators in Existing Firm-Level Criticality Studies

\begin{tabular}{|c|c|c|c|c|c|c|c|c|c|c|c|c|}
\hline Category & Indicator & Scope & 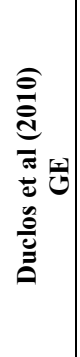 & 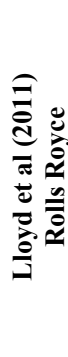 & 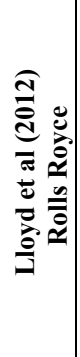 & 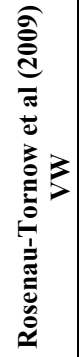 & 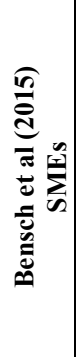 & 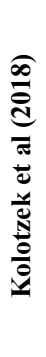 & 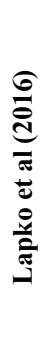 & 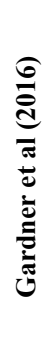 & 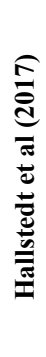 & 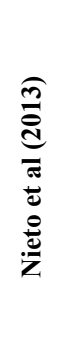 \\
\hline Business Risk & Impact on revenue & Internal & $\mathrm{X}$ & & & & & & & & & \\
\hline Business Risk & Ability to pass on cost & Internal & $\mathrm{X}$ & & & & & & & & & \\
\hline Business Risk & Vulnerability & Internal & & & & & & & & & $\mathrm{X}$ & \\
\hline Business Risk & Severity of impact of risk & Internal & & & & & & & & $\mathrm{X}$ & & \\
\hline Business Risk & $\begin{array}{l}\text { Sales of product(s) containing } \\
\text { critical material(s) as a percentage } \\
\text { of total sales }\end{array}$ & Internal & & & & & & & & $\mathrm{X}$ & & \\
\hline
\end{tabular}




\begin{tabular}{|c|c|c|c|c|c|c|c|c|c|c|c|c|}
\hline Business Risk & $\begin{array}{l}\text { Current revenue from product(s) } \\
\text { containing critical material(s) }\end{array}$ & Internal & & & & & & & & $\mathrm{X}$ & & \\
\hline Business Risk & $\begin{array}{l}\text { Future projected revenue from } \\
\text { product(s) containing critical } \\
\text { material(s) }\end{array}$ & Internal & & & & & & & & $\mathrm{X}$ & & \\
\hline Business Risk & Potential cost increase & Internal & $\mathrm{X}$ & $\mathrm{X}$ & $\mathrm{X}$ & & & & & & & \\
\hline Business Risk & $\begin{array}{l}\text { Unit cost of component/product } \\
\text { containing critical material(s) }\end{array}$ & Internal & $\mathrm{X}$ & $\mathrm{X}$ & $\mathrm{X}$ & & & & & & & \\
\hline Business Risk & $\begin{array}{l}\text { Unit cost of critical material(s) in } \\
\text { component/product }\end{array}$ & Internal & $\mathrm{X}$ & $\mathrm{X}$ & $\mathrm{X}$ & & & & & & & \\
\hline Business Risk & $\begin{array}{l}\text { Fraction of whole material cost for } \\
\text { unit }\end{array}$ & Internal & $\mathrm{X}$ & $\mathrm{X}$ & $\mathrm{X}$ & & & & & & & \\
\hline Business Risk & Production costs (cash costs) & Internal & & & & $\mathrm{X}$ & & & & & & \\
\hline Business Risk & Risk to key customers & Internal & & & & & & & & $\mathrm{X}$ & & \\
\hline Business Risk & Material / component lead time & External & & & & & & & $\mathrm{X}$ & & & \\
\hline Business Risk & $\begin{array}{l}\text { Concentration of revenue in few } \\
\text { clients }\end{array}$ & Internal & & & & & & & $\mathrm{X}$ & & & \\
\hline Business Risk & Non-forecasted upside demand & Internal & & & & & & & $\mathrm{X}$ & & & \\
\hline Business Risk & $\begin{array}{l}\text { Delivery capability (vs lead } \\
\text { time/shortages) }\end{array}$ & Internal & & & & & & & $\mathrm{X}$ & & & \\
\hline Business Risk & Cost competition & External & & & & & & & $\mathrm{X}$ & & & \\
\hline Business Risk & Price pressure & External & & & & & & & $\mathrm{X}$ & & & \\
\hline Co-Production Risk & Co-production risk & External & $\mathrm{X}$ & & & & & & & & $\mathrm{X}$ & \\
\hline Co-Production Risk & $\begin{array}{l}\text { By-product character / co- } \\
\text { production }\end{array}$ & External & & & & & & & $\mathrm{X}$ & & & \\
\hline Co-Production Risk & Companion metal fraction & External & & & & & $\mathrm{X}$ & $\mathrm{X}$ & & & & \\
\hline Demand Risk & Demand risk & External & $\mathrm{X}$ & & & & $\mathrm{X}$ & & & & & \\
\hline Demand Risk & Demand growth & External & & & & $\mathrm{X}$ & $\mathrm{X}$ & & $\mathrm{X}$ & & & \\
\hline Demand Risk & Competing demand for a material & External & & & & $\mathrm{X}$ & $\mathrm{X}$ & & $\mathrm{X}$ & & & \\
\hline Demand Risk & $\begin{array}{l}\text { Demand from alternative } \\
\text { applications }\end{array}$ & External & & & & & & & & & & $\mathrm{X}$ \\
\hline Demand Risk & Demand increase risk & External & & & & & $\mathrm{X}$ & $\mathrm{X}$ & & & & \\
\hline Demand Risk & Future demand technology & External & & & & & $\mathrm{X}$ & $\mathrm{X}$ & & & & \\
\hline Demand Risk & Demand fluctuation & External & & & & & & & $\mathrm{X}$ & & & \\
\hline Environmental & $\begin{array}{l}\text { Environmental regulation (e.g. } \\
\text { policy decisions, legislation) }\end{array}$ & External & & & & & & & & & $\mathrm{X}$ & \\
\hline Environmental & Soci- and ecological impact risk & External & & & & & & & & & $\mathrm{X}$ & \\
\hline Environmental & Anthropogenic vs natural flows & External & & & & & & & & & $\mathrm{X}$ & \\
\hline Environmental & $\begin{array}{l}\text { Social and environmental } \\
\text { restrictions }\end{array}$ & External & & & & & & & & & & $\mathrm{X}$ \\
\hline Environmental & Damage to health and ecosystems & External & & & & & & $\mathrm{X}$ & $\mathrm{X}$ & & & \\
\hline Environmental & Environmental regulations & External & & & & & & & & & & $\mathrm{X}$ \\
\hline $\begin{array}{l}\text { Exploration and/or } \\
\text { Mining }\end{array}$ & $\begin{array}{l}\text { Lack of investments in exploration } \\
\text { of new sources }\end{array}$ & External & & & & $\mathrm{X}$ & & & & & & \\
\hline $\begin{array}{l}\text { Exploration and/or } \\
\text { Mining }\end{array}$ & Degree of exploration & External & & & & $\mathrm{X}$ & & & & & & \\
\hline $\begin{array}{l}\text { Exploration and/or } \\
\text { Mining }\end{array}$ & Investment in mining & External & & & & $\mathrm{X}$ & & & & & & \\
\hline
\end{tabular}




\begin{tabular}{|c|c|c|c|c|c|c|c|c|c|c|c|c|}
\hline Geopolitical & Sourcing and geopolitical risk & External & $\mathrm{X}$ & & & & & & & & & \\
\hline Geopolitical & $\begin{array}{l}\text { Political stability in sourcing } \\
\text { countries }\end{array}$ & External & & & & & & & & & $\mathrm{X}$ & \\
\hline Geopolitical & Instability of producing country & External & & & & & $\mathrm{X}$ & & & & & \\
\hline Geopolitical & Stability of producing country & External & & $\mathrm{X}$ & $\mathrm{X}$ & & & & & & & \\
\hline Geopolitical & Country related risk & External & & & & $\mathrm{X}$ & & & & & & \\
\hline Geopolitical & International trade environment & External & & & & & & & & & & $\mathrm{X}$ \\
\hline Geopolitical & Political risk & External & & & & & $\mathrm{X}$ & $\mathrm{X}$ & & & & \\
\hline Geopolitical & Country risk political stability & External & & & & & $\mathrm{X}$ & $\mathrm{X}$ & & & & \\
\hline Geopolitical & Country risk policy potential & External & & & & & $\mathrm{X}$ & $\mathrm{X}$ & & & & \\
\hline Geopolitical & Country risk regulation & External & & & & & $\mathrm{X}$ & $\mathrm{X}$ & & & & \\
\hline Geopolitical & Export quotas & External & & & & & & & $\mathrm{X}$ & & & \\
\hline $\begin{array}{l}\text { Physical, Geological } \\
\text { Abundance }\end{array}$ & Abundance in earth's crust & External & $\mathrm{X}$ & & & & & & & & & \\
\hline $\begin{array}{l}\text { Physical, Geological } \\
\text { Abundance }\end{array}$ & $\begin{array}{l}\text { Geological measures } \\
\text { (abundance/scarcity) }\end{array}$ & External & & & & & & & & & $\mathrm{X}$ & \\
\hline Price & Historic price volatility & External & $\mathrm{X}$ & & & & & & & & & \\
\hline Price & Material cost increase & External & & & & & & & & & $\mathrm{X}$ & \\
\hline Price & Sensitivity to price fluctuation & External & & $\mathrm{X}$ & & & & & $\mathrm{X}$ & & & \\
\hline Price & Price of critical material & External & & & & & & & & $\mathrm{X}$ & & \\
\hline Price & Price volatility & External & & $\mathrm{X}$ & $\mathrm{X}$ & & & & & & & \\
\hline Price & Price fluctuations & External & & & & & & & $\mathrm{X}$ & & & \\
\hline Price & Price increase & External & & & & & & & $\mathrm{X}$ & & & \\
\hline Production Capacity & $\begin{array}{l}\text { Time needed to expand production } \\
\text { capacity (exploration of new } \\
\text { sources) }\end{array}$ & External & & & & $\mathrm{X}$ & & & $\mathrm{X}$ & & & \\
\hline Production Capacity & $\begin{array}{l}\text { Limited production and capacity of } \\
\text { mine, smelter, refinery, freight }\end{array}$ & External & & & & $\mathrm{X}$ & & & & & & \\
\hline Production Capacity & Mine/refinery capacity utilization & External & & & & $\mathrm{X}$ & & & & & & \\
\hline Production Capacity & Future market capacity & External & & & & $\mathrm{X}$ & & & & & & \\
\hline Production Capacity & Production shortages & External & & & & & & & $\mathrm{X}$ & & & \\
\hline Recycling & Recyclability & External & & & & & & & & & $\mathrm{X}$ & \\
\hline Recycling & $\begin{array}{l}\text { Environmental regulation (e.g. } \\
\text { policy decisions, legislation) }\end{array}$ & External & & & & $\mathrm{X}$ & $\mathrm{X}$ & & & & & $\mathrm{X}$ \\
\hline Recycling & $\begin{array}{l}\text { Low/impossible recyclability (low } \\
\text { recycling rate, volume, efficiency) }\end{array}$ & External & & & & $\mathrm{X}$ & & & $\mathrm{X}$ & & & \\
\hline Recycling & Recycling rate & External & & $\mathrm{X}$ & $\mathrm{X}$ & & $\mathrm{X}$ & $\mathrm{X}$ & & & & \\
\hline Recycling & Material recovery competition & External & & & & & & & $\mathrm{X}$ & & & \\
\hline Regulation & REACH & External & & & & & & & $\mathrm{X}$ & & & \\
\hline Regulation & RoHS & External & & & & & & & $\mathrm{X}$ & & & \\
\hline Regulation & WEEE & External & & & & & & & $\mathrm{X}$ & & & \\
\hline Regulation & Emission legislation & External & & & & & & & $\mathrm{X}$ & & & \\
\hline Regulation & ELV directive & External & & & & & & & $\mathrm{X}$ & & & \\
\hline Regulation & Dodd Frank Act & External & & & & & & & $\mathrm{X}$ & & & \\
\hline
\end{tabular}




\begin{tabular}{|c|c|c|c|c|c|c|c|c|c|c|c|c|}
\hline Regulation & $\begin{array}{l}\text { California Transparency in Supply } \\
\text { Chains Act }\end{array}$ & External & & & & & & & $\mathrm{X}$ & & & \\
\hline Social Impact & Conflict elements & External & & & & & & & & & $X$ & \\
\hline Social Impact & Phosphorous content & External & & & & & & & & & $\mathrm{X}$ & \\
\hline Stock / Reserves & $\begin{array}{l}\text { Lack of stock at exchanges, } \\
\text { producers and manufacturers }\end{array}$ & External & & & & $\mathrm{X}$ & & & & $\mathrm{X}$ & & \\
\hline Stock / Reserves & Known stockpiles & External & & & & & & & & $\mathrm{X}$ & & \\
\hline Stock / Reserves & Stock keeping & External & & & & $\mathrm{X}$ & & & & & & \\
\hline Substitutability & Market substitutability & External & $\mathrm{X}$ & & & & & & & & & \\
\hline Substitutability & Firm's ability to substitute & Internal & $\mathrm{X}$ & & & & & & & & & \\
\hline Substitutability & Substitutability & External & & & & & & & & & $\mathrm{X}$ & \\
\hline Substitutability & Potential for substitution & External & & & & & & & & $\mathrm{X}$ & & \\
\hline Substitutability & Substitutability & External & & $\mathrm{X}$ & $\mathrm{X}$ & & $\mathrm{X}$ & $\mathrm{X}$ & & & & \\
\hline Substitutability & No substitutes & External & & & & & & & $\mathrm{X}$ & & & \\
\hline Supplier Risk & $\begin{array}{l}\text { High concentration in producing } \\
\text { countries }\end{array}$ & External & & & & & $\mathrm{X}$ & & & & & $\mathrm{X}$ \\
\hline Supplier Risk & $\begin{array}{l}\text { High concentration in producing } \\
\text { companies }\end{array}$ & External & & & & & $\mathrm{X}$ & & & & & $\mathrm{X}$ \\
\hline Supplier Risk & Country concentration & External & & & & $\mathrm{X}$ & & & & & & \\
\hline Supplier Risk & $\begin{array}{l}\text { Availability of resources needed to } \\
\text { mine and produce critical materials }\end{array}$ & External & & & & & & & & & & $\mathrm{X}$ \\
\hline Supplier Risk & Concentration risk & External & & & & & $\mathrm{X}$ & $\mathrm{X}$ & & & & \\
\hline Supplier Risk & Country concentration & External & & & & & $\mathrm{X}$ & $\mathrm{X}$ & & & & \\
\hline Supplier Risk & $\begin{array}{l}\text { Sourcing from different sources } \\
\text { impacts quality }\end{array}$ & External & & & & & & & $\mathrm{X}$ & & & \\
\hline Supplier Risk & Monopoly supply & External & & & & & & & & & $\mathrm{X}$ & \\
\hline Supplier Risk & $\begin{array}{l}\text { Monopoly supply (\# of material } \\
\text { sources) }\end{array}$ & External & & $\mathrm{X}$ & $\mathrm{X}$ & & & & & & & \\
\hline Supplier Risk & Producer diversity & External & & & & & & & & & & $\mathrm{X}$ \\
\hline Supplier Risk & Very concentrated supply chain & External & & & & & & & $\mathrm{X}$ & & & \\
\hline Supplier Risk & Niche monopolistic market & External & & & & & & & $\mathrm{X}$ & & & \\
\hline Supplier Risk & Single supplier available & External & & & & & & & $\mathrm{X}$ & & & \\
\hline Supplier Risk & $\begin{array}{l}\text { Limited number of manufacturers } \\
\text { and suppliers }\end{array}$ & External & & & & & & & $\mathrm{X}$ & & & \\
\hline Supplier Risk & $\begin{array}{l}\text { Failure to provide required quality } \\
\text { of materials }\end{array}$ & External & & & & & & & $\mathrm{X}$ & & & \\
\hline Supplier Risk & $\begin{array}{l}\text { Failure to deliver/perform to client } \\
\text { requirements }\end{array}$ & External & & & & & & & $\mathrm{X}$ & & & \\
\hline Supply & Percent of world supply used & Internal & $\mathrm{X}$ & & & & & & & & & \\
\hline Supply & Supply risk & External & & & & & & & & & $\mathrm{X}$ & \\
\hline Supply & Likelihood of disruption & External & & & & & & & & $\mathrm{X}$ & & \\
\hline Supply & Total market availability & External & & & & & & & & $\mathrm{X}$ & & \\
\hline Supply & Likelihood of disruption & External & & $\mathrm{X}$ & $\mathrm{X}$ & & & & & & & \\
\hline Supply & $\begin{array}{l}\text { Likelihood of substance becoming } \\
\text { unavailable due to REACH }\end{array}$ & External & & $\mathrm{X}$ & $\mathrm{X}$ & & & & & & & \\
\hline Supply & Current market balance & External & & & & $\mathrm{X}$ & & & & & & \\
\hline Supply & Supply reduction risk & External & & & & & $\mathrm{X}$ & $\mathrm{X}$ & & & & \\
\hline
\end{tabular}




\begin{tabular}{|l|l|l|l|l|l|l|l|l|l|l|l|l|}
\hline Supply & Static reach reserves & External & & & & & $X$ & $X$ & & & \\
\hline Supply & Static reach resources & External & & & & & $X$ & $X$ & & & & \\
\hline
\end{tabular}




\subsection{Example Firm-Level Scorecard}

Table 6.4.1. Example Firm-Level Scorecard

Criticality Risk Measurement Tool: Material / Product / Segment A Profitability

\begin{tabular}{|l|l|l|l|l|}
\hline & Finance & Procurement & Marketing & Production \\
\hline Risk Level & $\begin{array}{c}\text { Revenue } \\
(\% \text { of total })\end{array}$ & $\begin{array}{c}\text { Price Volatility } \\
(\% \text { change })\end{array}$ & Price Elasticity & Substitutability \\
\hline Very High & & & & \\
\hline High & & & & \\
\hline Medium & & & & \\
\hline Low & & & & \\
\hline Very Low & & & & \\
\hline
\end{tabular}

Design \& Product Concept Viability

\begin{tabular}{|l|l|l|l|l|}
\hline & Finance & Procurement & Marketing & Production \\
\hline Risk Level & $\begin{array}{c}\text { Material Fraction } \\
\text { of Product Cost } \\
(\%)\end{array}$ & Supplier Risk & $\begin{array}{c}\text { Segment Market } \\
\text { Share (\%) }\end{array}$ & $\begin{array}{c}\text { Material Utilization } \\
(\%)\end{array}$ \\
\hline Very High & & & & \\
\hline High & & & & \\
\hline Medium & & & & \\
\hline Low & & & & \\
\hline Very Low & & & & \\
\hline
\end{tabular}

\section{Production}

\begin{tabular}{|l|l|l|l|l|}
\hline & Finance & Procurement & Marketing & Production \\
\hline Risk Level & Gross Margin (\%) & $\begin{array}{c}\text { Inventory Variance } \\
\text { Ratio (\%) }\end{array}$ & $\begin{array}{l}\text { Supplier Reliability } \\
\text { Production } \\
\text { Efficiency (\%) }\end{array}$ \\
\hline Very High & & & & \\
\hline High & & & & \\
\hline Medium & & & & \\
\hline Low & & & & \\
\hline
\end{tabular}




\section{Appendix C}

\subsection{CEA Methodology Supplemental Information}

Table 7.1.1.: Critical Material Composition per Light Bulb (given in grams)

\begin{tabular}{|l|c|}
\hline Material & $\begin{array}{c}\text { CREE } \\
\text { High Bay LED }\end{array}$ \\
\hline Cerium & $1.73 \mathrm{E}-03$ \\
\hline Europium & $1.28 \mathrm{E}-03$ \\
\hline Gadolinium & $1.48 \mathrm{E}-03$ \\
\hline Gallium & $5.38 \mathrm{E}-02$ \\
\hline Indium & $1.91 \mathrm{E}-02$ \\
\hline Yttrium & $7.81 \mathrm{E}-02$ \\
\hline & $\mathbf{1 . 5 5 E - 0 1}$ \\
\hline
\end{tabular}

Critical material intensity was calculated based on the critical material composition of each light bulb and the other four key model inputs (population, dietary requirements, growing space, and lighting requirements). To feed one person for one year under the scenario modeled in this work would require 12 high bay LED bulbs. To feed the projected world population in 2050 would require approximately 113.2 billion high bay LED bulbs. This is equivalent to 18,473 metric tons of critical materials. 
Table 7.1.2.: USDA "Healthy U.S.-Style Eating Pattern" Intake Recommendations by Volume (USDA 2015)

\begin{tabular}{|l|c|c|c|}
\hline Category & $\begin{array}{c}\text { Daily } \\
\text { (cups) }\end{array}$ & $\begin{array}{c}\text { Weekly } \\
\text { (cups) }\end{array}$ & $\begin{array}{c}\text { Annually } \\
\text { (cups) }\end{array}$ \\
\hline Vegetables: Dark Green & 0.21 & 1.5 & 78 \\
\hline Vegetables: Red \& Orange & 0.78 & 5.5 & 286 \\
\hline Vegetables: Legumes & 0.21 & 1.5 & 78 \\
\hline Vegetables: Starchy & 0.71 & 5 & 261 \\
\hline Vegetables: Other & 0.57 & 4 & 209 \\
\hline Fruits & 2 & 14 & 730 \\
\hline & 4.5 & 31.5 & 1,642 \\
\hline
\end{tabular}

Given the types and quantities of food to produce in order to meet the stated dietary requirements, the amount of growing space can be calculated. This is accomplished by using the recommended consumption of each crop in pounds, the yield per square foot of each crop in pounds, and the edible portion of each crop by percentage. For example, the USDA recommended consumption of dark green vegetables is 1.5 cups per week or 78 cups per year (2015). To meet half of this requirement with spinach would require consumption of 39 cups per year. Based on the density of spinach (30 grams per cup), a total of 2.59 pounds of spinach must be consumed annually. According to the USDA, the edible portion of raw spinach is equal to $72 \%$ (2018). This means that, in order to produce 2.59 pounds for consumption, a total of 3.59 pounds must be grown. Using the required annual mass ( 3.59 pounds in this case), the average yield per square foot ( 0.30 pounds for spinach), and the number of annual harvests ( 6 for spinach), the amount of required physical growing space can be calculated. To produce half of the annual requirement of dark green vegetables using spinach would require approximately 2 square feet. Table 7.1.3. lists the growing space needed per person, per year for each crop and intake requirement in the baseline food production scenario. 
Table 7.1.3.: Total Growing Space per Person, per Crop Annually

\begin{tabular}{|l|c|c|c|c|c|}
\hline Crop & $\begin{array}{c}\text { Yield per } \\
\text { Square } \\
\text { Foot (lbs) }\end{array}$ & $\begin{array}{c}\text { Annual } \\
\text { Production } \\
\text { Needed } \\
\text { (lbs) }\end{array}$ & $\begin{array}{c}\text { Harvests } \\
\text { per Year }\end{array}$ & $\begin{array}{c}\text { Yield per } \\
\text { Square } \\
\text { Foot per } \\
\text { Year (lbs) }\end{array}$ & $\begin{array}{c}\text { Growing } \\
\text { Space } \\
\text { Needed } \\
\text { (sq ft) }\end{array}$ \\
\hline Broccoli & 0.42 & 17.15 & 6 & 15.81 & 2 \\
\hline Cantaloupe & 1.00 & 252.45 & 4 & 16.69 & 16 \\
\hline Cucumbers & 0.25 & 12.32 & 6 & 9.13 & 2 \\
\hline Eggplant & 0.42 & 11.64 & 4 & 7.34 & 2 \\
\hline $\begin{array}{l}\text { Green } \\
\text { Beans }\end{array}$ & 0.50 & 19.60 & 6 & 18.25 & 2 \\
\hline Kale & 0.50 & 2.51 & 7 & 25.55 & 1 \\
\hline Onions & 0.65 & 20.44 & 3 & 6.47 & 4 \\
\hline Peppers & 0.25 & 57.44 & 4 & 4.56 & 13 \\
\hline Potatoes & 0.37 & 57.48 & 3 & 3.81 & 16 \\
\hline Spinach & 0.30 & 3.60 & 6 & 12.31 & 2 \\
\hline Strawberries & 0.80 & 123.27 & 3 & 7.96 & 16 \\
\hline $\begin{array}{l}\text { Summer } \\
\text { Squash }\end{array}$ & 0.40 & 30.85 & 7 & 20.44 & 2 \\
\hline Tomatoes & 0.38 & 62.53 & 4 & 6.84 & 10 \\
\hline \multicolumn{1}{|c|}{ TOTAL } & & 671 & & & 87 \\
\hline
\end{tabular}

Once the specific types and quantities of food are defined and the amount of growing space is established, the lighting requirements can be determined. Plants require photosynthetically active radiation (PAR) to grow and thrive. This type of light occurs specifically between 400 and 700 nanometers on the spectral range and includes purple, blue, green, yellow, orange, and red light. Plants predominantly use blue, red, and purple rays and, depending on the stage of plant growth, different colors of light are more and less beneficial. During the seedling stage, plants need more blue light. During the vegetative stage, plants need more purple light. Finally, during the flowering stage plants need more red light. This is important because different artificial light bulbs emit light from different parts of the spectral range, and no current artificial 
light technology can precisely replicate the light emitted from the sun. This means that different light bulbs will emit light from different parts of the spectrum.

Plants also need exposure to a certain amount and duration of photosynthetic light each day. This is quantified by two metrics. The amount of light needed to grow plants is a function of the daily light integral (DLI) (Runkle 2006). The duration of light needed by each crop is a function of the photoperiod (Runkle 2006). The DLI refers to the amount of light, measured in moles per square meter per day $\left(\mathrm{mol} \mathrm{m} \mathrm{m}^{2} \mathrm{~d}\right)$. The photoperiod refers to the duration of light, measured in hours per day $(h / d)$. Different types of crops have different DLI requirements and different photoperiods. In this study there are two sets of light requirements, one for greens (i.e. spinach and kale), and one for the other 11 crops which fall into the category of tomatoes, melons, and vining crops. Crops in the greens category have an optimal DLI of $16 \mathrm{~mol} \mathrm{~m}^{2} \mathrm{~d}$ and a minimum photoperiod of $14 \mathrm{~h} / \mathrm{d}$ (Runkle 2006). Crops in the tomatoes, melons, and vining crops category have an optimal DLI of $35 \mathrm{~mol} \mathrm{~m}^{2} \mathrm{~d}$ and a minimum photoperiod of $18 \mathrm{~h} / \mathrm{d}$ (Runkle 2006).

Once the DLI and the photoperiod have been established, the next step is to determine how to provide the corresponding amount of light needed. In other words, we need to know how much of the light requirement for any given crop can be provided by one bulb. The light output of bulbs is reported in terms of photosynthetic photon flux density (PPFD), which is a measure of the amount of light emitted in a specific area each second $\left(u m o l m^{2} s\right)$. Although manufacturer specifications for light bulbs aren't provided in terms of DLI, the DLI can be used to calculate lighting requirements in terms of PPFD. For example, greens have a target PPFD of 243, and tomatoes, melons, and vining crops have a target PPFD of 347. Based on manufacturer data, we know that the CREE linear LED fixture used in our model produces an average PPFD of 805 umol $\mathrm{m}^{2} \mathrm{~s}$. To provide the target PPFD of $347 \mathrm{umol} \mathrm{m}^{2} \mathrm{~s}$ required by tomatoes, melons, and vining crops would require $0.43 \mathrm{CREE}$ high bay LED fixtures per square meter. The final step is to convert fixtures per square meter to fixtures per square feet. The average PPFD for the high bay fixture used in the model is $805 \mathrm{umol} \mathrm{m}^{2} \mathrm{~s}$. Table 7.1.4. lists the number bulbs per crop. 
Table 7.1.4. Number of Bulbs per Crop

\begin{tabular}{|l|c|}
\hline & $\begin{array}{c}\text { CREE } \\
\text { High Bay } \\
\text { LED }\end{array}$ \\
\hline Broccoli & 0.3 \\
\hline Cantaloupe & 2.4 \\
\hline Cucumbers & 0.3 \\
\hline Eggplant & 0.3 \\
\hline Green Beans & 0.3 \\
\hline Kale & 0.0 \\
\hline Onions & 0.4 \\
\hline Peppers & 2.0 \\
\hline Potatoes & 1.8 \\
\hline Spinach & 0.0 \\
\hline Strawberries & 1.9 \\
\hline $\begin{array}{l}\text { Summer } \\
\text { Squash }\end{array}$ & 0.4 \\
\hline Tomatoes & 1.5 \\
\hline \multicolumn{1}{|c|}{ TOTAL: } & $\mathbf{1 1 . 5}$ \\
\hline
\end{tabular}




\subsection{Determining Critical Material Intensity of Horticultural Lighting Technologies}

Figure 7.2.1.: Determining Critical Material Intensity of Horticultural Lighting Technologies

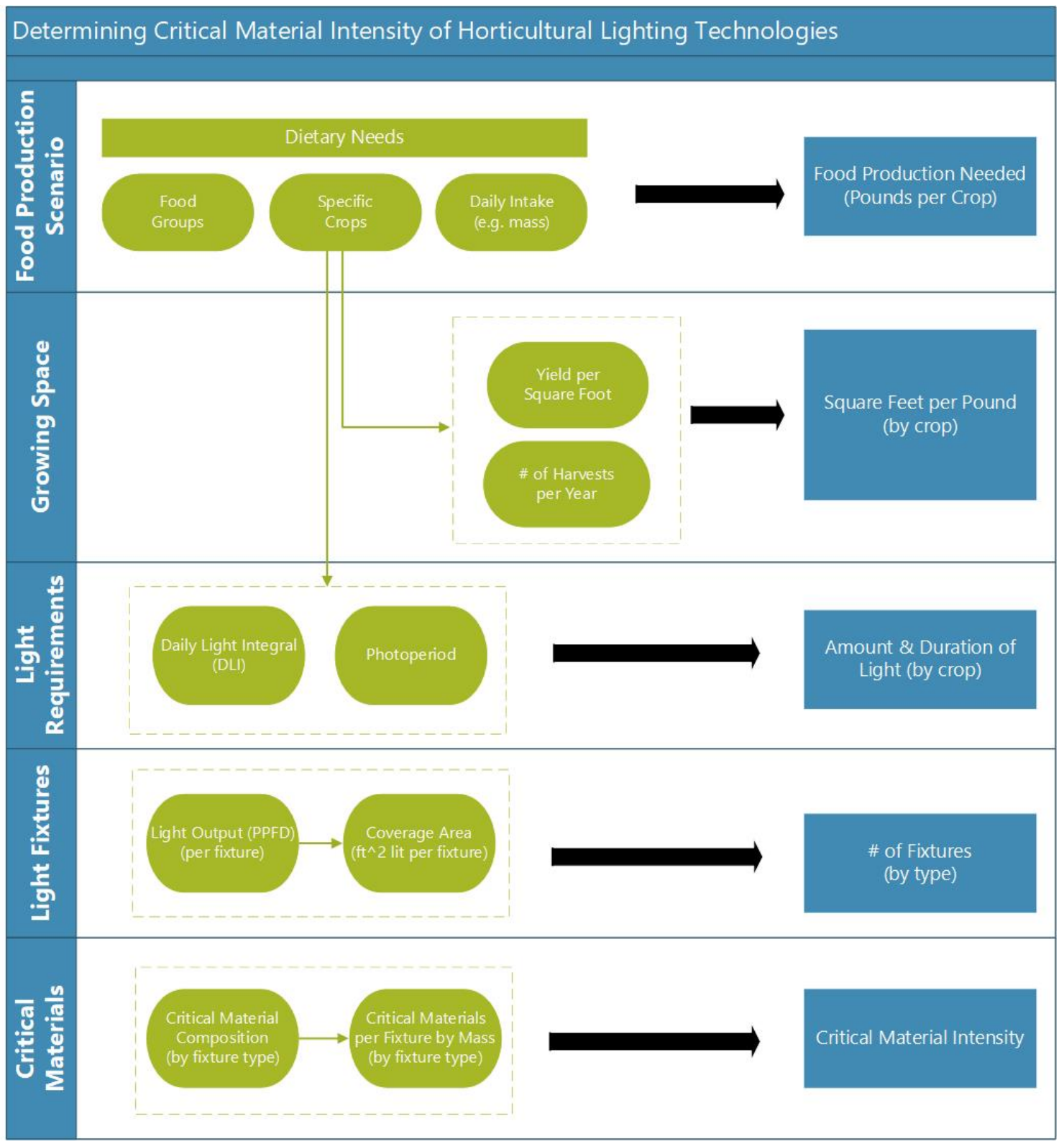


7.3. Mass and Cost of Critical Materials by Lighting Technology

Table 7.3.1. Mass and Cost of Critical Materials by Lighting Technology

\begin{tabular}{|l|c|c|}
\hline & Mass / Bulb (g) & $\begin{array}{c}\text { Critical Material } \\
\text { Cost / Bulb (\$) }\end{array}$ \\
\hline HID Metal Halide & $6.10 \mathrm{E}-01$ & $3.37 \mathrm{E}-02$ \\
\hline T8 LFL & $1.69 \mathrm{E}-03$ & $7.24 \mathrm{E}-05$ \\
\hline High Bay LED & $1.55 \mathrm{E}-01$ & $1.31 \mathrm{E}-02$ \\
\hline
\end{tabular}




\section{Appendix D}

\subsection{Price Volatility and Firm Performance}

To further understand the dynamic between critical material price volatility and firm performance, annual and quarterly data was analyzed for three firms that rely heavily on rhenium: Boeing, General Electric (GE), and Pratt \& Whitney (a subsidiary of United Technologies). Boeing is the world's largest jet manufacturer, and GE and Pratt \& Whitney are two of the three largest consumers of rhenium in the U.S. (alloy manufacturer Cannon Muskegon is the third largest). Figure 1 shows the percent change in the annual profit of each firm between 2007 and 2012, relative to the price of rhenium. Figure 3 shows the change in quarterly profit for each firm over the same time period. The trailing performance of each firm after 2008's massive rhenium price spike suggests a negative correlation between the price of rhenium and profit. This is particularly evident in Boeing's performance. The impact appears to bottom out around 2010 when a gradual recovery can be seen for all three firms in 2011 and in GE and Boeing in 2012.

Figure 8.1.1. Annual Price of Rhenium vs. Annual Profit of GE, Boeing, and Pratt \& Whitney, $2007-2012$

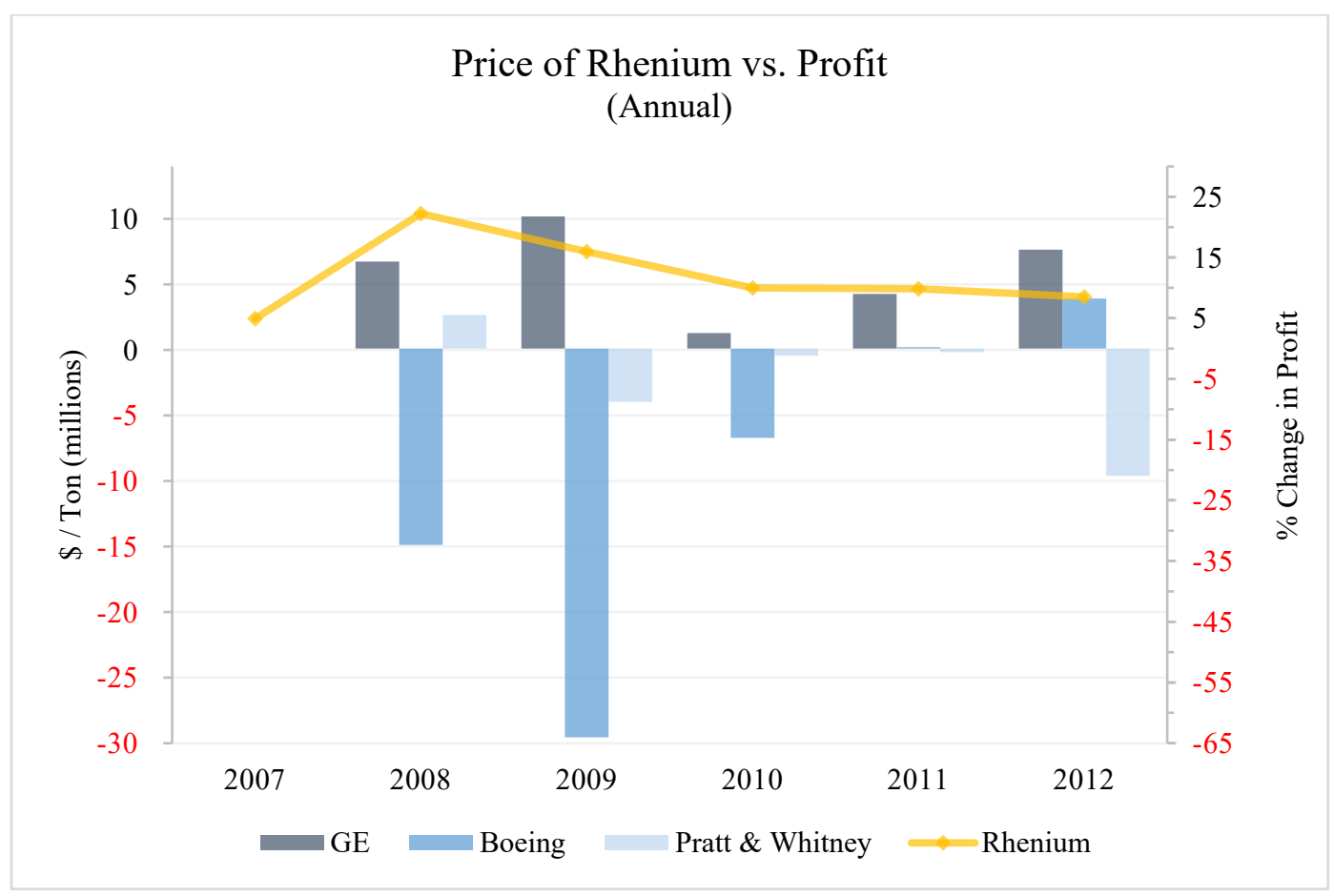


Figure 8.1.2. Quarterly Price of Rhenium vs. Quarterly Profit of GE, Boeing, and Pratt \& Whitney, 2007 - 2012

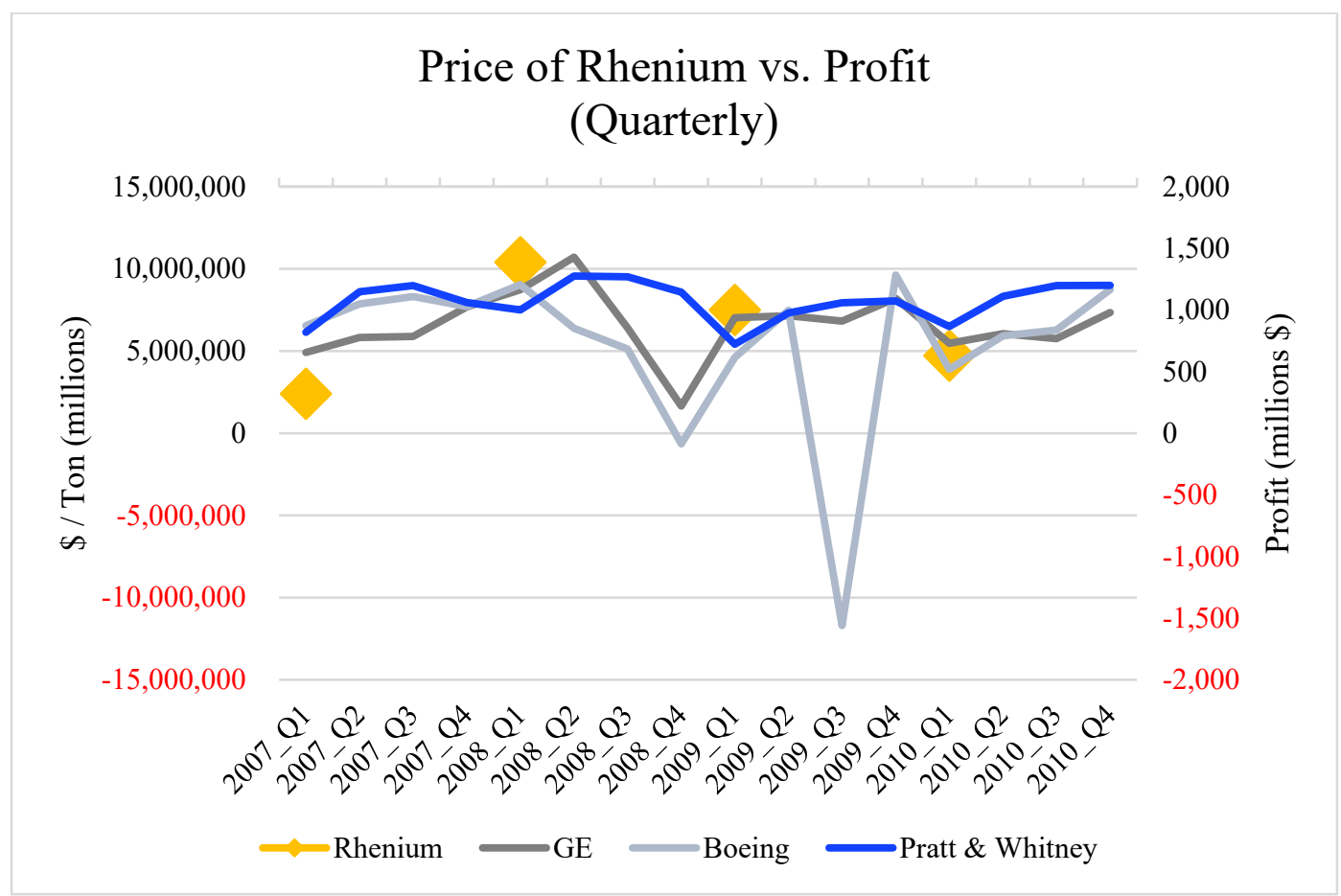

Both the annual and the quarterly data suggest an impact and recovery cycle in which an initial supply disruption (caused by the 2008 price spike), causes both short- and long-term damage to firm performance. Within four quarters of the rhenium price spike, GE profit declined by $-81 \%$ and Boeing profit declined by $-107 \%$. Pratt \& Whitney profit also declined, but more gradually. Within five quarters of the rhenium price spike, Pratt \& Whitney experienced a $-28 \%$ decline in profit. Volatility persists among all three firms over the 8 quarters with Boeing showing the greatest variation in performance. 
Figure 8.1.3. Annual Financial Performance of Boeing vs. Price of Rhenium

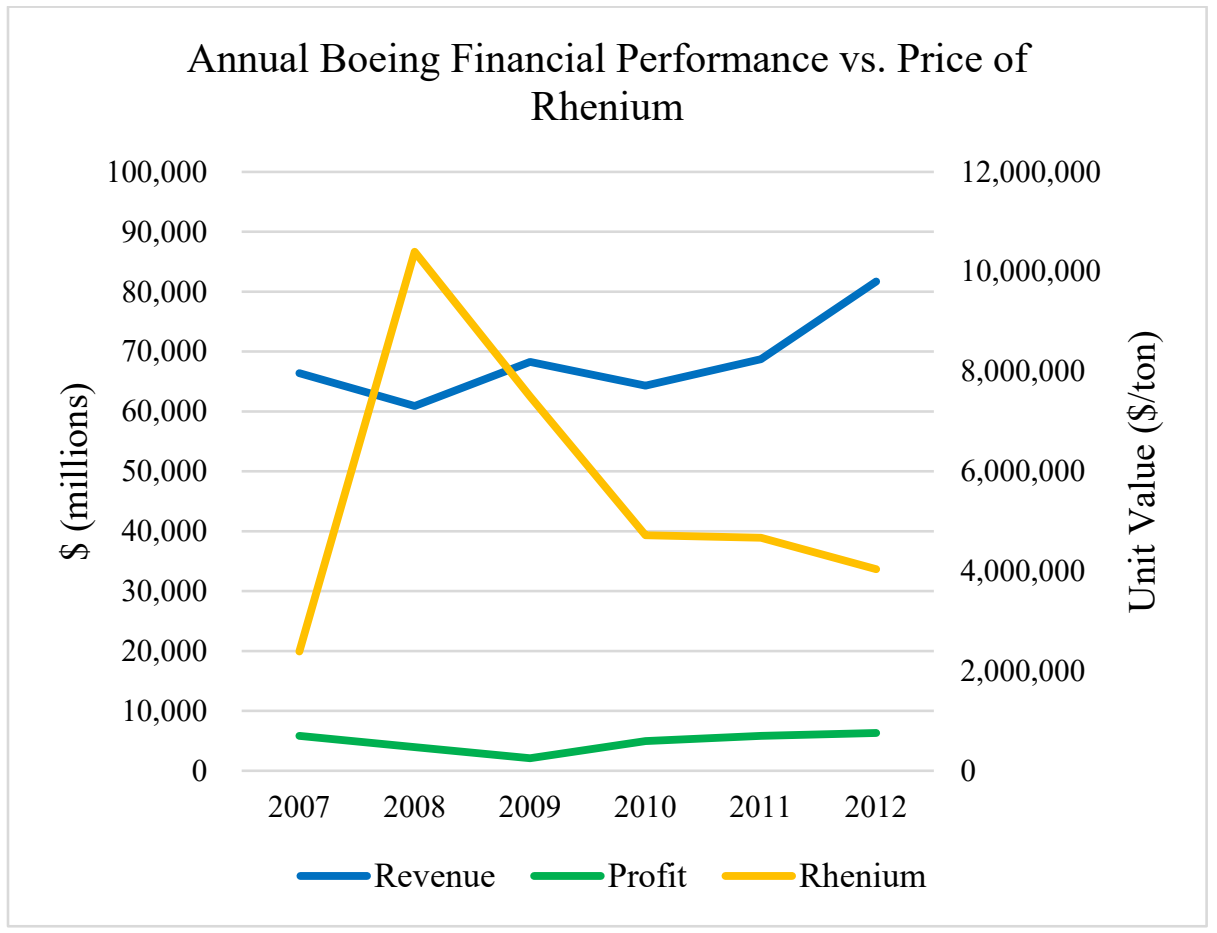

Figure 8.1.4. Annual Variation in Boeing Financial Performance vs. Price of Rhenium

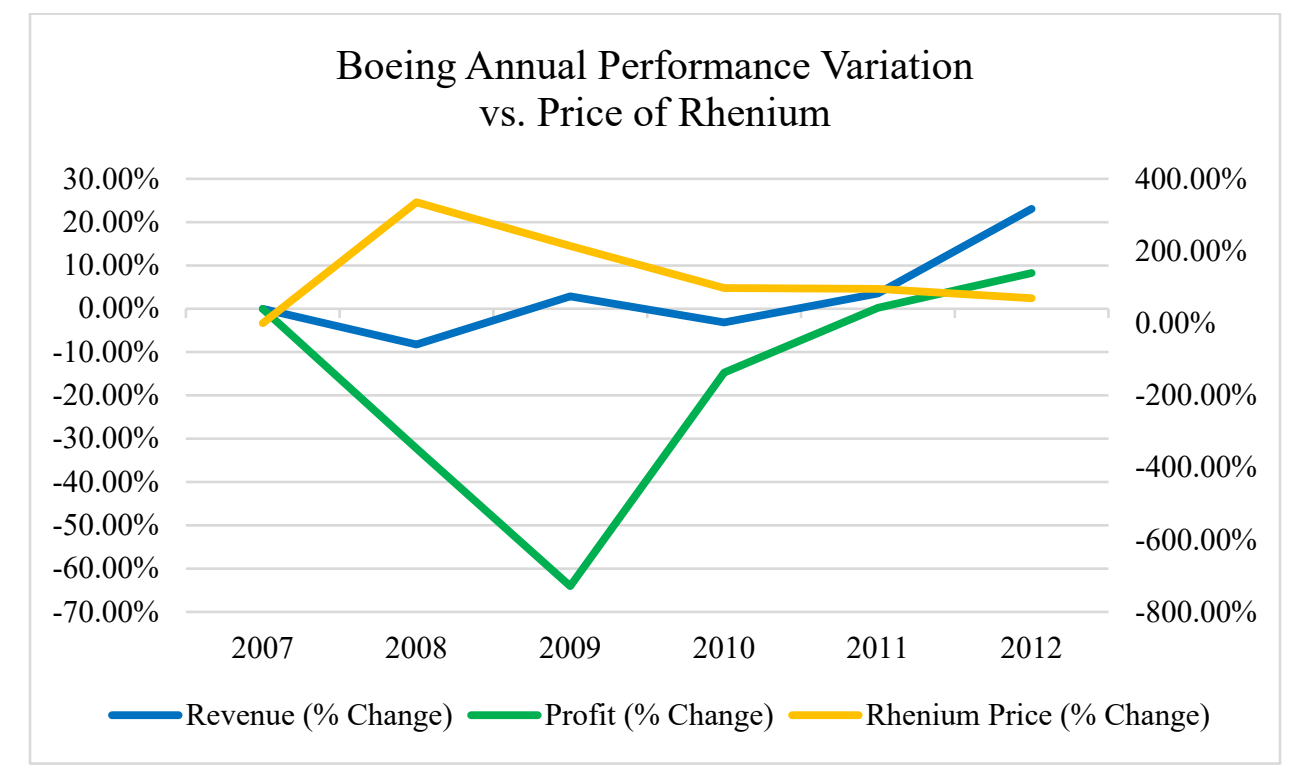


Figure 8.1.5. Quarterly Financial Performance of Boeing vs. Price of Rhenium

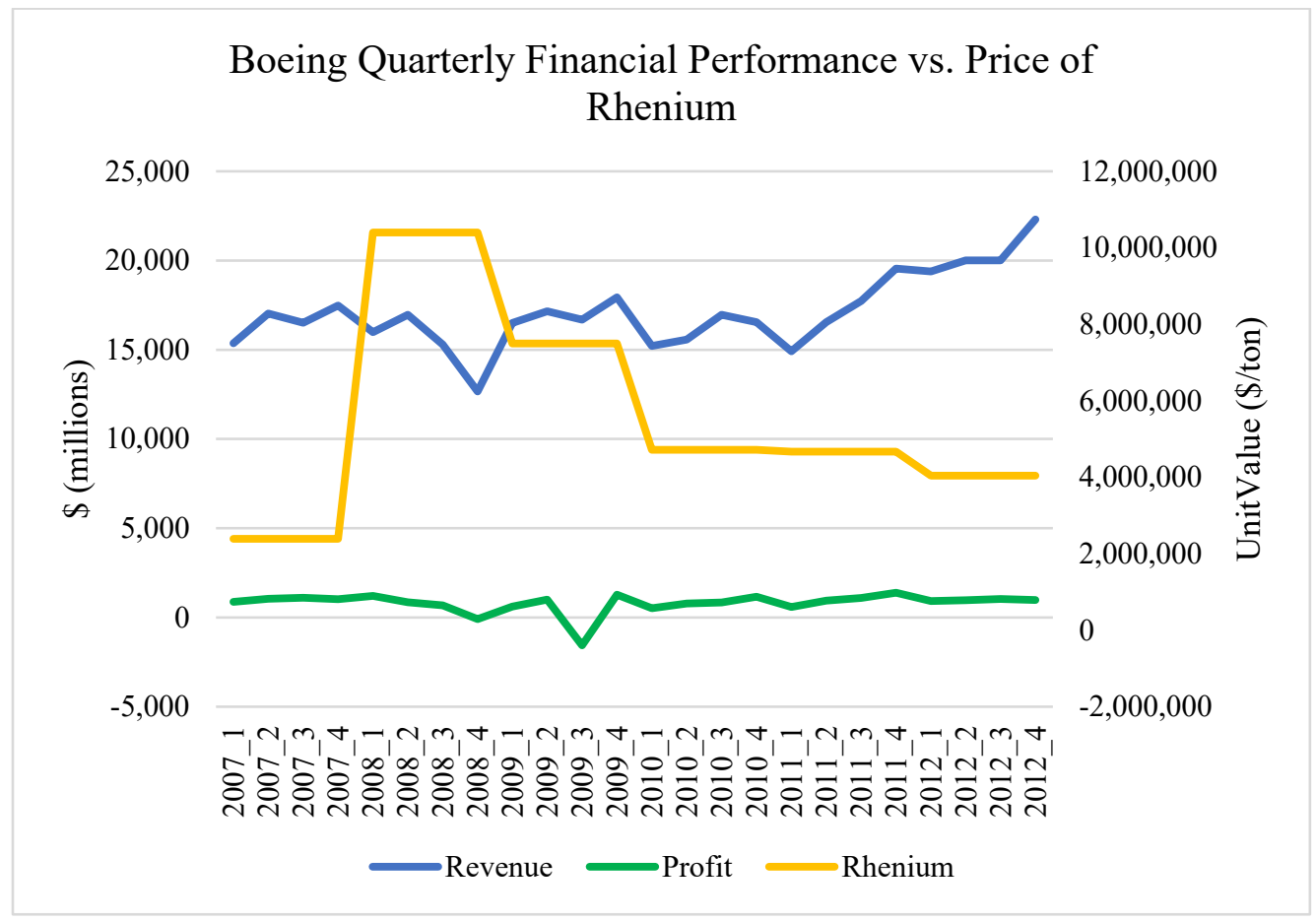

Figure 8.1.6. Quarterly Variation in Boeing Financial Performance vs. Price of Rhenium

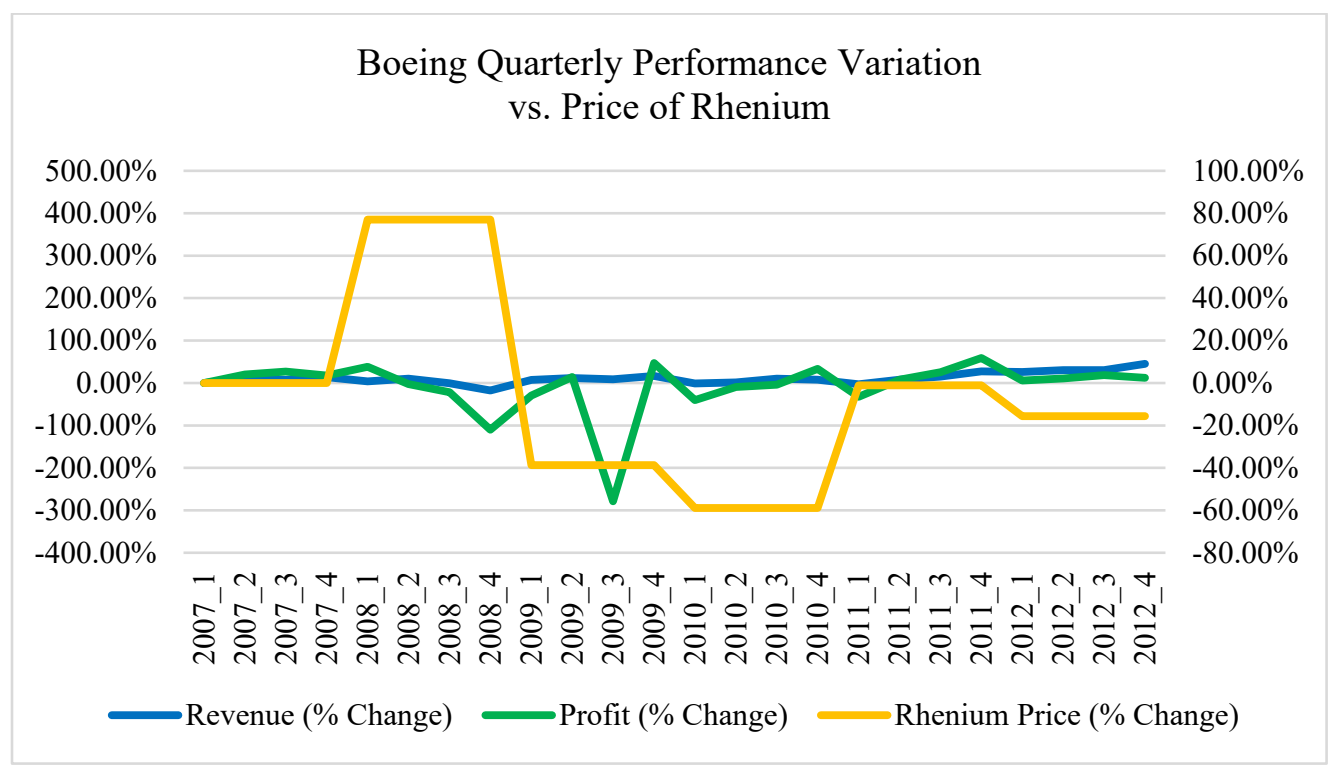


Figure 8. 1.7. Annual Financial Performance of General Electric (GE) Aviation vs. Price of Rhenium

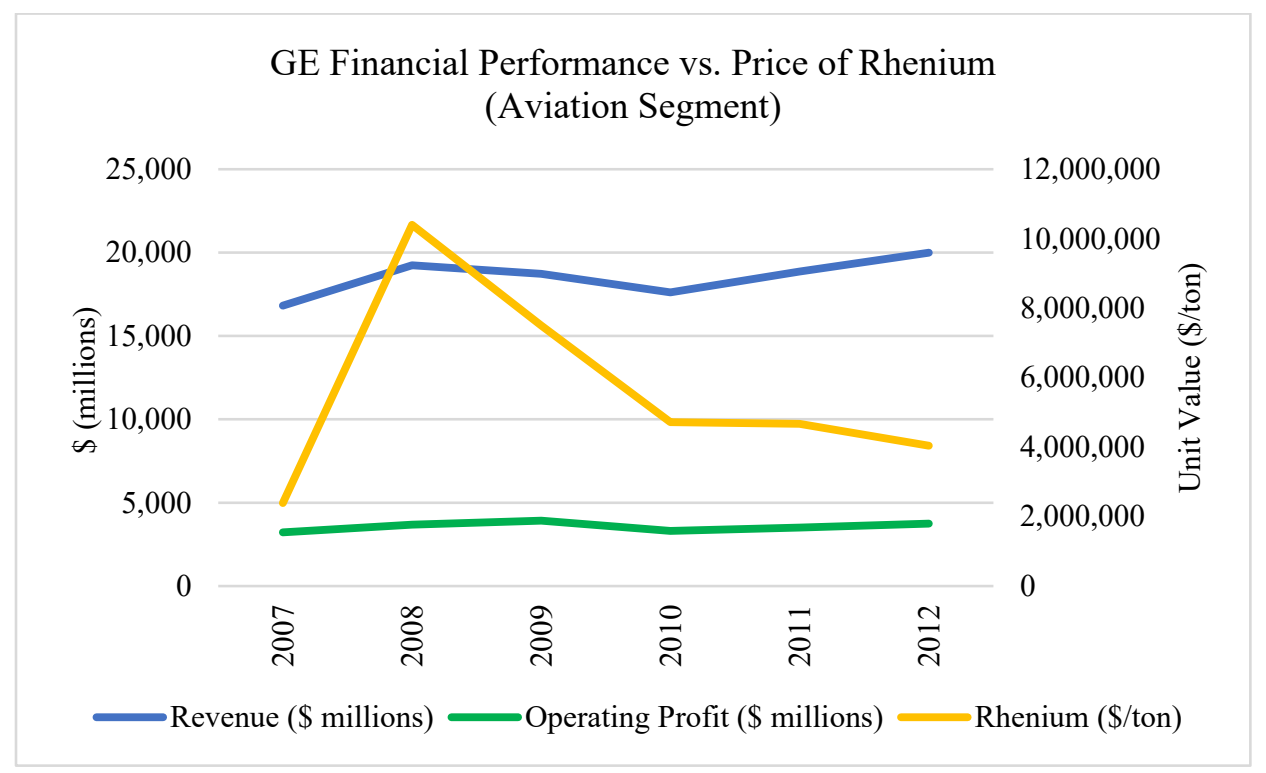

Figure 8.1.8. Annual Variation in General Electric (GE) Aviation Financial Performance vs. Price of Rhenium

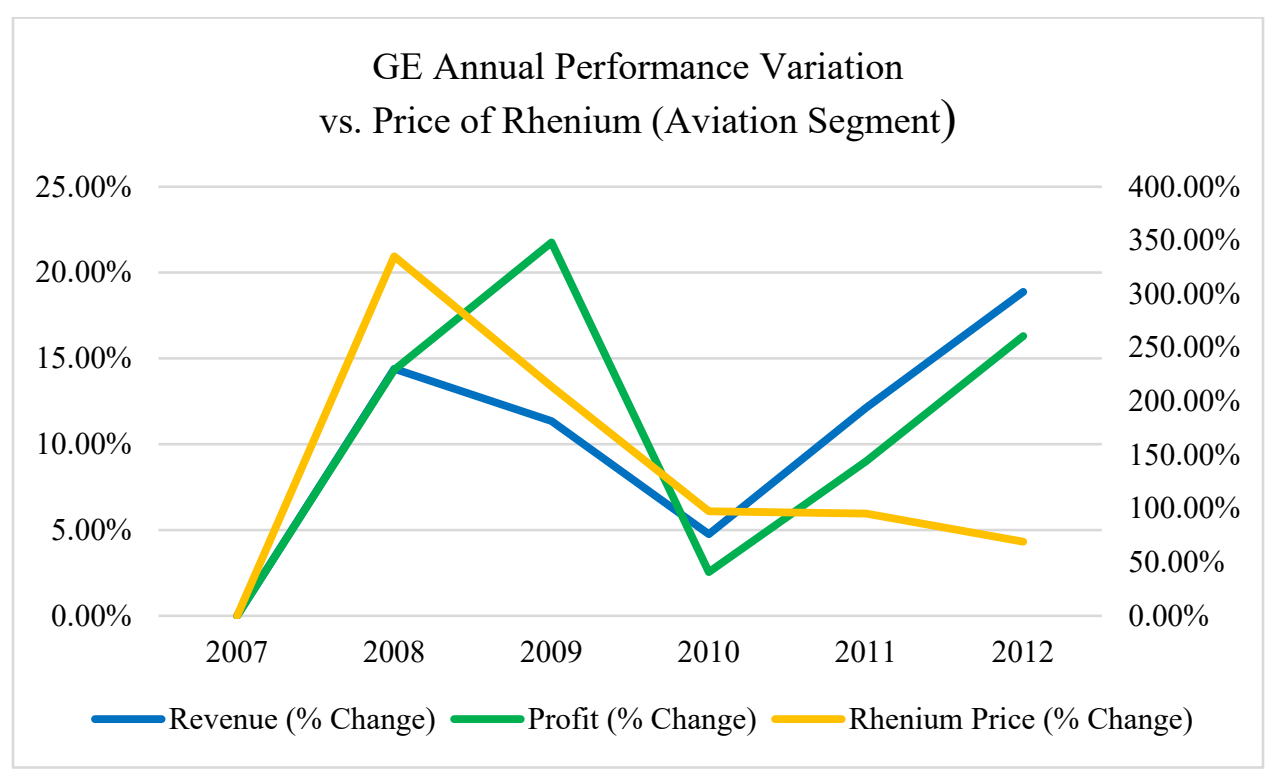


Figure 8.1.9. Quarterly Financial Performance of General Electric (GE) Aviation vs. Price of Rhenium

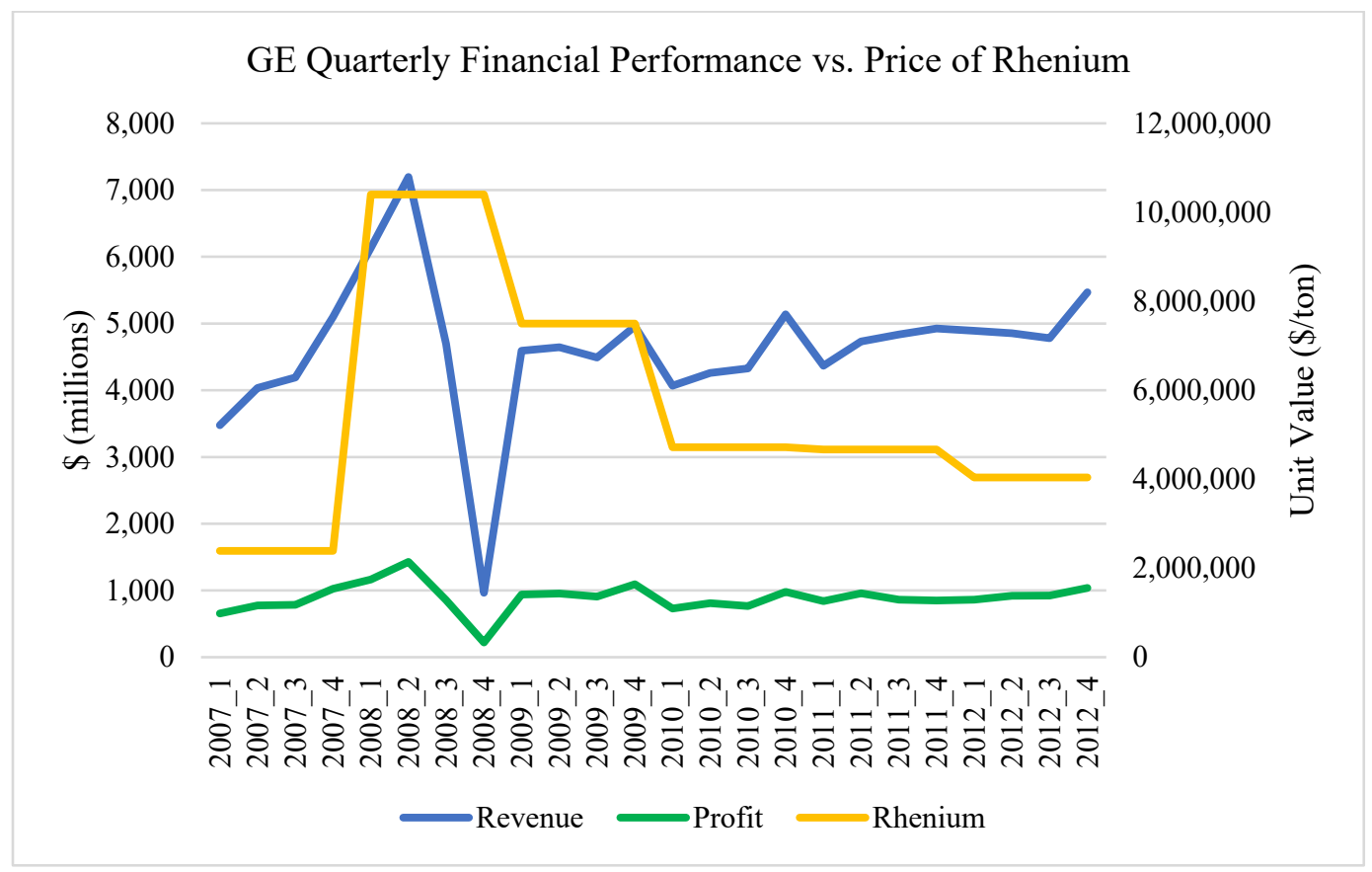

Figure 8.1.10. Quarterly Variation in General Electric (GE) Aviation Financial Performance vs. Price of Rhenium

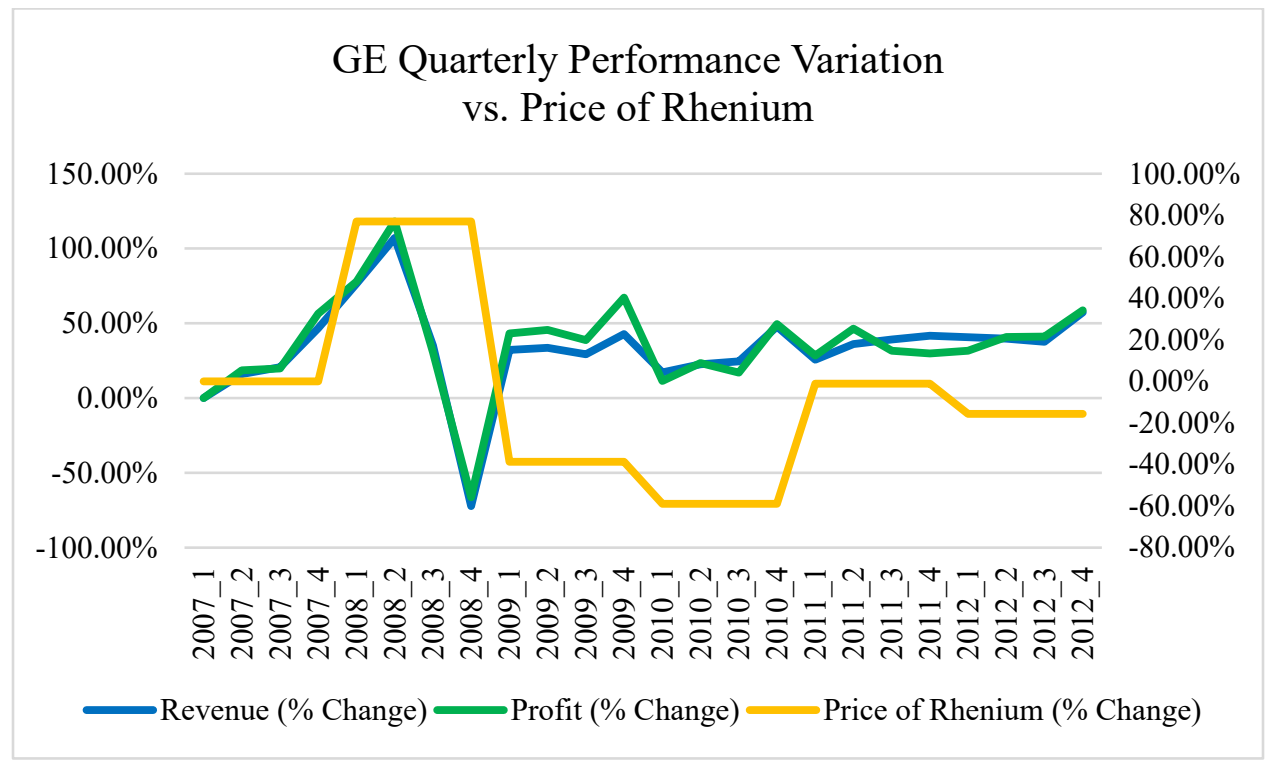


Figure 8.1.11. Annual Financial Performance of Pratt \& Whitney vs. Price of Rhenium

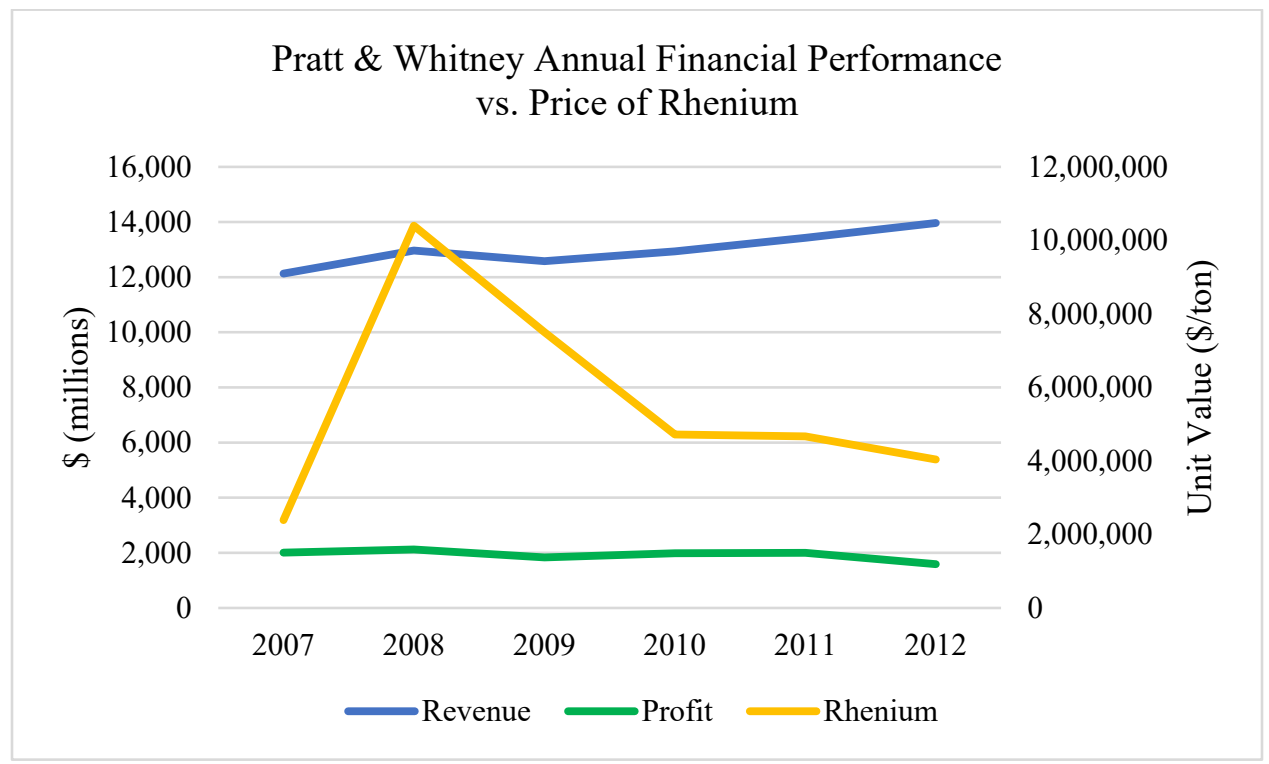

Figure 8.1.12. Annual Variation in Pratt \& Whitney Financial Performance vs. Price of Rhenium

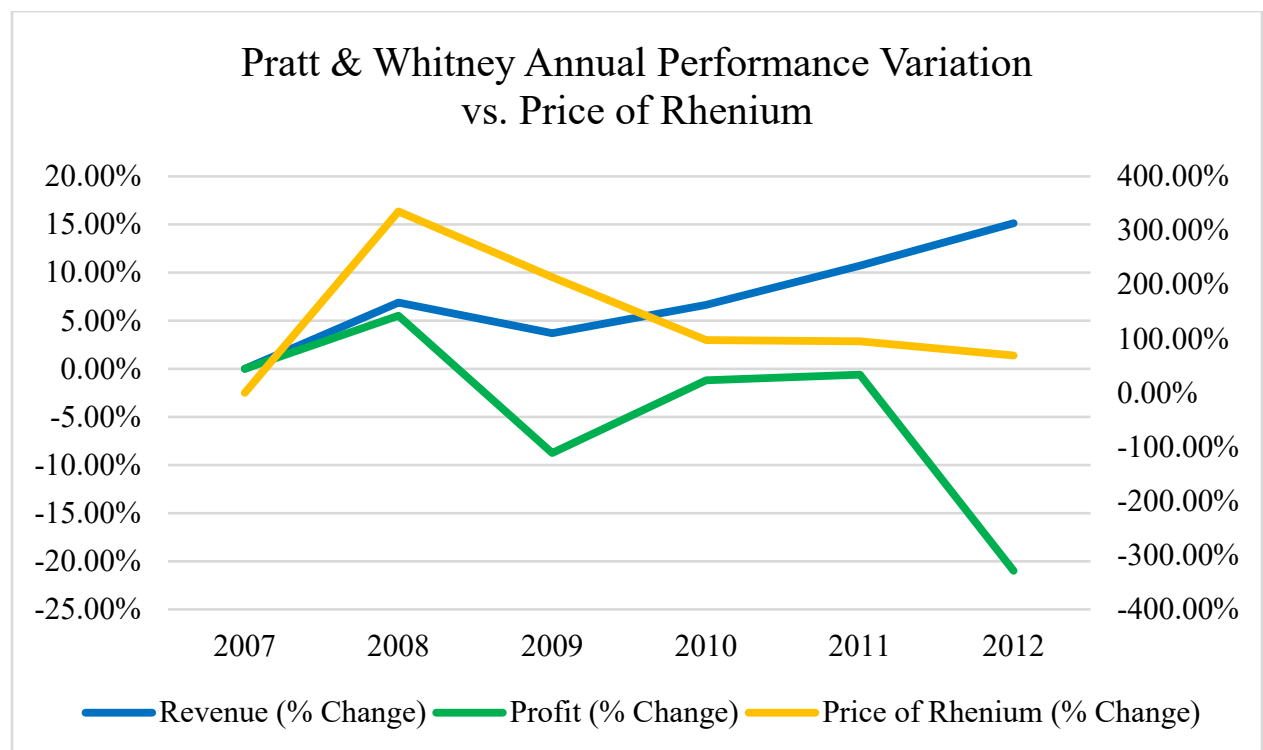


Figure 8.1.13. Quarterly Financial Performance of Pratt \& Whitney vs. Price of Rhenium

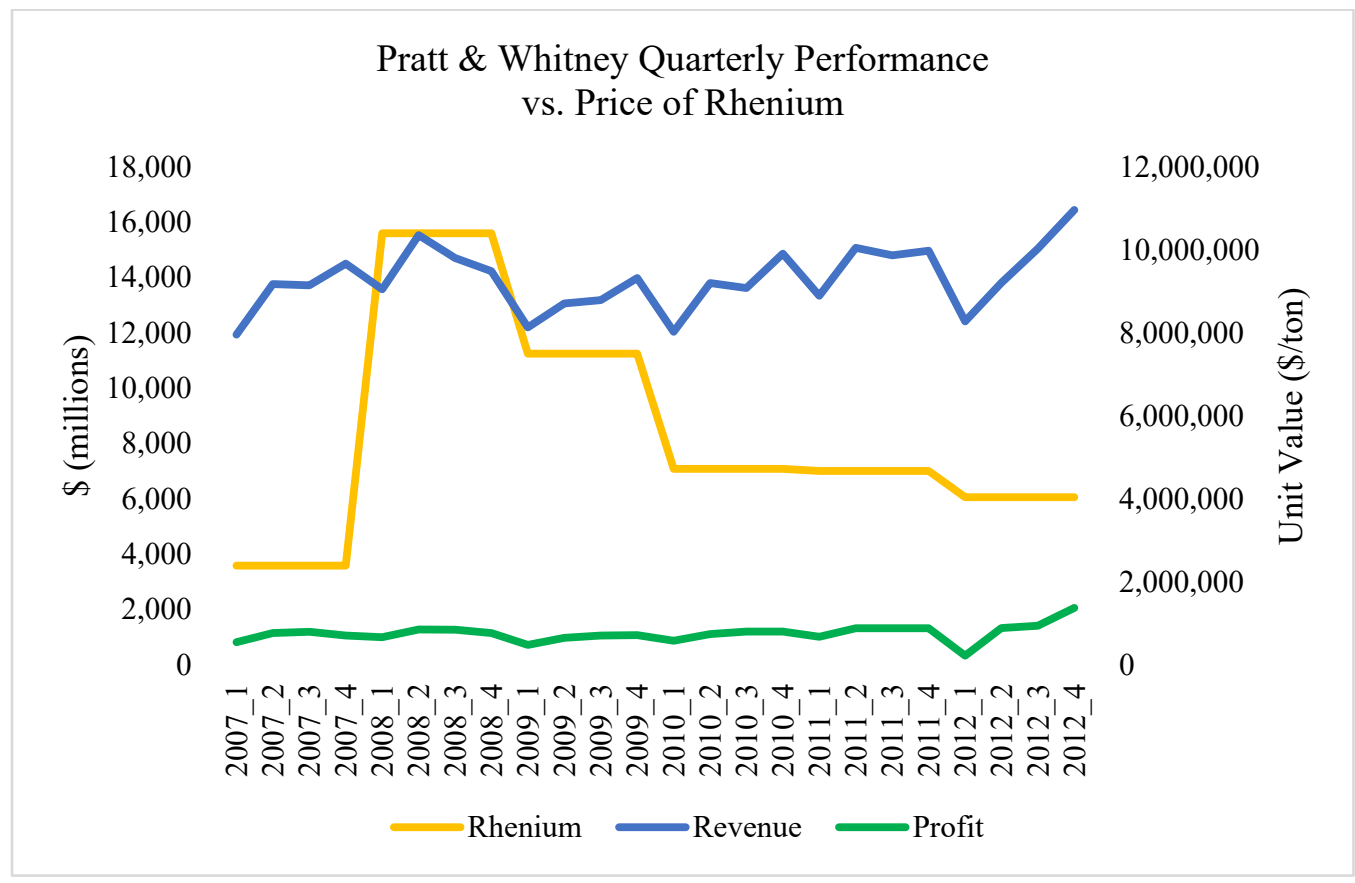

Figure 8.1.14. Quarterly Variation in Pratt \& Whitney Financial Performance vs. Price of Rhenium

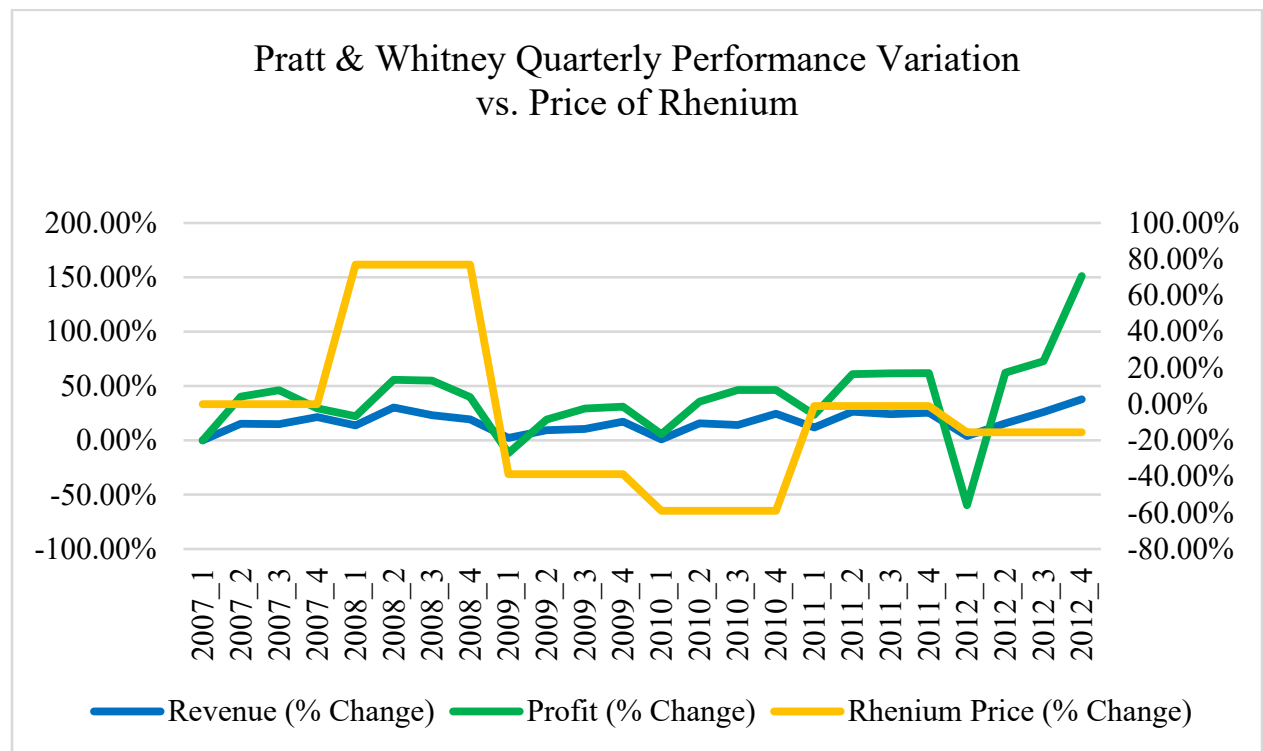




\section{References}

Achzet, B. and C. Helbig (2013). "How to evaluate raw material supply risks - an overview." Resources Policy 38: 435-447.

AEA Technology (2010). Review of the Future Resource Risks Faced by UK Business and an Assessment of Future Viability. London.

AEA Technology (2011). Raw materials critical to the Scottish economy. Edinburgh.

Agarwal, S., J. Ofori and K. Raghavan (2012). Managing rough waters: How to steer a course to stability with commodity price volatility as the new norm, Deloitte Consulting, LLP.

Agency, E. A. S. (2013). Rolls-Royce plc Trent XWB series engines. EASA Type Certificate Data Sheet.

Agrilyst, Cornell University, and Urban Ag News. "State of Indoor Farming 2017." Agrilyst. Accessed April 24, 2019. https://www.agrilyst.com/stateofindoorfarming2017/.

Alonso, E., Gregory, J., Field, F., Kirchain, R. (2007). Material Availability and the Supply Chain: Risks, Effects, and Responses. Environmental Science \& Technology 41(19): 6649-6656.

Anderson, C.S. (2019). Indium. Mineral Commodity Summary, US Geological Survey. Retrieved April 23, 2019, from https://minerals.usgs.gov/minerals/pubs/commodity/indium/mcs2019-indiu.pdf.

Angerer, G., F. Marscheider-Weidemann, A. Lüllmann, L. Erdmann, M. Scharp, V. Handke and M. Marwede (2009). "Raw materials for emerging technologies: The influence of sector-specific feedstock demand on future raw materials consumption in material-intensive emerging technologies." Karlsruhe: Fraunhofer ISI.

Bach, V., N. Finogenova, M. Berger, L. Winter and M. Finkbeiner (2017). "Enhancing the assessment of critical resource use at the country level with the SCARCE method-Case study of Germany." Resources Policy 53: 283-299.

Bauer, D., D. Diamond, J. Li, M. McKittrick, D. Sandalow and P. Telleen (2011). "Critical Materials Strategy. US Department of Energy.": 1-166.

Bauer, D., D. Diamond, J. Li, D. Sandalow, P. Telleen and B. Wanner (2010). "US Department of Energy Critical Materials Strategy."

Bensch, S., C. Kolotzek, C. Helbig, A. Thorenz and A. Tuma (2015). Decision Support System for the Sustainability Assessment of Critical Raw Materials in SMEs. 2015 48th Hawaii International Conference on System Sciences (HICSS), IEEE.

Blechman, Barry M., and David M. Sloss. National Security and Strategic Minerals: An Analysis of U.S. Dependence on Foreign Sources of Cobalt. Boulder, CO: Westview Press, 1985. 
Blengini, G. A., Nuss, P., Dewulf, J., Nita, V., Peirò, L. T., Vidal-Legaz, B., ... \& Pellegrini, M. (2017). EU methodology for critical raw materials assessment: Policy needs and proposed solutions for incremental improvements. Resources Policy 53, 12-19.

Brown, T. (2018). "Measurement of mineral supply diversity and its importance in assessing risk and criticality." Resources Policy.

Brown, T. J., T. Bide, A. S. Walters, N. E. Idoine, R. A. Shaw, S. D. Hannis, P. A. J. Lusty and R. Kendall (2011). "World Mineral Production. 2005-09." British Geological Survey: 118.

Buchert, M., D. Schüler, D. Bleher and P. d. N. U. p. l'environnement (2009). Critical metals for future sustainable technologies and their recycling potential, UNEP DTIE; Öko-Institut.

Buchert, M., Manhart, A., Bleher, D., \& Pingel, D. (2012). Recycling critical raw materials from waste electronic equipment. Freiburg: Öko-Institut eV, 49(0): 30-40.

Buijs, B. and H. Sievers (2011). "Critical thinking about critical minerals: Assessing risks related to resource security." Polinares EU Policy on Natural Resources. The Hague: Clingendael International Energy Programme.

Bustamante, M. L. and G. Gaustad (2014). "Challenges in assessment of clean energy supplychains based on byproduct minerals: A case study of tellurium use in thin film photovoltaics." Applied Energy 123: 397-414.

Cannella, S., A. P. Barbosa-Póvoa, J. M. Framinan and S. Relvas (2013). "Metrics for bullwhip effect analysis." Journal of the Operational Research Society 64(1): 1-16.

Chapman, P., M. Christopher, U. Jüttner, H. Peck and R. Wilding (2002). "Identifying and managing supply chain vulnerability." Logistics \& Transport Focus 4(4): 59-70.

Cullbrand, K. and O. Magnusson (2012). "The use of potentially critical materials in passenger cars." Chalmers University, Sweden.

CREE Inc. (2018). "Annual Report 2018." Retreived from https://investor.cree.com/staticfiles/1093a940-b534-47eb-8966-24898912364a.

Daw, G. (2017). "Security of mineral resources: A new framework for quantitative assessment of criticality." Resources Policy 53: 173-189.

Deloitte Sustainability et al. (2017). Study on the review of the list of critical raw materials (European Commission, Brussels). Brussels, European Commission.

Department of Defense (2017). Strategic and Critical Materials Operations Report To Congress, Department of Defense, Office of the Undersecretary of Defense for Acquisition, Technology, and Logistics. 
Duclos, S. J., J. P. Otto and D. G. Konitzer (2010). "Design in an era of constrained resources." Mechanical Engineering 132(9): 36.

Duclos, S., 2016. Evaluating and Solving Industrial Material Sustainability Challenges. GE Experiences.

EC (2010). "Critical raw materials for the EU. Report of the Ad-hoc Working Group on defining critical raw materials." Ad-hoc Working Group: July 2010: 84.

EC (2014). "Report on Critical Raw Materials for the EU. Report of the Ad hoc Working Group on defining critical raw materials.": 41.

Gambogi, J. (2019a). Rare Earths. Mineral Commodity Summary, US Geological Survey. Retrieved April 23, 2019, from https://minerals.usgs.gov/minerals/pubs/commodity/rare_earths/mcs-2019-raree.pdf

Gambogi, J. (2019b). Yttrium. Mineral Commodity Summary, US Geological Survey. Retrieved April 23, 2019, from https://minerals.usgs.gov/minerals/pubs/commodity/rare_earths/mcs-2019yttri.pdf

Gardner, L. and J. Colwill (2016). "A framework for the resilient use of critical materials in sustainable manufacturing systems." Procedia CIRP 41: 282-288.

Gardner, L. and J. Colwill (2018). "A framework and decision support tool for improving value chain resilience to critical materials in manufacturing." Production \& Manufacturing Research 6(1): 126-148.

Gaustad, G., Krystofik, M., Bustamante, M., \& Badami, K. (2018). Circular economy strategies for mitigating critical material supply issues. Resources, Conservation and Recycling, 135, 2433.

GlobalData Energy. "Rare Earths: Chinese Dominance Unchallenged despite Newer Discoveries.” Mining Technology | Mining News and Views Updated Daily, July 16, 2018. https://www.mining-technology.com/comment/rare-earths-chinese-dominance-unchallengeddespite-newer-discoveries/.

Glöser-Chahoud, S., L. Tercero Espinoza, R. Walz and M. Faulstich (2016). "Taking the Step towards a More Dynamic View on Raw Material Criticality: An Indicator Based Analysis for Germany and Japan." Resources 5(4): 45.

Graedel, T., G. Gunn and L. Tercero Espinoza (2014). "Metal resources, use and criticality." Critical metals handbook: 1-19. 
Graedel, T. E., R. Barr, C. Chandler, T. Chase, J. Choi, L. Christoffersen, E. Friedlander, C. Henly, C. Jun and N. T. Nassar (2012). "Methodology of metal criticality determination." Environmental science \& technology 46(2): 1063-1070.

Graedel, T. E., E. Harper, N. T. Nassar, P. Nuss and B. K. Reck (2015). "Criticality of metals and metalloids." Proceedings of the National Academy of Sciences 112(14): 4257-4262.

Graedel, T. E., E. M. Harper, N. T. Nassar and B. K. Reck (2015). "On the materials basis of modern society." Proceedings of the National Academy of Sciences 112(20): 6295-6300.

Graedel, T. E. and B. K. Reck (2016). "Six Years of Criticality Assessments: What Have We Learned So Far?" Journal of Industrial Ecology 20(4): 692-699.

Griffin, G., Gaustad, G., \& Badami, K. (2019). "A framework for firm-level critical material supply management and mitigation." Resources Policy 60: 262-276.

Gunn, G. (2014). Critical metals handbook, John Wiley \& Sons.

Hallstedt, S. I. and O. Isaksson (2017). "Material criticality assessment in early phases of sustainable product development." Journal of Cleaner Production 161: 40-52.

Hatayama, H. and K. Tahara (2015). "Criticality assessment of metals for Japan's resource strategy." Materials Transactions 56(2): 229-235.

Hatayama, H., \& Tahara, K. (2018). Adopting an objective approach to criticality assessment: Learning from the past. Resources Policy, 55, 96-102.

Helbig, C., C. Kolotzek, A. Thorenz, A. Reller, A. Tuma, M. Schafnitzel and S. Krohns (2017). "Benefits of resource strategy for sustainable materials research and development." Sustainable materials and technologies 12: 1-8.

Helbig, C., L. Wietschel, A. Thorenz and A. Tuma (2016). "How to evaluate raw material vulnerability-An overview." Resources Policy 48: 13-24.

Helferich, O. K. and R. L. Cook (2002). Securing the supply chain, Council of logistics management.

Hendricks, K. and V. R. Singhal (2005a). "An empirical analysis of the effect of supply chain disruptions on long-run stock priec performance and equity risk of the firm." Production and Operations Management 14(1):35-52.

Hendricks, K. B. and V. R. Singhal (2005b). "Association between supply chain glitches and operating performance." Management Science 51(5): 695-711.

Hendricks, K. B. and V. R. Singhal (2007). "The Effect of Demand-Supply Mismatches on Equity Volatility: An Analysis of Different Types of Supply Chain Risks." 
Hillman, M. and H. Keltz (2007). "Managing risk in the supply chain: a quantitative study." AMR Research (January): 1-24.

Investing News Network. (2018, December 06). Rare Earth Elements Prices 101. Retrieved from https://investingnews.com/daily/resource-investing/critical-metals-investing/rare-earthinvesting/rare-earth-metals-prices/

Jasiński, D., M. Cinelli, L. C. Dias, J. Meredith and K. Kirwan (2018). "Assessing supply risks for non-fossil mineral resources via multi-criteria decision analysis." Resources Policy 58: 150158.

Jaskula, B.W. (2019). Gallium. Mineral Commodity Summary, US Geological Survey. Retrieved April 23, 2019, from https://minerals.usgs.gov/minerals/pubs/commodity/gallium/mcs-2019galli.pdf.

John, D. (2015). Rhenium--A Rare Metal Critical to Modern Transportation, US Geological Survey.

Kellner, Tomas. "Up, Up and Away: GE's Billion Dollar Bet on Ceramic Super Material Is Taking Off." GE Reports, September 18, 2015. Retrieved from https://www.ge.com/reports/post/123737823440/up-up-and-away-ges-billion-dollar-bet-on/.

Knobloch, V., T. Zimmermann and S. Gößling-Reisemann (2018). "From criticality to vulnerability of resource supply: The case of the automobile industry." Resources, Conservation and Recycling 138: 272-282.

Kolotzek, C., C. Helbig, A. Thorenz, A. Reller and A. Tuma (2018). "A company-oriented model for the assessment of raw material supply risks, environmental impact and social implications." Journal of Cleaner Production 176: 566-580.

Lapko, Y., P. Trucco and C. Nuur (2016). "The business perspective on materials criticality: Evidence from manufacturers." Resources Policy 50: 93-107.

Lee, H. L., V. Padmanabhan and S. Whang (1997a). "The Bullwhip Effect in Supply Chains." Sloan Management Review 38(3): 93-102.

Lee, H. L., V. Padmanabhan and S. Whang (1997b). "Information distortion in a supply chain: The bullwhip effect." Management Science 43(4): 546-558.

Lipmann, A. (2005). "Rhenium." Lipmann Walton and Co Ltd.

Lloyd, S., A. Clifton, J. Lee, L. Elghali and C. France (2012). "A framework for environmental risk management." The Aeronautical Journal 116(1183): 941-961. 
Lloyd, S., J. Lee, A. Clifton, L. Elghali and C. France (2012). Ecodesign through environmental risk management: a focus on critical materials. Design for Innovative Value Towards a Sustainable Society, Springer: 374-379.

Mancheri, N. A., Sprecher, B., Bailey, G., Ge, J., \& Tukker, A. (2019). Effect of Chinese policies on rare earth supply chain resilience. Resources, Conservation and Recycling, 142, 101112.

Martha, J. and S. Subbakrishna (2002). "Targeting a just-in-case supply chain for the inevitable next disaster." SUPPLY CHAIN MANAGEMENT REVIEW, V. 6, NO. 5 (SEPT./OCT. 2002), P. 18-23: ILL.

Miehe, R., R. Schneider, F. Baaij and T. Bauernhansl (2016). "Criticality of material resources in industrial enterprises-Structural basics of an operational model." Procedia CIRP 48: 1-9.

Mitroff, I. and C. Alpaslan (2003). Preparing for Evil.

Morley, N. and D. Eatherley (2008). Material Security: Ensuring resource availability for the UK economy, C-Tech Innovation Limited.

Mottura, A. and R. C. Reed (2014). What is the role of rhenium in single crystal superalloys? MATEC Web of conferences, EDP Sciences.

MSP-REFRAM (2017). Rhenium Production. MSP-REFRAM Final Conference. Brussels.

Nassar, N. T., T. E. Graedel and E. Harper (2015). "By-product metals are technologically essential but have problematic supply." Science Advances 1(3): e1400180.

National Research Council (2008). Minerals, critical minerals, and the US economy, National Academies Press.

Nieto, A., K. Guelly and A. Kleit (2013). "Addressing criticality for rare earth elements in petroleum refining: the key supply factors approach." Resources Policy 38(4): 496-503.

Oak Ridge National Laboratory. "Ceramic Matrix Composites Take Flight in LEAP Jet Engine." ScienceDaily. ScienceDaily, January 3, 2017. http://www.sciencedaily.com/releases/2017/01/170103151742.htm.

Olhager, J. (2003). Strategic positioning of the order penetration point. International journal of production economics, 85(3): 319-329.

Polyak, D. E. (2017). Rhenium. US Geological Survey Minerals Yearbook - 2015 [Advance Release], US Geological Survey.

Polyak, D. E. (2018). Rhenium. Mineral Commodity Summary, US Geological Survey. 
Punkkinen, H., Mroueh, U. M., Wahlström, M., Youhanan, L., \& Stenmarck, Å. (2017). Critical metals in end-of-life products: Recovery potential and opportunities for removal of bottlenecks of recycling. Nordic Council of Ministers.

Rahman, S. M., Kim, J., Lerondel, G., Bouzidi, Y., Nomenyo, K., \& Clerget, L. (2017). Missing research focus in end-of-life management of light-emitting diode (LED) lamps. Resources, Conservation and Recycling 127: 256-258.

Ramsey, J., W. East and S. Daintith (2017). 2017 Full Year Results.

Rhee, S. W., Choi, H. H., \& Park, H. S. (2013). Performance evaluation of material separation from spent fluorescent lamps using the thermal end-cutting method. Journal of Material Cycles and Waste Management 15(4): 503-509.

Rolls-Royce Holdings, plc (2018). Annual Report 2017. London.

Romm, J. (2016, April 2). 5 Charts That Illustrate The Remarkable LED Lighting Revolution. Retrieved from https://thinkprogress.org/5-charts-that-illustrate-the-remarkable-led-lightingrevolution-83ecb6c1f472/

Rosenau-Tornow, D., P. Buchholz, A. Riemann and M. Wagner (2009). "Assessing the longterm supply risks for mineral raw materials - a combined evaluation of past and future trends." Resources Policy 34(4): 161-175.

Runkle, E. (2006, November). Daily Light Integral Defined. Retrieved from https://gpnmag.com/article/daily-light-integral-defined/

Runkle, E. (2015, March). Light Wavebands \& Their Effects on Plants. Retreived from http://flor.hrt.msu.edu/assets/Uploads/Light-wavebands.pdf.

SMM Information \& Technology Co, Ltd. (n.d.). Shanghai Metals Market. Retrieved April 23, 2019, from https://www.metal.com/

Schoolderman, H. and R. Mathlener (2011). "Minerals and Metals Scarcity in Manufacturing: the Ticking Time Bomb-Sustainable Materials Management." London, UK: PwC.

Sheffi, Y. and J. B. Rice Jr (2005). "A supply chain view of the resilient enterprise." MIT Sloan Management Review 47(1): 41.

Sprecher, B., I. Daigo, S. Murakami, R. Kleijn, M. Vos and G. J. Kramer (2015). "Framework for Resilience in Material Supply Chains, With a Case Study from the 2010 Rare Earth Crisis." Environmental science \& technology 49(11): 6740-6750.

U.S. Department of Agriculture. (2015, December). Appendix 3. USDA Food Patterns: Healthy U.S.-Style Eating Pattern. Retrieved from

https://health.gov/dietaryguidelines/2015/guidelines/appendix-3/. 
U.S. Department of Energy. (2016, September). Revolution Now The Future Arrives for Five Clean Energy Technologies - 2016 Update. Retrieved from

https://www.energy.gov/eere/downloads/revolution-now-future-arrives-five-clean-energytechnologies-2016-update

United Nations Department of Economic and Social Affairs. (2017). World population projected to reach 9.8 billion in 2050, and 11.2 billion in 2100 | UN DESA Department of Economic and Social Affairs. Retrieved from https:/www.un.org/development/desa/en/news/population/worldpopulation-prospects-2017.html

"When the chain breaks." The Economist 17 June 2006: 19(US). Business Insights:

Essentials. Web. 10 Oct. 2018. 


\section{Data Sources}

USDA. (2018). USDA National Nutrient Database for Standard Reference. Retrieved from https://www.ars.usda.gov/northeast-area/beltsville-md-bhnrc/beltsville-human-nutritionresearch-center/nutrient-data-laboratory/docs/usda-national-nutrient-database-for-standardreference/

The Boeing Company. (2007). 2006 Form 10-K. Retrieved from https://www.sec.gov/Archives/edgar/data/12927/000119312507033902/d10k.htm.

The Boeing Company. (2008). 2007 Form 10-K. Retrieved from https://www.sec.gov/Archives/edgar/data/12927/000119312508032328/d10k.htm.

The Boeing Company. (2009). 2008 Form 10-K. Retrieved from https://www.sec.gov/Archives/edgar/data/12927/000119312509022654/d10k.htm.

The Boeing Company. (2010). 2009 Form 10-K. Retrieved from https://www.sec.gov/Archives/edgar/data/12927/000119312510024406/d10k.htm.

The Boeing Company. (2011). 2010 Form 10-K. Retrieved from https://www.sec.gov/Archives/edgar/data/12927/000119312511028490/d10k.htm.

The Boeing Company. (2012). 2011 Form 10-K. Retrieved from https://www.sec.gov/Archives/edgar/data/12927/000119312512048565/d255574d10k.htm.

The Boeing Company. (2013). 2012 Form 10-K. Retrieved from https://www.sec.gov/Archives/edgar/data/12927/000001292713000014/a201212dec3110k.htm.

The Boeing Company. (2014). 2013 Form 10-K. Retrieved from https://www.sec.gov/Archives/edgar/data/12927/000001292714000004/a201312dec3110k.htm.

The Boeing Company. (2015). 2014 Form 10-K. Retrieved from https://www.sec.gov/Archives/edgar/data/12927/000001292715000011/a201412dec3110k.htm.

The Boeing Company. (2016). 2015 Form 10-K. Retrieved from https://www.sec.gov/Archives/edgar/data/12927/000001292716000099/a201512dec3110k.htm.

The Boeing Company. (2017). 2016 Form 10-K. Retrieved from https://www.sec.gov/Archives/edgar/data/12927/000001292717000012/a201612dec3110ka.htm.

CREE Inc. (2000). 2000 Form 10-K. Retrieved from https://www.sec.gov/Archives/edgar/data/895419/000089541900000012/0000895419-00$\underline{000012-0001 . t x t}$. 
CREE Inc. (2001). 2001 Form 10-K. Retrieved from https://www.sec.gov/Archives/edgar/data/895419/000095014401506414/g71423e10-k.txt.

CREE Inc. (2002). 2002 Form 10-K. Retrieved from https://www.sec.gov/Archives/edgar/data/895419/000102140802011139/d10k.txt.

CREE Inc. (2003). 2003 Form 10-K. Retrieved from https://www.sec.gov/Archives/edgar/data/895419/000119312503054147/d10k.htm.

CREE Inc. (2004). 2004 Form 10-K. Retrieved from https://www.sec.gov/Archives/edgar/data/895419/000119312504144133/d10k.htm.

CREE Inc. (2005). 2005 Form 10-K. Retrieved from https://www.sec.gov/Archives/edgar/data/895419/000119312505170616/d10k.htm.

CREE Inc. (2006). 2006 Form 10-K. Retrieved from https://www.sec.gov/Archives/edgar/data/895419/000119312506179160/d10k.htm.

CREE Inc. (2007). 2007 Form 10-K. Retrieved from https://www.sec.gov/Archives/edgar/data/895419/000119312507187409/d10k.htm.

CREE Inc. (2008). 2008 Form 10-K. Retrieved from https://www.sec.gov/Archives/edgar/data/895419/000119312508181391/d10k.htm.

CREE Inc. (2009). 2009 Form 10-K. Retrieved from https://www.sec.gov/Archives/edgar/data/895419/000119312509177499/d10k.htm.

CREE Inc. (2010). 2010 Form 10-K. Retrieved from https://www.sec.gov/Archives/edgar/data/895419/000119312510192307/d10k.htm.

CREE Inc. (2011). 2011 Form 10-K. Retrieved from https://www.sec.gov/Archives/edgar/data/895419/000119312511225630/d10k.htm.

CREE Inc. (2012). 2012 Form 10-K. Retrieved from https://www.sec.gov/Archives/edgar/data/895419/000089541912000044/cree06242012x10k.htm.

CREE Inc. (2013). 2013 Form 10-K. Retrieved from https://www.sec.gov/Archives/edgar/data/895419/000089541913000044/cree06302013x10k.htm.

CREE Inc. (2014). 2014 Form 10-K. Retrieved from https://www.sec.gov/Archives/edgar/data/895419/000089541914000045/cree06292014x10k.htm. 
CREE Inc. (2015). 2015 Form 10-K. Retrieved from

https://www.sec.gov/Archives/edgar/data/895419/000089541915000058/cree-

06282015x10k.htm.

General Electric Company. (2007). 2006 Form 10-K. Retrieved from

https://www.sec.gov/Archives/edgar/data/40545/000004054507000017/frm10k.htm.

General Electric Company. (2008). 2007 Form 10-K. Retrieved from

https://www.sec.gov/Archives/edgar/data/40545/000004054508000011/frm10k.htm.

General Electric Company. (2009). 2008 Form 10-K. Retrieved from

https://www.sec.gov/Archives/edgar/data/40545/000004054509000012/frm10k.htm.

General Electric Company. (2010). 2009 Form 10-K. Retrieved from https://www.sec.gov/Archives/edgar/data/40545/000004054510000010/frm10k.htm.

General Electric Company. (2011). 2010 Form 10-K. Retrieved from https://www.sec.gov/Archives/edgar/data/40545/000119312511047479/d10k.htm.

General Electric Company. (2012). 2011 Form 10-K. Retrieved from https://www.sec.gov/Archives/edgar/data/40545/000004054512000016/ge10k.htm.

General Electric Company. (2013). 2012 Form 10-K. Retrieved from https://www.sec.gov/Archives/edgar/data/40545/000004054513000036/geform10k2012.htm.

General Electric Company. (2014). 2013 Form 10-K. Retrieved from https://www.sec.gov/Archives/edgar/data/40545/000004055414000023/geform10k2013.htm.

General Electric Company. (2015). 2014 Form 10-K. Retrieved from https://www.sec.gov/Archives/edgar/data/40545/000004054515000030/ge10k2014.htm.

General Electric Company. (2016). 2015 Form 10-K. Retrieved from https://www.sec.gov/Archives/edgar/data/40545/000004054516000145/ge10k2015.htm.

General Electric Company. (2017). 2016 Form 10-K. Retrieved from https://www.sec.gov/Archives/edgar/data/40545/000004054517000010/ge10k2016.htm.

General Electric Company. (2009). 2008 Annual Report. Retrieved from https://www.ge.com/ar2008/downloads.html.

General Electric Company. (2010). 2009 Annual Report. Retrieved from https://www.ge.com/ar2009/downloads.html.

General Electric Company. (2011). 2010 Annual Report. Retrieved from https://www.ge.com/ar2010/downloads.html. 
General Electric Company. (2012). 2011 Annual Report. Retrieved from https://www.ge.com/sites/default/files/GE_AR11_EntireReport.pdf.

General Electric Company. (2013). 2012 Annual Report. Retrieved from https://www.ge.com/ar2012/pdf/GE_AR12.pdf.

General Electric Company. (2014). 2013 Annual Report. Retrieved from https://www.ge.com/ar2013/pdf/GE AR13.pdf.

General Electric Company. (2015). 2014 Annual Report. Retrieved from https://www.ge.com/ar2014/assets/pdf/GE_AR14.pdf.

General Electric Company. (2016). 2015 Annual Report. Retrieved from https://www.ge.com/ar2015/assets/pdf/GE_AR15.pdf.

General Electric Company. (2017). 2016 Annual Report. Retrieved from https://www.ge.com/ar2016/assets/pdf/GE_AR16.pdf.

United Technologies Corporation. (2009). 2008 Financial and Corporate Responsibility Performance. Retrieved from http://www.utc.com/Investors/Pages/Annual-Reports-and-ProxyStatements.aspx.

United Technologies Corporation. (2010). 2009 Financial and Corporate Responsibility Performance. Retrieved from http://www.utc.com/Investors/Pages/Annual-Reports-and-ProxyStatements.aspx.

United Technologies Corporation. (2011). 2010 Financial and Corporate Responsibility Performance. Retrieved from http://www.utc.com/Investors/Pages/Annual-Reports-and-ProxyStatements.aspx.

United Technologies Corporation. (2012). 2011 Financial and Corporate Responsibility Performance. Retrieved from http://www.utc.com/Investors/Pages/Annual-Reports-and-ProxyStatements.aspx.

United Technologies Corporation. (2013). 2012 Financial and Corporate Responsibility Performance. Retrieved from http://www.utc.com/Investors/Pages/Annual-Reports-and-ProxyStatements.aspx.

United Technologies Corporation. (2014). 2013 Financial and Corporate Responsibility Performance. Retrieved from http://www.utc.com/Investors/Pages/Annual-Reports-and-ProxyStatements.aspx.

United Technologies Corporation. (2015). 2014 Financial and Corporate Responsibility Performance. Retrieved from http://www.utc.com/Investors/Pages/Annual-Reports-and-ProxyStatements.aspx. 
United Technologies Corporation. (2016). 2015 Financial and Corporate Responsibility Performance. Retrieved from http://www.utc.com/Investors/Pages/Annual-Reports-and-ProxyStatements.aspx.

United Technologies Corporation. (2017). 2016 Financial and Corporate Responsibility Performance. Retrieved from http://www.utc.com/Investors/Pages/Annual-Reports-and-ProxyStatements.aspx. 